\title{
Whole-Core Depletion Studies in Support of Fuel Specification for the Next Generation Nuclear Plant (NGNP) Core
}

\author{
by
}

T. K. Kim, W. S. Yang, T. A. Taiwo, and H. S. Khalil

Nuclear Engineering Division

9700 South Cass Avenue

Argonne National Laboratory

Argonne, IL 60439

July 30, 2004 
Argonne National Laboratory, a U.S. Department of Energy Office of Science laboratory, is operated by The University of Chicago under contract W-31-109-Eng-38.

DISCLAIMER
This report was prepared as an account of work sponsored by an agency of
the United States Government. Neither the United States Government nor
any agency thereof, nor The University of Chicago, nor any of their
employees or officers, makes any warranty, express or implied, or assumes
any legal liability or responsibility for the accuracy, completeness, or
usefulness of any information, apparatus, product, or process disclosed, or
represents that its use would not infringe privately owned rights. Reference
herein to any specific commercial product, process, or service by trade name,
trademark, manufacturer, or otherwise, does not necessarily constitute or
imply its endorsement, recommendation, or favoring by the United States
Government or any agency thereof. The views and opinions of document
authors expressed herein do not necessarily state or reflect those of the
United States Government or any agency thereof, Argonne National
Laboratory, or The University of Chicago.

Available electronically at http://www.osti.gov/bridge/

Available for a processing fee to U.S. Department of Energy and its contractors, in paper, from:

U.S. Department of Energy

Office of Scientific and Technical Information

P.O. Box 62

Oak Ridge, TN 37831-0062

phone: (865) 576-8401

fax: (865) 576-5728

email: reports@adonis.osti.gov 


\section{Table of Contents}

Page

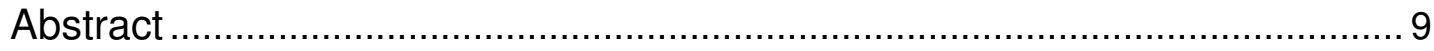

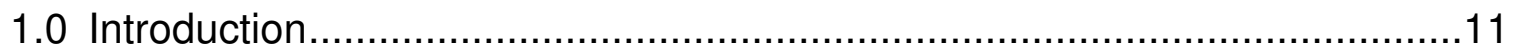

2.0 Description of NGNP Core and Fuel Elements ......................................14

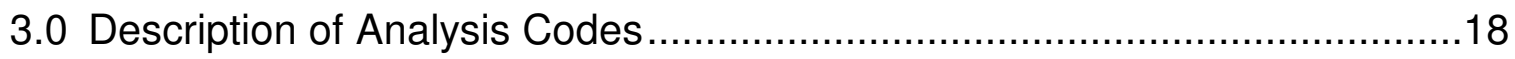

3.1 WIMS8 and DRAGON Lattice Codes ...................................................... 18

3.2 REBUS-3/DIF3D Fuel Cycle Analysis Code System ..................................... 21

3.3 WIMS/DIF3D/REBUS-3 Calculation Procedure ……………………........... 23

4.0 NGNP Depletion Sensitivity Studies with WIMS8 Lattice Code...................25

4.1 Trend of Multiplication Factor with Fuel Parameters ………....................... 25

4.2 Estimation of Core Cycle Length and Discharge Burnup ……..................... 29

5.0 Whole-Core Model Evaluation and Studies............................................33

5.1 REBUS-3/DIF3D Whole-Core Model for NGNP Core ………….................. 33

5.2 Verification and Sensitivity Studies of REBUS-3/DIF3D Model ..................... 36

5.3 Radial Peaking Factor Calculation with MCNP4C ..................................... 44

5.4 Fuel Management Option - Single-Batch Core........................................... 47

5.5 Fuel Management Option - Two-Batch Equilibrium Core ……………....... 51

5.6 Fuel Management Option - Three-Batch Equilibrium Core.......................... 61

5.7 Evaluation of Two- and Three-Batch Transitional Cores.............................. 66

5.8 Summary of Fuel Management Studies ..................................................... 70

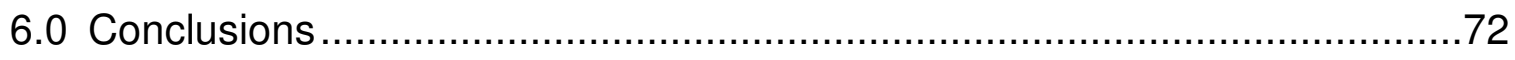

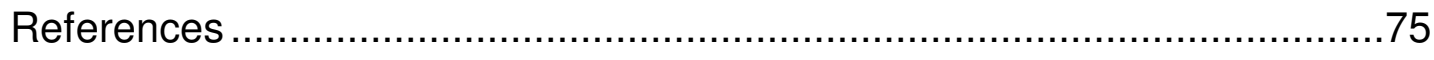




\section{List of Tables}

Page

Table 1. NGNP Fuel Element Data. 16

Table 2. NGNP Reference Values and Investigated Ranges of Fuel Particle

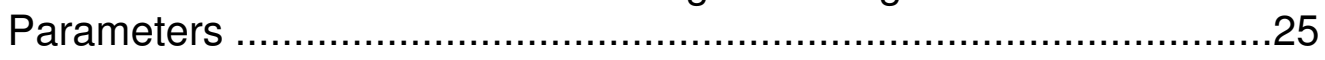

Table 3. Cycle Length and Discharge Burnup for Optimum Packing Ratio.......32

Table 4. Single-Batch Fuel Management Option with $350 \mu \mathrm{m}$ and $425 \mu \mathrm{m}$ Kernel-Diameter Fuel.

Table 5. Two-Batch Fuel Management Option with $350 \mu \mathrm{m}$ and $425 \mu \mathrm{m}$ Diameter Fuel.

Table 6. Three-Batch Fuel Management Option with $350 \mu \mathrm{m}$ and $425 \mu \mathrm{m}$

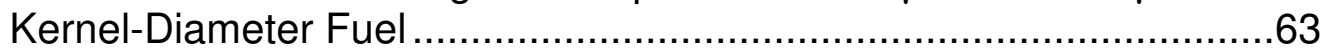

Table 7. Summary of NGNP Excess Reactivity, Peak Power and Fluence ......71

Table 8. Summary of NGNP Heavy-Metal Loading, Cycle Length and Discharge Burnup 


\section{List of Figures}

Page

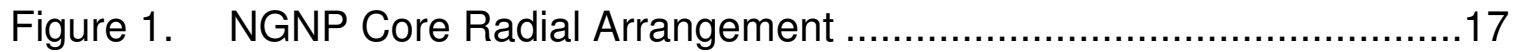

Figure 2. Standard Fuel Assembly of NGNP .........................................17

Figure 3. Eigenvalue Letdown Curve with Constant Flux Level.....................21

Figure 4. ISOTXS File Generation Procedure ….......................................24

Figure 5. $\mathrm{k}_{\infty}$ Letdown Curve for $200 \mu \mathrm{m}$ Kernel ........................................26

Figure 6. $\mathrm{k}_{\infty}$ Letdown Curve for $300 \mu \mathrm{m}$ Kernel .........................................26

Figure 7. $\mathrm{k}_{\infty}$ as Function of Moderator to Fuel Ratio....................................26

Figure 8. Fission Yield per Absorption (Eta) and Fast Fission Factor for

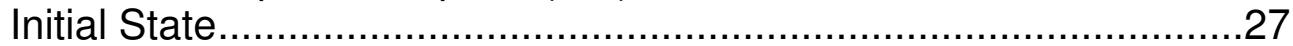

Figure 9. Thermal Utilization Factors for Initial State ..................................27

Figure 10. Resonance Escape Probability (p) and Double

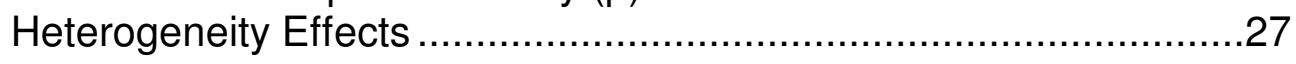

Figure 11. Thermal-to-Fast Flux Ratio (Thermal Cutoff Energy $=4 \mathrm{eV}$ ) ..........28

Figure 12. Critical Burnup vs. Moderator-to-Fuel Ratio ..................................30

Figure 13. Cycle Length vs. Moderator-to-Fuel Ratio .....................................31

Figure 14. DIF3D Core Model for NGNP Whole-Core Calculations ..................34

Figure 15. Fuel Element $\mathrm{k}_{\infty}$ from WIMS8 and REBUS3 Depletion

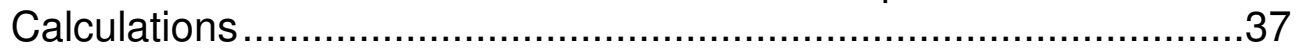

Figure 16. Fuel Element Burnup-Dependent Multiplication Factors with Lumped and Explicit Fission Products Models ...............................38

Figure 17. Whole Core Burnup-Dependent Multiplication Factors with Lumped and Explicit Fission Product Models. 39

Figure 18. Sensitivity Study on Number of Axial Burn Zones .........................40

Figure 19. Comparison of Equilibrium and Non-Equilibrium Results ................42

Figure 20. k-effective with 6- and 32-Group REBUS-3/DIF3D Calculations ......43

Figure 21. Simplified Core Model for Peaking Factor Estimation with MCNP4C

Figure 22. Pin Power Distribution in Fuel Element Adjacent to Inner Reflector

Figure 23. Core Total Power Peaking Factor as Function of Burnup (Single-Batch Core: $350 \mu \mathrm{m}$ Kernel-Diameter Case) 


\section{List of Figures}

Page

Figure 24. Core Axial Power Distributions at Beginning and End of Cycle (Single-Batch Core: $350 \mu \mathrm{m}$ Kernel-Diameter Case)

Figure 25. Core Radial Power Distributions for Single-Batch Core with $350 \mu \mathrm{m}$ Kernel-Diameter Fuel

Figure 26. Core Axial Power Distributions at Beginning and End of Cycle (Single-Batch Core: $425 \mu \mathrm{m}$ Kernel-Diameter Case)

Figure 27. Core Radial Power Distributions for Single-Batch Core with $425 \mu \mathrm{m}$ Kernel-Diameter Fuel

Figure 28. Two-Batch Fuel Management Scheme for NGNP Core. .52

Figure 29. BOC Axial Power Distributions at Leading Peak Power Locations for the Two-Batch Core with $425 \mu \mathrm{m}$ Kernel-Diameter Fuel

Figure 30. EOC Axial Power Distributions at Leading Peak Power Locations for the Two-Batch Core with $425 \mu \mathrm{m}$ Kernel-Diameter Fuel

Figure 31. Radial Power Distribution for Two-Batch Core with $425 \mu \mathrm{m}$ Kernel-Diameter Fuel

Figure 32. Radial Power Distribution for Modified Two-Batch Core with $425 \mu \mathrm{m}$ Kernel-Diameter Fuel .55

Figure 33. Alternating Fuel Pattern Scheme for Two-Batch Core .57

Figure 34. BOC Axial Power Distributions for Two-Batch Alternating Fuel Pattern and Regular Shuffling Scheme with $425 \mu \mathrm{m}$ Kernel-Diameter Fuel .58

Figure 35. EOC Axial Power Distributions for Two-Batch Alternating Fuel Pattern and Regular Shuffling Scheme with $425 \mu \mathrm{m}$ Kernel-Diameter Fuel

Figure 36. BOC Axial Power Distributions at Leading Column Power Locations for Alternating Fuel Pattern Two-Batch Core with $425 \mu \mathrm{m}$ Diameter Fuel.

Figure 37. EOC Axial Power Distributions at Leading Column Power Locations for Alternating Fuel Pattern Two-Batch Core with $425 \mu \mathrm{m}$ Diameter Fuel .59

Figure 38. Radial Power Distributions for Alternating Fuel Pattern Two-Batch Core with $425 \mu \mathrm{m}$ Kernel-Diameter Fuel. 


\section{List of Figures}

Figure 39. Three-Batch Fuel Management Scheme for NGNP Core .62

Figure 40. Radial Power Distribution for Three-Batch Core with $425 \mu \mathrm{m}$ Diameter Fuel.

Figure 41. BOC Axial Power Distribution at Leading Peak Power Locations for Three-Batch Core with $425 \mu \mathrm{m}$ Diameter Fuel

Figure 42. EOC Axial Power Distribution at Leading Peak Power Locations for Three-Batch Core with $425 \mu \mathrm{m}$ Diameter Fuel

Figure 43. Core k-effective and Total Peaking Factor during Transitional Cycles for Two-Batch Fuel Management Scheme with $425 \mu \mathrm{m}$ Kernel-Diameter Fuel

Figure 44. Core k-effective and Total Peaking Factor during Transitional Cycles for Three-Batch Fuel Management Scheme with $425 \mu \mathrm{m}$ Kernel-Diameter Fuel

Figure 45. Average Discharge Burnup during Transitional Cycles for Two-Batch Fuel Management Scheme with $425 \mu \mathrm{m}$ Kernel-Diameter Fuel

Figure 46. Average Discharge Burnup during Transitional Cycles for Three-Batch Fuel Management Scheme with $425 \mu \mathrm{m}$ Kernel-Diameter Fuel

Figure 47. BOC Axial Power Distributions during Transitional Cycles for Two-Batch Fuel Management Scheme with $425 \mu \mathrm{m}$ Kernel-Diameter Fuel

Figure 48. BOC Axial Power Distributions during Transitional Cycles for Three-Batch Fuel Management Scheme with $425 \mu \mathrm{m}$ Kernel-Diameter Fuel 


\begin{abstract}
Whole-core deterministic depletion models have been developed and utilized for analyzing the NGNP core. This activity was conducted to support the Advanced GasCooled Reactor (AGR) fuel qualification program. This report complements an earlier one in which lattice and stochastic code models for the NGNP were developed and assessed.
\end{abstract}

The fuel cycle optimization study performed in this work is for an NGNP with a VHTR prismatic core design that employs a once-through fuel cycle. A single fuel particle (fissile) is assumed, though enrichment zoning can be employed for optimizing the core power distribution. The current work assumes the targeted core operational cycle length is 18 to 24 months to be consistent with current practices in U.S. utilities and an average fuel discharge burnup of 100 to $150 \mathrm{GWd} /$.

The WIMS8 lattice code is used for preliminary analysis of the NGNP core with respect to meeting performance goals for the cycle length and discharge burnup under the constraints on fuel specification parameters such as the fuel diameter, fuel enrichment, and fuel packing fraction in the graphite compact. The preliminary evaluation facilitated limiting the search space for the more computationally expensive whole-core depletion calculations, by providing a narrow range for the pertinent design parameters to be evaluated.

The whole-core depletion studies evaluated various fuel management schemes (single-, two-, and three-batch schemes) for the equilibrium and transitional cycles. The study evaluated the impact of radial and axial fuel shuffling on the core power peaking and reactivity swing, which directly affect reactor safety requirements. The neutron fluence loads on the fuel particle designs that meet reactor core performance requirements (e.g., the cycle length and discharge burnup) were also evaluated.

The current study indicated that within the limits on the fuel packing fraction (less than $30 \%$ ) and the fuel enrichment (less than 15\%), only the two-batch fuel management scheme can meet simultaneously the targeted cycle length and discharged burnup goals. The single-batch scheme could only satisfy the cycle length goal (about 18 month) when a fuel kernel diameter of $425 \mu \mathrm{m}$ is employed. By increasing the number of fuel batches, it is possible to increase the average discharge burnup to $100 \mathrm{GWd/t}$ with a two-batch scheme and $115 \mathrm{GWd} / \mathrm{t}$ with a three-batch scheme. The reactivity swing can be reduced by a factor of 2.4 if the three-batch fuel management scheme is used relative to the single-batch scheme. The application of more fuel batches and fuel shuffling would also help to reduce the power peaking factor. However, the cycle length is reduced to less than 15 months for the three-batch scheme. The fast fluence limit of $4 \times 10^{21} \mathrm{n} / \mathrm{cm}^{2}(E>$ $0.18 \mathrm{MeV}$ ) is also exceeded slightly by the three-batch scheme, while it is satisfied by the single-and two-batch schemes. The study also found that utilizing axial element shuffling is possible but would provide only limited benefit to the reduction of the power peaking factor. (The axial power peaking for the fuel columns actually increased in this case.) 


\subsection{Introduction}

An Advanced Gas-Cooled Reactor (AGR) program focused on fuel development and qualification is currently ongoing to support the USDOE goal of developing and demonstrating a Next Generation Nuclear Plant (NGNP) that is based on the Generation IV Very High Temperature Reactor (VHTR) concept. The objectives of the AGR fuel program are to (1) provide baseline fuel qualification dataset in support of the licensing and operation of the VHTR, (2) support near-term deployment of an AGR for commercial energy production in the United States by reducing market entry risks posed by technical uncertainties associated with fuel production, and (3) utilize international collaborations to leverage the USDOE resources. [1] The coated-particle fuels that can be used in the prismatic- and pebble-bed-type modular reactors are being investigated under this program. While there is a broad body of U.S. and international fuels data applicable to the VHTR designs, they are not sufficient to address specific prismatic-core manufacturing parameters and the higher fuel performance requirements (i.e., higher burnup, operating temperature and temperature gradients, and fast neutron exposure). Consequently, there has been a focus on manufacturing and testing the fuel design used in the prismatic core concepts, using more recent fuel specifications.

Reactor physics tasks have been defined to support the AGR fuel qualification program. These tasks include independent confirmation and support for efforts to specify such key fuel design parameters as fissile enrichment, fuel particle size, and fuel packing fraction in the fuel compacts. An important objective is to provide timely assurance that these parameters are appropriately specified in the AGR program fuel performance tests to be conducted in the Advanced Test Reactor (ATR) at INEEL and that they satisfy key NGNP performance and safety objectives. The physics effort would also provide estimates of the maximum power and fluence loads expected on the fuel particle designs that meet reactor core performance requirements (e.g., the cycle length.)

In response to the physics requirements, NGNP core models have been developed using deterministic tools for lattice and whole-core calculations. This effort complements similar activities ongoing at INEEL in which stochastic Monte Carlo codes are being employed. The ANL effort was divided into two parts. In the first, an investigation of the deterministic code 
capabilities was performed primarily by comparing the code predictions to those obtained with the Monte Carlo MCNP code. A preliminary assessment of the various reactor physics items that are needed to model adequately the prismatic modular reactor designs was also done. The findings of this study were reported in Reference 2. In the second study, which is embodied in the current work, a whole-core calculation path has been developed for the physics analysis of the VHTR prismatic core. With the model it is possible to provide preliminary estimates of the cycle length, discharge burnup, fluence, and power distributions that are attainable with the current fuel specifications.

The fuel cycle optimization study performed in this study assumes that the NGNP utilizes a VHTR prismatic core design that employs a once-through fuel cycle. A single fuel particle (fissile) will be used, as opposed to the application of fissile and fertile fuel particles as in some previous prismatic gas-cooled core designs. Enrichment zoning can be employed for optimizing the core power distribution. The current work assumes that the targeted core operational cycle length is 18 to 24 months to be consistent with current practices in U.S. utilities and an average fuel discharge burnup of 100 to $150 \mathrm{GWd} / \mathrm{t}$.

Design constraints have been imposed on the fuel packing fraction in the compact, the fuel kernel diameter, and the fuel enrichment. It has been indicated by fuels expert that the fuel packing fraction should be below $40 \%$. A limit of $30 \%$ has been used for this work. In the current study, the fuel enrichment required to meet the targeted cycle length and burnup will be determined. However there is a limit of $20 \%$ imposed by the AGR program for non-proliferation reasons and for the planned fuel test specifications. Previous studies indicated a value in the 12$15 \%$ range will probably be sufficient, and hence a limit of $15 \%$ is considered in this work. Regarding the fuel kernel size, a diameter in the 350 to $450 \mu \mathrm{m}$ range has been recommended by the fuel experts. For the purpose of sensitivity studies, the thicknesses of the buffer, inner and outer pyrolytic carbon, and $\mathrm{SiC}$ layers can be assumed constant from the reference values that have been specified in the fuels specifications. In addition to these constraints, it is desirable to minimize the core reactivity control requirements and to have core designs with reactivity coefficients that ensure reactor safety. 
The expected output data from this study include power peaking factors, fluence, and fuel burnup levels consistent with the cycle length. It is currently proposed that the peak fuel temperature be less than $1250^{\circ} \mathrm{C}$ at operating conditions. Somewhat lower peak fuel temperatures are however desirable, if possible. The peak fast fluence should be less than $4 \times 10^{21} \mathrm{n} / \mathrm{cm}^{2}$ $(>0.18 \mathrm{MeV})$.

In Section 2.0, the characteristics of the VHTR core and fuel element are briefly described. Because the current effort is not a design activity, the NGNP point design [3] based on a GT-MHR core design previously developed by General Atomics [4] has been assumed; features unique to the VHTR prismatic core are used to augment the core description (an example is the absence of fertile fuel in the NGNP).

The lattice and core physics tools employed in this study are discussed in Section 3.0, along with a description of the calculational path involving the codes. To gain preliminary understanding of the VHTR prismatic core behavior during reactor fuel operation (burnup), sensitivity studies have been performed using the two-dimensional lattice codes for core scoping study. Results of this core scoping study are presented in Section 4.0. This study provides the analyst a reduction of the problem search space that would have been required for the whole-core calculations.

The whole-core models and results of parametric studies are summarized in Section 5.0. The impact of different fuel management schemes on core performance is discussed in that section. Single-batch, two-batch, and three-batch fuel management schemes were investigated, and the impacts of fuel shuffling, both radially and axially, were also investigated.

In Section 6.0, the conclusions from this work and potential future activities are discussed. 


\subsection{Description of NGNP Core and Fuel Elements}

The current study is not directed towards the design of the NGNP core. It is focused on providing confirmatory data that the fuel to be tested under the advanced gas cooled reactor fuels program would be adequate for meeting the system design targets on cycle length, burnup, and safety. Consequently, the core design parameters for the study have been obtained from existing NGNP point design [3] based on the General Atomics design for the GT-MHR. [4] It is recognized that final design and specifications for the NGNP would be quite different from that for the GT-MHR.

Based on the GT-MHR design, the current NGNP reactor core consists of hexagonal graphite fuel and reflector elements, and reactivity control material. The core is designed for a power level of $600 \mathrm{MWt}$ and a power density of $6.6 \mathrm{~W} / \mathrm{cm}^{3}$. [4] The core radial arrangement extracted from Ref. 4 is shown in Figure 1. An annular core design is assumed for the NGNP. This annular design is dictated by the requirement of passive core heat removal that ensures the fuel temperature is less than $1,600^{\circ} \mathrm{C}$ during a conduction cooldown event. The core is composed of fuel or graphite reflector columns. The active core has 102 fuel columns that are located in rings 6,7, and 8 . Ten graphite fuel elements (blocks) comprise a fuel column. (The height of the active core is $7.93 \mathrm{~m}$ and the effective inner and outer diameters are $2.96 \mathrm{~m}$ and $4.83 \mathrm{~m}$, respectively.) Each fuel element contains holes for fuel and burnable compacts, and full-length channels for helium coolant flow. The inner five rings of the core contain removable graphite columns. Removable columns are also located in rings 9 and 10. Beyond the outer removable columns are the permanent side reflectors.

Thirty-six of the outer reflector columns and twelve core columns have channels for control rods. The twelve in-core columns are reserved for start-up and shutdown functions. The thirty-six control rods located in the outer reflector are used for operational power control and trip of the reactor. Additionally to these rods there are also 18 columns in the active core containing channels for reserve shutdown material.

In the GT-MHR design in Ref. 4, the core reactivity is controlled by a combination of lumped burnable poison, movable poison and a negative temperature coefficient. In the event that 
the movable control rods are inoperable, an independent reserve shutdown control is utilized. This control mechanism employs borated pellets that are released into the reserve shutdown channel in the active core.

The axial dimension of the fuel and graphite elements is $79.3 \mathrm{~cm}$. The principal fuel element structural material is $\mathrm{H}-451$ graphite (density is $1.74 \mathrm{~g} / \mathrm{cm}^{3}$ ) in the form of a right hexagonal prism, with a flat-to-flat width of $36 \mathrm{~cm}$. There are differences between the three types of elements containing fuel in the active core (i.e., the standard fuel elements, reserve shutdown elements, and control elements). The standard fuel element contains a regular pattern of fuel and coolant channels (there is a central position for the fuel-element handling hole). There are about two fuel holes per each coolant hole in the standard fuel element. The control and reserve shutdown elements differ from the standard fuel elements because they contain larger diameter channels of different sizes $(9.53 \mathrm{~cm}$ and $10.16 \mathrm{~cm}$ diameter $)$ that replace 24 fuel and 11 coolant holes. These holes are for the control rods/material. Fuel element geometrical details can be found in Ref. 4.

The NGNP fuel is contained in fuel compacts that are loaded into the fuel holes. Each compact has a diameter of $1.245 \mathrm{~cm}$ and a height of $4.93 \mathrm{~cm}$. Coated fuel particles (TRISO) are dispersed in the compact graphite medium. In the GT-MHR design, a mixture of fissile and fertile fuel kernels are utilized. In the current conceptualization of the NGNP, only fissile fuel is being considered for non-proliferation reasons. The fuel form is uranium oxy-carbide $\left(\mathrm{UC}_{0.5} \mathrm{O}_{1.5}\right)$, in order to minimize kernel migration of $\mathrm{UO}_{2}$. Table 1 contains data for the fuel compact. The fuel element has 216 fuel compacts (including six lumped burnable poison rods) and 108 coolant holes (see Figure 2). In the current study, the lumped burnable poison rods have not been modeled. The pitch of the coolant hole or fuel compact is $1.8796 \mathrm{~cm}$ and the radii of the fuel compact and fuel holes are 0.6223 and $0.635 \mathrm{~cm}$, respectively. There are 102 large coolant holes with $0.794 \mathrm{~cm}$ radius and 6 small coolant holes with $0.635 \mathrm{~cm}$ radius. 
Table 1. NGNP Fuel Element Data.

\begin{tabular}{|l|c|l|r|}
\hline & Radius, cm & Material & Density, g/cc \\
\hline Fuel Particle & & & \\
- Fuel kernel & 0.0175 & $\mathrm{UC}_{0.5} \mathrm{O}_{1.5}$ & 10.50 \\
- Buffer & 0.0275 & Graphite & 1.00 \\
- Inner Pyro-Carbon & 0.0310 & Graphite & 1.90 \\
- SiC & 0.0345 & SiC & 3.20 \\
- Outer Pyro-Carbon & 0.0385 & Graphite & 1.87 \\
\hline Fuel compact & 0.6225 & Graphite & 1.1995 \\
\hline Coolant $^{\text {a) }}$ & 0.6350 & He & 0.0032 \\
\hline Graphite Element $^{\text {b) }}$ & & Graphite & 1.74 \\
\hline
\end{tabular}

a) Helium gas was replaced with a void in this study.

b) Graphite element side-to-side width is $35.997 \mathrm{~cm}$, and fuel and coolant hole pitch is $1.8796 \mathrm{~cm}$. 


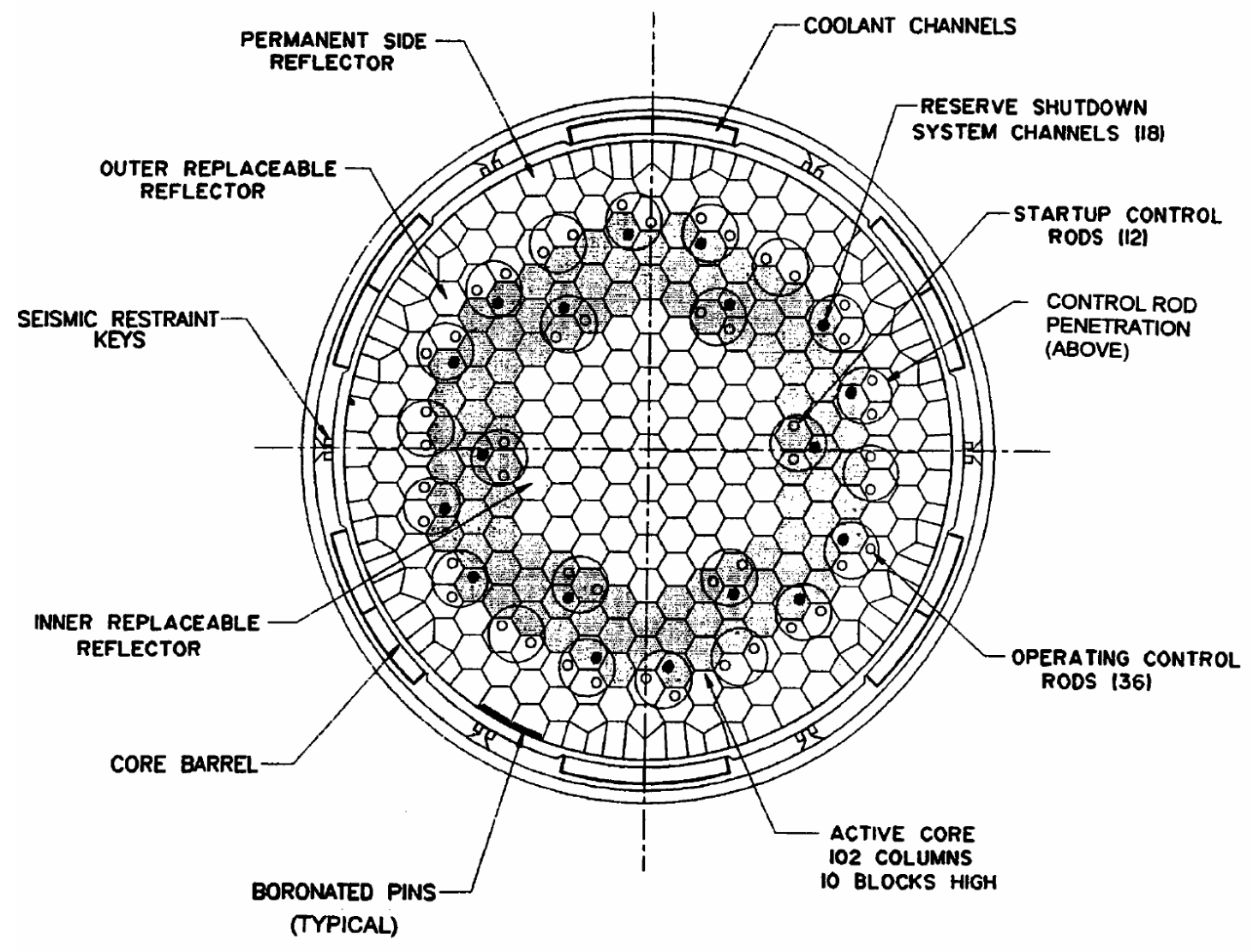

Figure 1. NGNP Core Radial Arrangement.

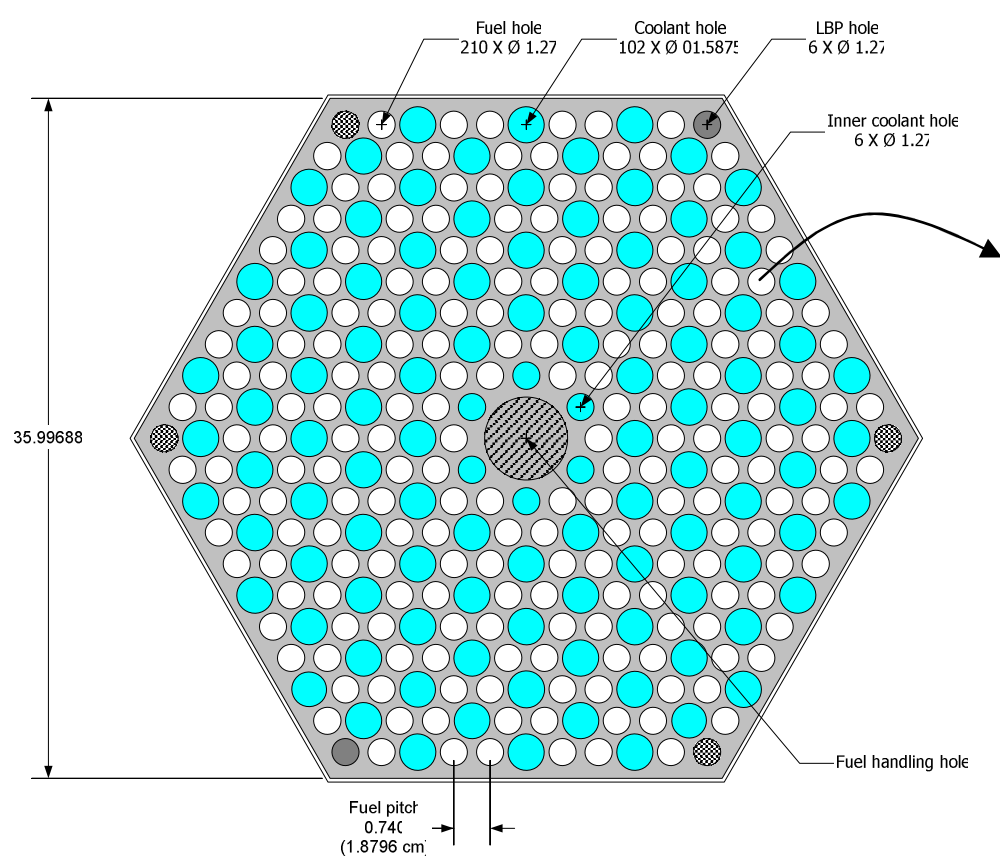

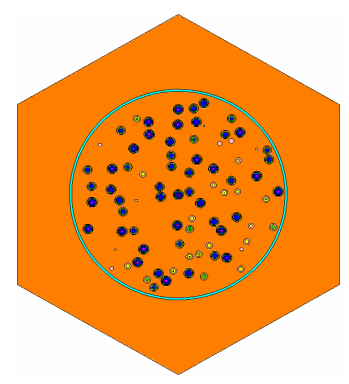

Fuel pin cell

Coolant hole Fuel compact

Figure 2. Standard Fuel Assembly of NGNP. 


\subsection{Description of Analysis Codes}

The NGNP prismatic design has several levels of heterogeneity effects that require proper treatment in order to obtain accurate physics predictions for the core. The fuel elements are hexagonal prismatic blocks of graphite containing parallel vertical holes, arranged in a triangular pitch, into which fuel or burnable poison (BP) compacts are loaded or which are vacant and serve as coolant flow paths. Other holes are also employed as pathways for control rods and fuel loading devices. The fuel compacts comprise of multi-layer ceramic-coated particles dispersed in a graphite matrix. Significant neutronic heterogeneities are created by these small particles. Fuel element heterogeneity arising from the heterogeneous arrangement of fuel, BP and coolant channels in the element, also exists in this design. Core level heterogeneity is also present because of the annular core layout that employs inner and outer reflector zones and the fueled core zone.

Deterministic analysis codes have been utilized in the current studies. The traditional whole-core analysis path using both two-dimensional lattice capability and three-dimensional whole-core nodal tools has been developed for analyzing the NGNP. For the lattice calculations in this study, the WIMS8 and DRAGON codes [5,6] have been used for modeling the fuel element. Depletion calculations are performed with the REBUS-3/DIF3D whole-core analysis code. $[7,8,9]$ Brief descriptions of the codes are provided in following sub-sections.

\section{1 WIMS8 and DRAGON Lattice Codes}

The bulk of the lattice calculations for this study were performed with the WIMS8 code. The DRAGON code was however utilized to provide an independent check of the depletion

results obtained with WIMS8, as the two codes provide models for the treatment of particulate fuel in a matrix. For completeness, therefore, the two codes are briefly discussed in this Section. A more detailed discussion of the lattice code models used for the NGNP can be found in Ref 2.

The WIMS8 code provides an extensive software package for neutronics calculations.[5] The code employs an open structure that permits the linking of various models to create a calculational scheme for a given thermal reactor design. These could range from simple homogeneous cells to complex whole-core calculations. Most generally, however, the lattice 
capabilities of the code are used for reactor analysis. Geometries are available for analyzing PWR, BWR, VVER, AGR, RBMK, CANDU, other reactor core designs, storage pools, and experiments. Methods for the neutron flux solution in WIMS8 include collision probability (1-D or 2-D), method of characteristics, $S_{n}$ method (1-D or 2-D), diffusion theory, and hybrid methods. The code also provides an integrated Monte Carlo method (MONK) for the purpose of internal validation. WIMS8 is supplied with 69- and 172-group libraries based on the validated JEF2.2 nuclear data. It is noted that the WIMS8 code has the PROCOL module that provides a collision probability calculation capability for particulate fuel in an annular geometry that could be used in flux solvers to model the double heterogeneity effect of that fuel form.

The DRAGON code has a collection of models for simulating the neutronic behavior of a unit cell or a fuel lattice in a nuclear reactor. [6] The typical functionalities found in most modern lattice codes are contained in DRAGON. These include interpolation of microscopic cross sections supplied by means of standard libraries; resonance self-shielding calculations in multidimensional geometries; multigroup and multidimensional neutron flux calculations which can take into account neutron leakage; transport-transport or transport-diffusion equivalence calculations; and modules for editing condensed and homogenized nuclear properties for reactor calculations. The code also performs isotopic depletion calculations. The code user must however supply cross sections in one of the following standard formats: DRAGON, MATXS (TRANSX-CTR), WIMSD4, WIMS-AECL, and APOLLO. Macroscopic cross sections can also be read by DRAGON via the input data stream. At ANL, the 69- and 172-group cross section libraries created in WIMSD4-format by the Reduced Enrichment for Research and Test Reactors (RERTR) project are used with the DRAGON code.

An assessment of the accuracy of the WIMS8 and DRAGON codes when used for analyzing the NGNP fuel element has been done by comparing results from the codes to those from the high fidelity MCNP4C code. [11] Results show that eigenvalues, power distributions, neutron spectra, and magnitude of the double heterogeneity effect predicted with the deterministic codes generally agree well with the reference values obtained from MCNP4C calculations with stochastic (random) particle distribution models. 
The accuracy of the WIMS8 depletion calculation has been evaluated by comparing the code results to those from the DRAGON code for an NGNP fuel element problem. The fuel element used in the problem contains fuel with kernels diameter of $350 \mu \mathrm{m}$ and has a specific power density of $128.2 \mathrm{~W} / \mathrm{g}$-initial-heavy-metal.

The element eigenvalue and heavy-metal number densities as function of burnup calculated by the WIMS8 and DRAGON codes have been compared. As observed for the static calculations summarized in Ref. 2, the initial eigenvalue predicted by DRAGON is higher than the WIMS8 value by $602 \mathrm{pcm}$ (the MCNP4C result is always between the results of the two codes). At high burnup, however, the DRAGON eigenvalue is lower than the corresponding WIMS8 value (e.g., by 749 pcm at 500 EFPD).

These discrepancies are mainly caused by the different flux levels for the same power density and the different isotopic depletion chains used in the codes. For the flux calculation, the DRAGON code accounts for the fission energy yield only (due to the WIMS-ANL library used), while the WIMS8 code accounts for both the fission and capture energy yields. As a result, the energy yield is underestimated by about $2-3 \%$ in DRAGON calculations, which give a higher flux level for the same power density.

For more consistent comparison, the depletion calculations were repeated with a constant flux level, and the resulting eigenvalue letdown curves are plotted in Figure 3. It can be seen that the DRAGON eigenvalue is consistently higher than the WIMS8 eigenvalue for the whole depletion period. Very similar eigenvalue letdown trends are however predicted by the two codes. This comparison provides an independent check of the WIMS8 depletion chains. 


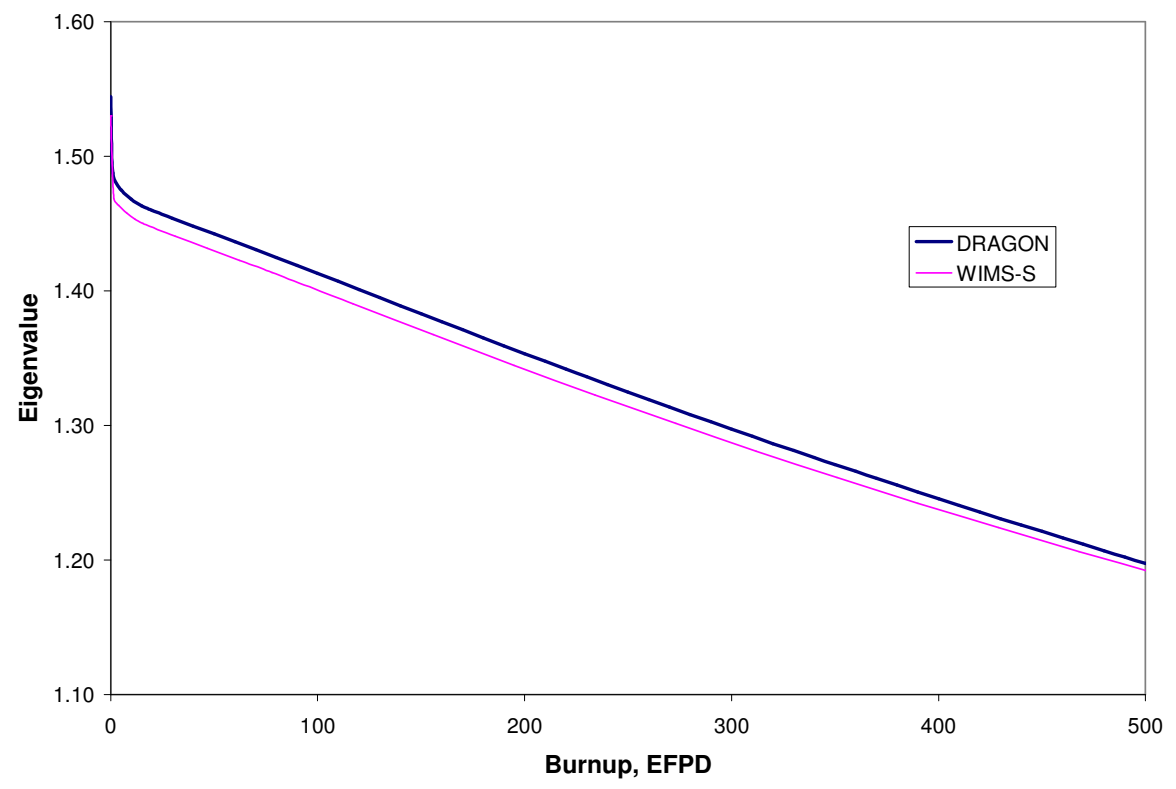

Figure 3. Eigenvalue Letdown Curve with Constant Flux Level.

\subsection{REBUS-3/DIF3D Fuel Cycle Analysis Code System}

A burnup module is required for depletion calculations that track the time evolution of the fuel nuclides. The transmutation equations for the heavy metals and the pertinent fission products are usually solved by the depletion module for discrete spatial zones (burn zones). In addition to the nuclide reaction rates obtained from the flux solver, the depletion module requires decay constants for the nuclides and fission yields of the fission products. The energy released per fission and capture are parameters that are also required for the depletion calculations. These parameters are generally obtained from the lattice code or from base cross section data sources like ENDF/B or JEF data libraries.

\section{REBUS-3 Depletion and Fuel Cycle Analysis Code}

The Argonne REBUS-3 code [7] was developed for fast reactor depletion and fuel cycle analysis and hence does not have thermal feedback capability. However, it provides attractive features for thermal reactor calculations. The code contains a robust algorithm that permits the user to specify the burnup nuclides and the transmutation chains for the nuclides. There is no 
limit on the number of nuclides that can be represented. Ten reaction types are permitted by the code. These are $(n, \gamma),(n, f),(n, p),(n, \alpha),(n, 2 n),(n, d),(n, t), \beta$ - decay, $\beta+$ decay, and alpha decay. The solution of the transmutation and decay equations are obtained using the block depletion approach that permits the user flexible definition of planar and axial depletion zones. The code also allows the specification of burnup-dependent microscopic cross sections that are fitted with respect to a base isotope. This permits the accurate treatment of the nuclide self-shielding and neutron spectrum effects with burnup. The REBUS-3 code allows the user to select from a menu of different flux solvers. These include the DIF3D finite-difference and nodal diffusion theory solvers, and the VARIANT nodal transport solver. Additionally, the code can use the TWODANT module for calculating the neutron flux and power distribution.

The REBUS-3 code contains unique features not generally found in three-dimensional burnup codes. These include the ability to perform equilibrium cycle calculation in addition to the common non-equilibrium calculation. An external cycle capability is also provided by the code for modeling mass flows at the post-irradiation cooling, reprocessing, and fabrication stages of the fuel cycle. For these cases, radioactive decay can be additionally modeled for specified time delays between various processes.

For the equilibrium (infinite repetition of periodic fuel management) type problems, the code uses specified external fuel supplies to load the reactor that is assumed operating under a fixed fuel management scheme. Optionally, reprocessing may be included in the specification of the external fuel cycle and discharged fuel may be recycled back into the reactor. For nonequilibrium (or explicit cycle-by-cycle) cases, the initial composition of the reactor core may be explicitly specified or the core may be loaded from external feeds, and discharged fuel may be recycled back into the reactor as in equilibrium problems. This second option permits modeling reactor operation under a specified periodic or non-periodic fuel management program. Four types of search procedures may be carried out in order to satisfy user-supplied constraints during fuel cyce calculations: 1) adjustment of the reactor burn cycle time to achieve a specified discharge burnup, 2) adjustment of the fresh fuel enrichment to achieve a specified multiplication constant at a specified point during the burn cycle, 3 ) adjustment of the control poison density to maintain a specified value of the multiplication constant throughout the reactor burn cycle, and 4) 
adjustment of the reactor burn cycle time to achieve a specified value of the eigenvalue at the end of the burn step.

\section{DIF3D Eigenvalue and Flux Solver}

The REBUS-3 code uses DIF3D or TWODANT as the flux and eigenvalue solver. The DIF3D module $[8,9,10]$ contains solution options for multigroup steady-state neutron diffusion and transport theory calculations. Cross section data provided in standard format (arbitrary group structure) are used in these calculations. Both nodal and finite-difference spatial discretization approaches are available in the code. The nodal options solves both the diffusion and transport equations in two- and three-dimensional hexagonal and cartesian geometries. One-, two- and three-dimensional orthogonal (rectangular and cylindrical) and triangular geometry diffusion theory problems are solved by the DIF3D finite difference option. Eigenvalue, adjoint, fixed source and criticality search problems are permitted. Upscattering and internal black boundary conditions are also treated by the code. Solution for anisotropic scattering is available in the nodal transport solver VARIANT which uses the variational nodal transport method. The robust

code editor allows flexible definition of edit regions and energy ranges. Flux and power density maps by mesh cell and regionwise balance integrals can be requested by the user.

\subsection{WIMS/DIF3D/REBUS-3 Calculation Procedure}

Whole-core physics calculations using deterministic codes are usually performed in three major steps. These are: (1) Calculation of cell or assembly (element) broad-group neutron cross sections using a lattice code; (2) Retrieving broad group cross sections and transferring cross sections to a whole-core analysis code; (3) Application of the cross-sections in multidimensional static and depletion calculations using a whole-core analysis code. The latter tool is also sometimes used for spatial kinetics calculations.

Depletion calculations for thermal reactors require that burnup dependent cross sections be available for the time points within the fuel irradiation interval. In order to provide this representation for the REBUS-3 depletion code, cross-section data for the different time points are required in the ISOTXS file format. However, since REBUS-3 accepts only one ISOTXS file 
during each calculation, the multiple ISOTXS files have to be merged. Consequently, the calculation path must include stages for generating the ISOTXS files and for merging the files. Figure 4 shows such a path.

Following the WIMS8 transport calculation, cross section data are stored in interface files. An auxiliary code, named WIMS_TXS, is used for writing the cross section data into ISOTXS file format. In this procedure, the ISOTXS files are generated separately for each burnup step. Hence, the number of ISOTXS files is identical to the number of burnup steps in the WIMS8 calculation. As a result, a merging procedure is necessary. The SDX code module is used for this purpose. Finally, in order to assign unique identifiers to the nuclides in each burnup step, another auxiliary code, called MDISO, is utilized.

Additionally to cross section data, the transmutation and decay chain data are also of importance in REBUS-3 calculations. These data are described in cards 9 and 25 of the REBUS-3 input file A.BURN. In order to obtain a result consistent with the WIMS8 code, the REBUS-3 code should use the same decay chain and fission-product yield data as WIMS8. These data have been obtained from the WIMS8 code authors [12] and utilized in the current study.

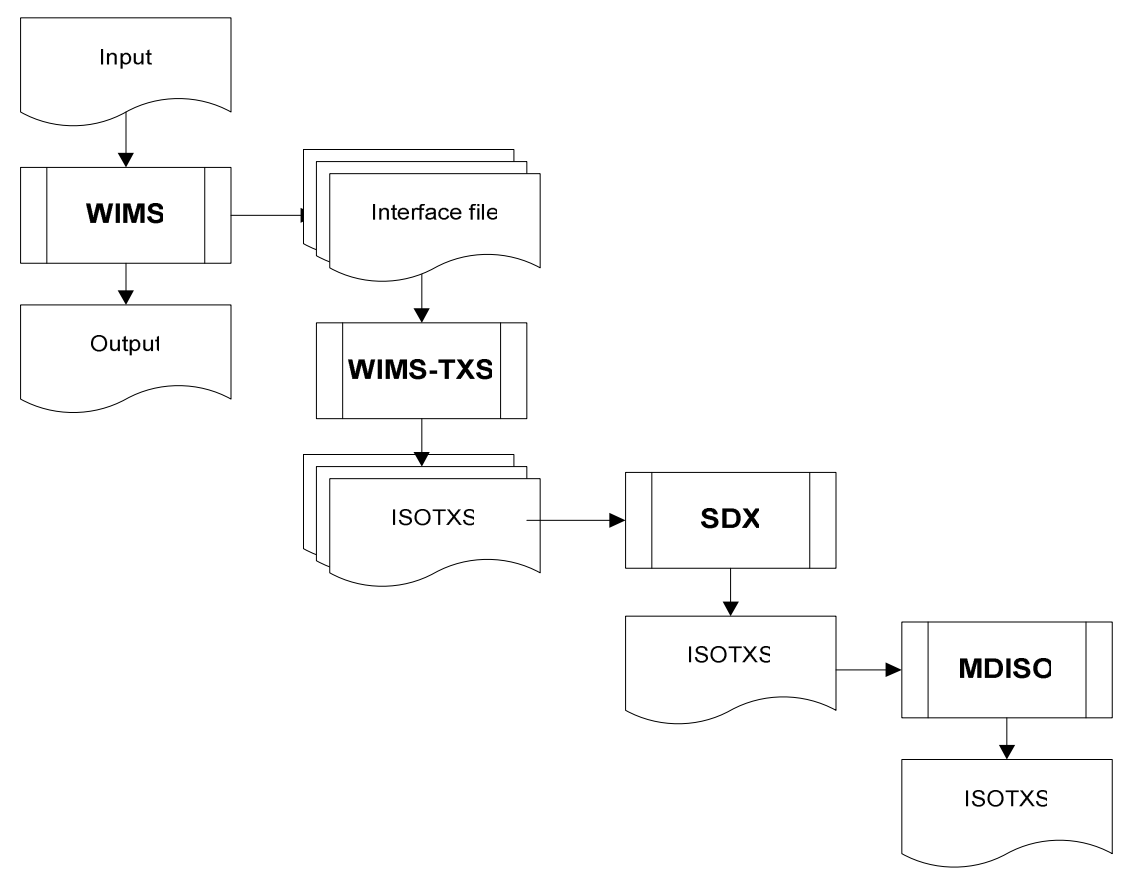

Figure 4. ISOTXS File Generation Procedure. 


\subsection{NGNP Depletion Sensitivity Studies with WIMS8 Lattice Code}

The goal of the current work is to develop whole-core depletion models and to use them to evaluate the feasibility of achieving the targeted performance goals of the NGNP core for a given fuel design. In order to narrow the scope of the design space that would have to be evaluated by the more computationally intensive whole-core calculations, preliminary parametric studies have been done using the WIMS8 code. The main objective of these studies is to optimize the fuel element design such that the discharge burnup and cycle length are maximized. The targeted discharge burnup is $>100 \mathrm{GWd} / \mathrm{t}$ and targeted cycle length is 18 to 24 months. The effects of fuel kernel size, particle packing fraction, and uranium enrichment were investigated, while using the NGNP reference values for the other design parameters such as the fuel compact size and particle coating thicknesses. Table 2 is a summary of the NGNP reference values (in this study) and investigated ranges of these fuel parameters.

Table 2. NGNP Reference Values and Investigated Ranges of Fuel Particle Parameters.

\begin{tabular}{|l|c|c|}
\hline Design Parameter & Reference Value & Investigated Range \\
\hline Uranium enrichment, w/o U-235 & 10.36 & 8 to 14 \\
\hline Fuel kernel size, $\mu \mathrm{m}$ & 350 & 200 to 500 \\
\hline Packing fraction & 0.280 & 0.1 to 0.5 \\
\hline
\end{tabular}

\subsection{Trend of Multiplication Factor with Fuel Parameters}

The $\mathrm{k}_{\infty}$ letdown curve as function of kernel size and packing fraction has been generated in order to investigate the impact of these fuel parameters on the cycle length. Figures 5 and 6 show the trends for cases using fuel kernel diameters of $200 \mu \mathrm{m}$ and $300 \mu \mathrm{m}$. Two distinct trends are evident regarding the critical burnup point (where $\mathrm{k}_{\infty}$ is 1.0 ) predicted by WIMS8. For a low moderator-to-fuel number density ratio $\left(\mathrm{N}_{\mathrm{C}} / \mathrm{N}_{\mathrm{U}}\right)$, e.g., the $300 \mu \mathrm{m}$ case and with high packing fraction (greater than 0.20), the burnup (cycle length) decreases with packing fraction. Conversely for high $\mathrm{N}_{C} / \mathrm{N}_{U}$ (e.g., the $200 \mu \mathrm{m}$ case and with low packing fraction), the cycle length increases with packing fraction. To provide fundamental understanding of reactivity trends resulting from variation in lattice design, the traditional four factors of the fuel element $\mathrm{k}_{\infty}$ at the initial state (beginning of life) have been evaluated using WIMS8 results. Figures 7 to 10 show 


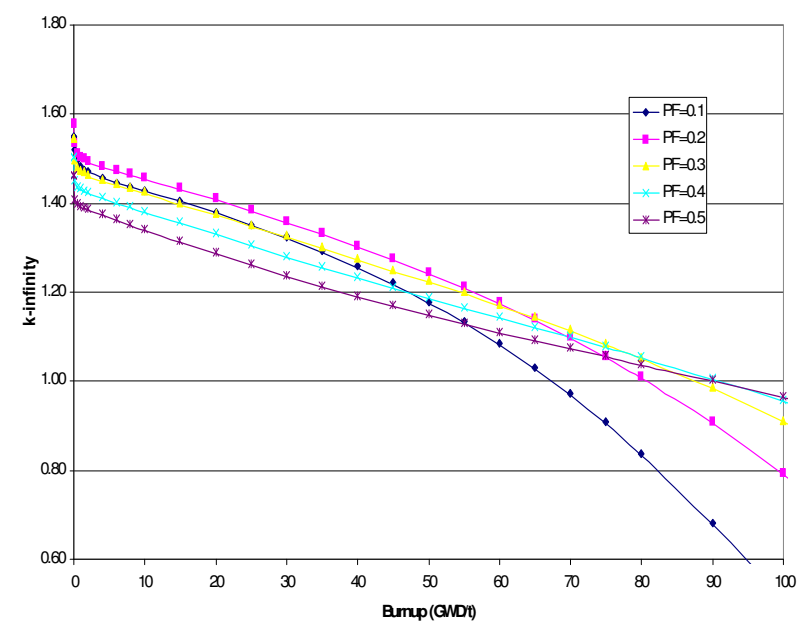

Figure 5. $k_{\infty}$ Letdown Curve for $200 \mu \mathrm{m}$ Kernel.

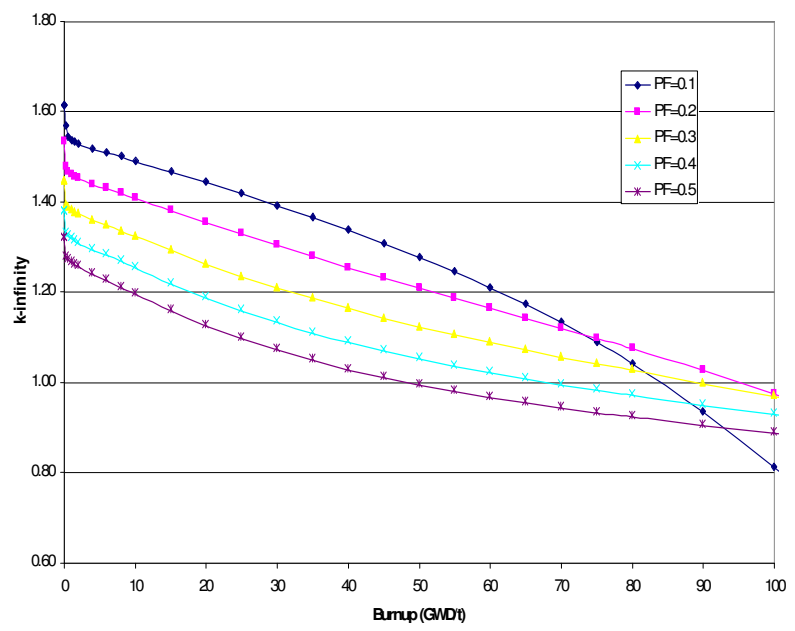

Figure 6. $\mathbf{k}_{\infty}$ Letdown Curve for $300 \mu \mathrm{m}$ Kernel.

the initial-state infinite multiplication factor $\left(\mathrm{k}_{\infty}\right)$ and the four factors for the NGNP fuel element as a function of $\mathrm{N}_{\mathrm{C}} / \mathrm{N}_{\mathrm{U}}$ for five different fuel kernel diameters (d). The four factors were determined using a thermal cutoff energy of $4 \mathrm{eV}$. It can be seen that the effect of moderator-tofuel ratio is much larger than that of fuel kernel size. As the moderator-to-fuel ratio increases, the fraction of epithermal neutrons absorbed in fuel material decreases, and the fraction of neutrons reaching thermal energies increases. This can be seen clearly from the thermal-to-fast flux ratios shown in Figure 11. As a result, the resonance escape probability $(p)$ increases with $\mathrm{N}_{\mathrm{C}} / \mathrm{N}_{\mathrm{U}}$, while the fast fission factor $(\varepsilon)$ and the thermal utilization factor $(f)$ decrease.

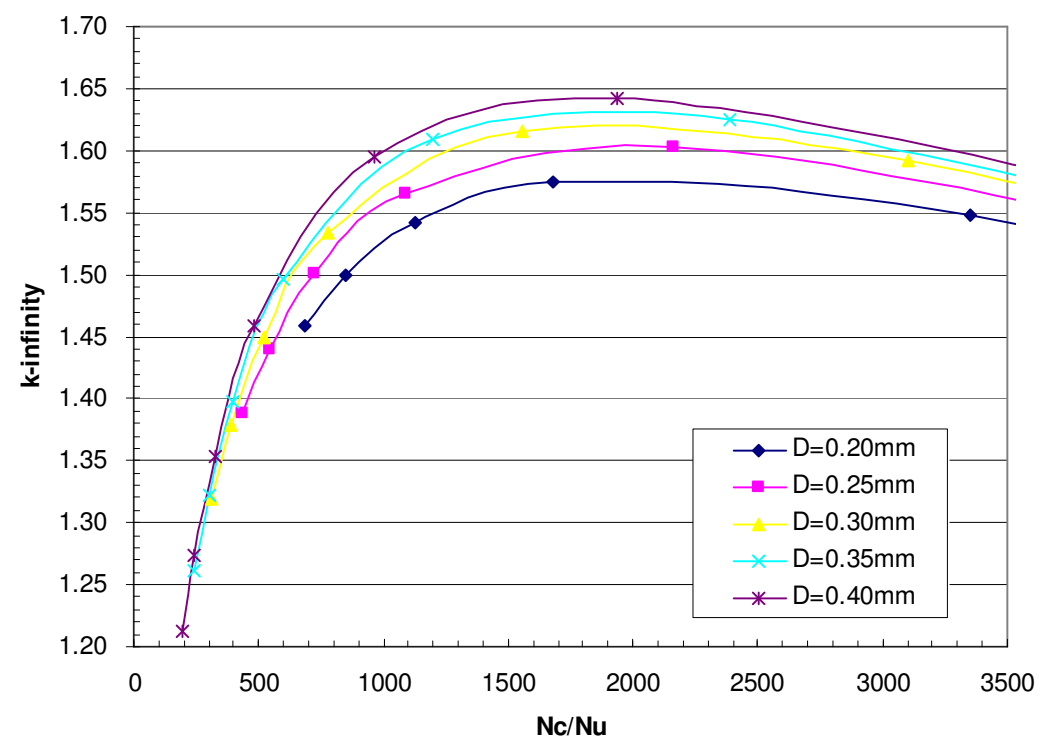

Figure 7. $\mathbf{k}_{\infty}$ as Function of Moderator to Fuel Ratio. 
Eta

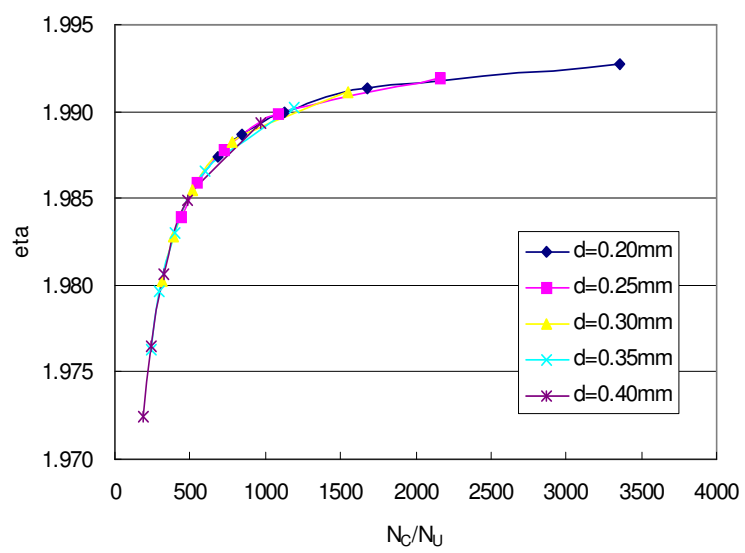

Fast Fission Factor

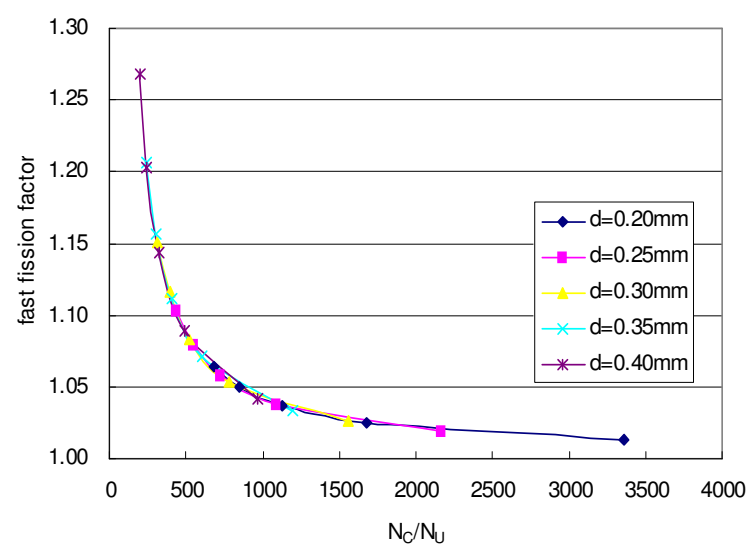

Figure 8. Fission Yield per Absorption (Eta) and Fast Fission Factor for Initial State.

Thermal Utilization Factor

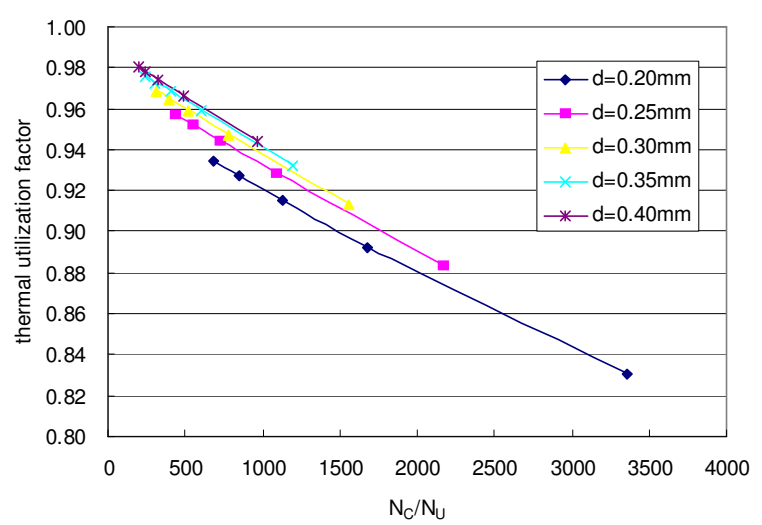

Thermal Absorption Fraction in $\mathrm{U}_{+} \mathrm{Si}$

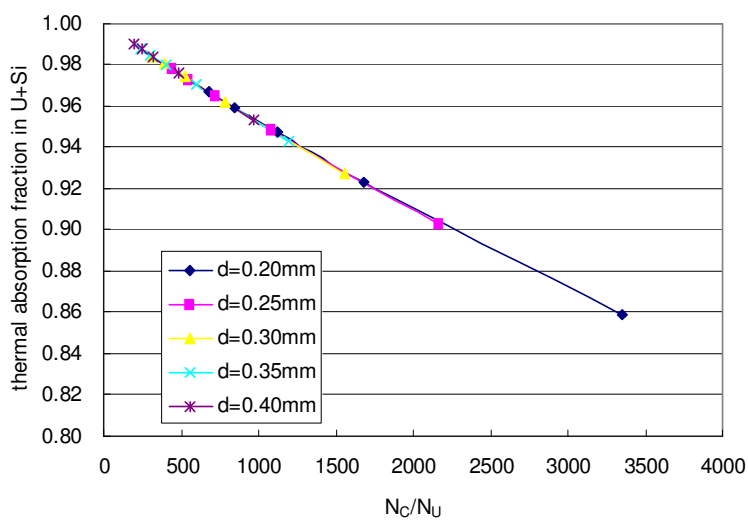

Figure 9. Thermal Utilization Factors for Initial State.

Resonance Escape Probability

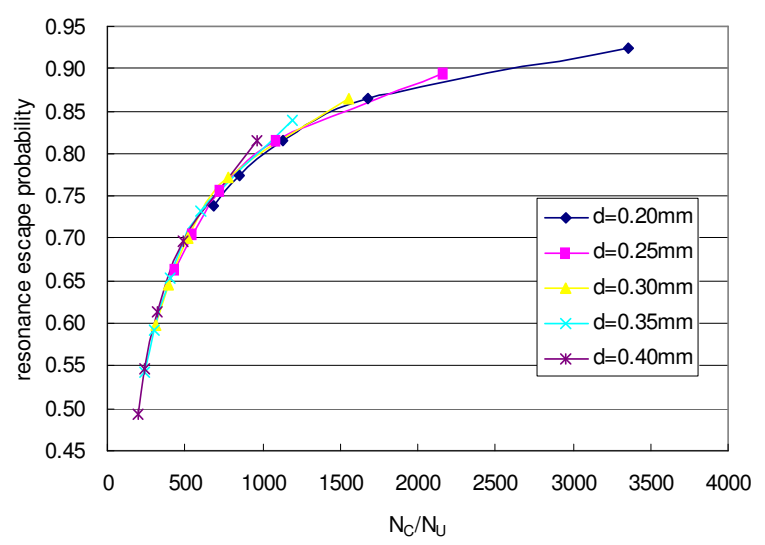

Double Heterogeneity Effects

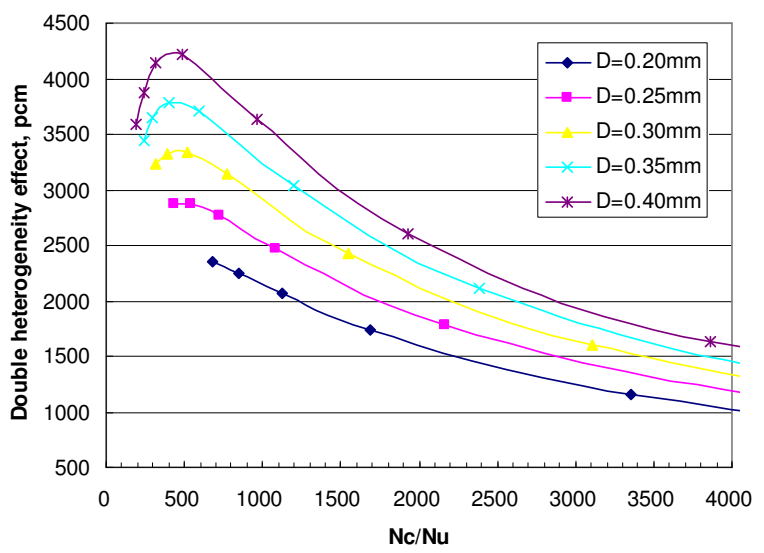

Figure 10. Resonance Escape Probability (p) and Double Heterogeneity Effects. 


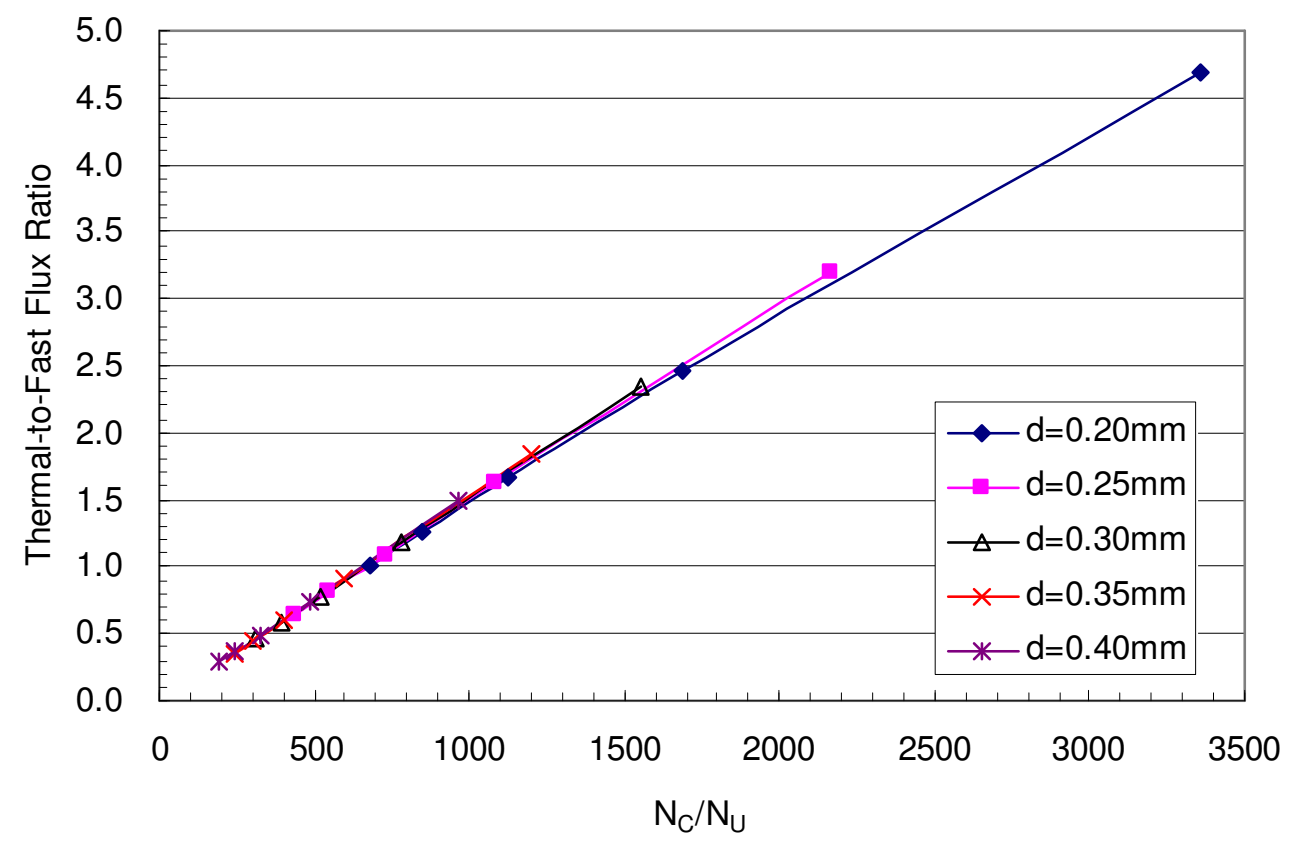

Figure 11. Thermal-to-Fast Flux Ratio (Thermal Cutoff Energy = $4 \mathrm{eV}$ ).

The fission neutron yield per thermal neutron absorption in fuel $(\eta)$ is relatively constant. At low moderator-to-fuel ratios, the resonance escape probability changes more rapidly than the other factors, and therefore an increase in the ratio increases $\mathrm{k}_{\infty}$. As the ratio increases, however, neutron thermalization tends to saturate and thermal neutron captures in the moderator offset the reduction in epithermal neutron captures. As a result, $\mathrm{k}_{\infty}$ initially increases with increasing moderator-to-fuel ratio, attains a maximum value, and then decreases. The optimum moderatorto-fuel number density ratio is approximately 1700 to 2100 . This optimum ratio slightly decreases with the kernel size.

To maximize the cycle length, it is desirable to design the fuel element around this optimum ratio. However, a highly under-moderated design is required to meet the targeted cycle length and discharge burnup with low enriched fuel as discussed below.

For a fixed moderator-to-fuel ratio, the thermal utilization factor increases with kernel size. This is due to the reduced neutron absorption in $\mathrm{Si}$ resulting from the fixed coating layer thicknesses assumed in this parametric study. (Silicon mass decreases with kernel size for fixed 
$\mathrm{N}_{\mathrm{C}} / \mathrm{N}_{\mathrm{U}}$ and coating layer thicknesses.) In fact, it was observed that the fraction of thermal neutrons absorbed in $\mathrm{U}$ and $\mathrm{Si}$ is almost independent of kernel size (see Figure 9). The resonance escape probability also increases slightly with kernel size because of increased self-shielding effect. The fission neutron yield per thermal neutron absorption and the fast fission factor were found to be relatively independent of kernel size.

\subsection{Estimation of Core Cycle Length and Discharge Burnup}

The (single-batch) critical burnup and cycle length have been calculated for different fuel kernel sizes and enrichments as a function of $\mathrm{N}_{C} / \mathrm{N}_{U}$, using the WIMS8 model for the NGNP fuel element. To account approximately for core leakage effects, the critical burnup is assumed reached when the assembly $\mathrm{k}_{\infty}$ is 1.05 (i.e., assuming a 5\% neutron leakage at the core boundary).

The critical burnup determined with this approach is presented in Figure 12 for different fuel kernel sizes and enrichments as a function of the moderator-to-fuel ratio. The legend denotes the uranium enrichment in weight percent and fuel kernel diameter in $\mu \mathrm{m}$. As aforementioned, at low fuel loadings (i.e., large moderator-to-fuel ratios), the initial-state $\mathrm{k}_{\infty}$ increases with increasing fuel loading due to increased thermal utilization factor. On the other hand, at high fuel loadings, initial-state $\mathrm{k}_{\infty}$ decreases with additional fuel loading due to reduced resonance escape probability. As a result, the critical burnup increases initially with increasing fuel loading, reaches a maximum value and then decreases. However, the moderator-to-fuel ratio for the maximum critical burnup (700 to 900) is much smaller than that for the maximum initial-state $\mathrm{k}_{\infty}$ (1700 to 2100), since the fuel burns out more quickly at low fuel loadings.

For a fixed kernel size and packing fraction, the critical burnup increases with increasing uranium enrichment as expected. It is also observed that for a fixed moderator-to-fuel ratio, the critical burnup increases slightly with increasing kernel size. 


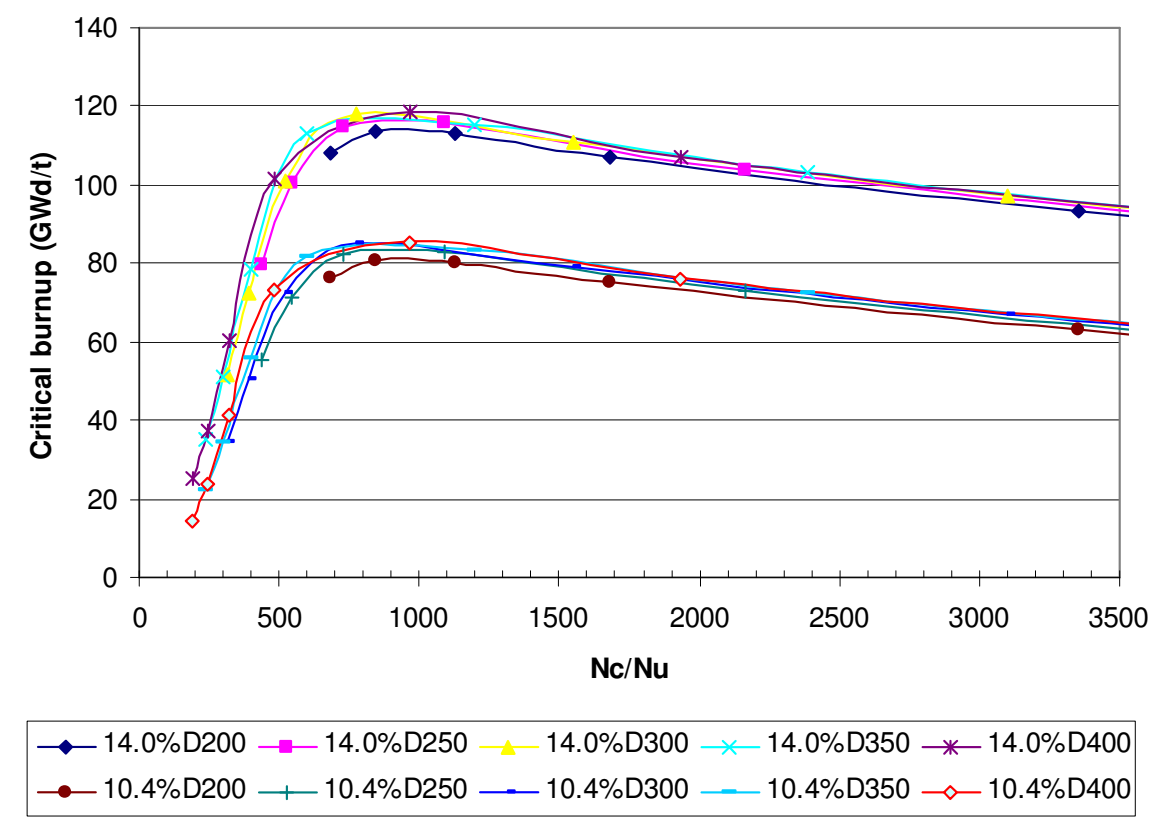

Figure 12. Critical Burnup vs. Moderator-to-Fuel Ratio.

Similar evaluation has been performed for the cycle length. The cycle length for a single-batch fuel management scheme, which was determined as the ratio of critical burnup to specific power, is shown in Figure 13 for different fuel kernel sizes and enrichments as a function of the moderator-to-fuel ratio. The cycle length increases initially with increasing fuel loading, reaches maximum value and then decreases. However, it shows a different behavior than the critical burnup, since the critical burnup is proportional to the cycle length and inversely proportional to the initial fuel loading. As a result, the moderator-to-fuel ratio for the maximum cycle length (400 to 600) is smaller than that for the maximum critical burnup (700 to 900).

For a fixed moderator-to-fuel ratio, the cycle length increases with enrichment and kernel size. Consequently, to increase the cycle length with a fixed amount of fissile loading, it is desirable to use a larger kernel size. It was also found that the targeted cycle length of 18 to 24 months could be met with a single batch scheme using enrichment of 10 to $15 \%$ and packing fraction of 0.2 to 0.3 . Achieving the targeted cycle length requires a small number of fuel batches, but a large number of batches are preferred for high discharge burnup and low reactivity control requirement. 


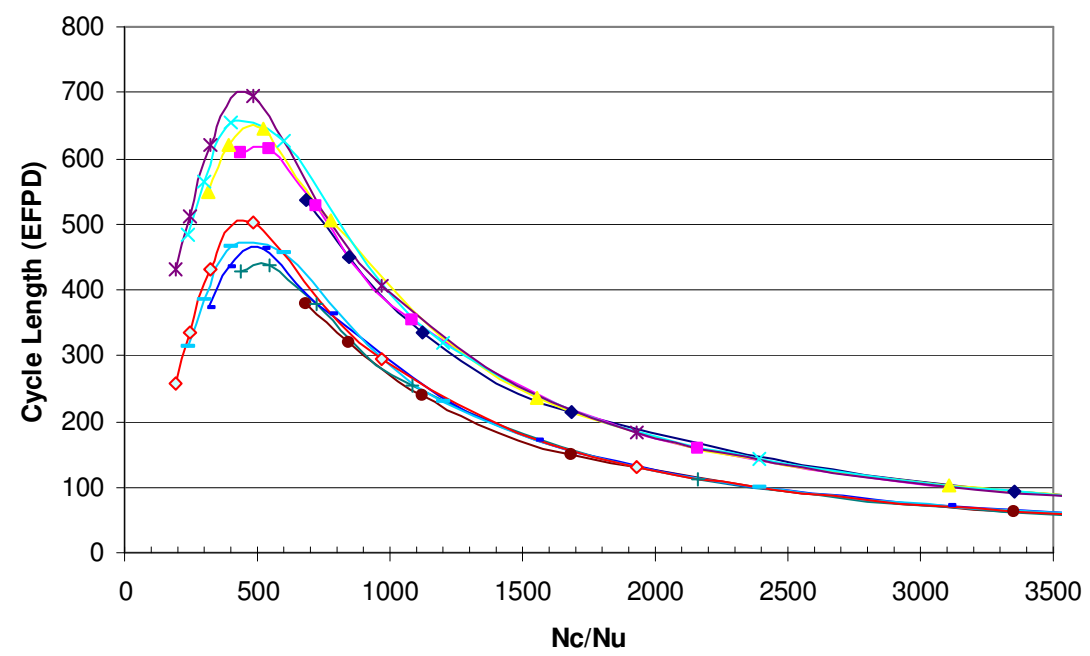

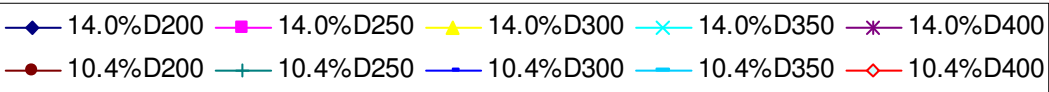

\section{Figure 13. Cycle Length vs. Moderator-to-Fuel Ratio.}

The cycle length and discharge burnup evaluated for the optimum packing fractions (i.e., moderator-to-fuel ratios) to maximize the cycle length are summarized in Table 3 . The threebatch results were estimated using a linear reactivity model. The results show that the optimum packing fraction decreases with increasing kernel size, but increases slightly with increasing enrichment. For the reference particle design parameters (350 $\mu \mathrm{m}$ kernel and $10.4 \%$ enrichment), the optimum packing fraction is found to be $\sim 0.25$.

For a single batch scheme, the discharge burnup achievable with this packing fraction is only $\sim 70 \mathrm{MWd} / \mathrm{kg}$, which is much lower than the target value of $100 \mathrm{MWd} / \mathrm{kg}$. This discharge burnup can be increased to the target burnup range with a three-batch fuel management scheme, but the cycle length is reduced to $\sim 240$ effective full power days (EFPD). The cycle length can be increased by the use of bigger kernel size and higher enrichment. For example, using $400 \mu \mathrm{m}$ diameter fuel kernel and 14\% enrichment, a discharge burnup of $\sim 150 \mathrm{MWd} / \mathrm{kg}$ and a cycle length of $\sim 350$ EFPD can be achieved with a three-batch scheme.

Based on these findings, the whole-core calculations would assume large diameter fuel kernels $(425 \mu \mathrm{m})$. However, a medium size kernel $(350 \mu \mathrm{m})$ would also be used for sensitivity studies. 
Table 3. Cycle Length and Discharge Burnup for Optimum Packing Ratio.

\begin{tabular}{|c|c|c|c|c|c|c|}
\hline \multirow{3}{*}{$\begin{array}{c}\text { Enrichment } \\
(\text { w/o U-235) }\end{array}$} & \multirow{2}{*}{$\begin{array}{c}\text { Kernel } \\
\text { diameter } \\
(\mu \mathrm{m})\end{array}$} & $\begin{array}{c}\text { Optimum } \\
\text { packing } \\
\text { ratio }\end{array}$ & $\begin{array}{c}\text { Cycle length } \\
(\text { EPFD) }\end{array}$ & $\begin{array}{c}\text { Discharge } \\
\text { burnup } \\
(\mathrm{GWd} / \mathrm{t})\end{array}$ & $\begin{array}{c}\text { Cycle length } \\
(\text { EPFD) }\end{array}$ & $\begin{array}{c}\text { Discharge } \\
\text { burnup } \\
(\mathrm{GWd} / \mathrm{t})\end{array}$ \\
\hline \multirow{5}{*}{14} & 200 & 0.625 & 590 & 95 & 295 & 143 \\
\cline { 2 - 7 } & 250 & 0.440 & 622 & 92 & 311 & 138 \\
\cline { 2 - 7 } & 300 & 0.329 & 653 & 93 & 327 & 139 \\
\cline { 2 - 7 } & 350 & 0.262 & 667 & 92 & 334 & 138 \\
\cline { 2 - 7 } & 400 & 0.209 & 697 & 97 & 349 & 146 \\
\cline { 2 - 7 } & 200 & 0.620 & 425 & 69 & 213 & 104 \\
\cline { 2 - 7 } & 250 & 0.432 & 446 & 67 & 223 & 101 \\
\cline { 2 - 7 } & 300 & 0.319 & 463 & 67 & 232 & 102 \\
\cline { 2 - 7 } & 350 & 0.253 & 484 & 68 & 242 & 103 \\
\hline
\end{tabular}




\subsection{Whole-Core Model Evaluation and Studies}

Whole-core analysis and optimization of the NGNP fuel cycle has been performed using the REBUS-3/DIF3D/WIMS8 calculational path discussed in Section 3.0. The fuel management optimization study of this work is minimized by using the information garnered from the lattice studies of Section 4.0. Consequently, for the whole-core depletion studies, two kinds of fuel elements have been considered: one employing a $350 \mu \mathrm{m}$ diameter fuel (enrichment of 10\% and packing fraction of 0.289 ) and the other $425 \mu \mathrm{m}$ fuel (enrichment of $14 \%$ and packing fraction of 0.25). The larger size fuel kernel is considered the base case. In Section 5.1, the REBUS-3/DIF3D model used for the whole-core calculations are first discussed. Justifications for some of the simplifying assumptions that were employed are provided in Section 5.2. Various fuel management and fuel shuffling schemes have been evaluated. These include single-, two-, and three-batch schemes with radial and axial fuel element shuffling. An evaluation of the transitional cycle for the two-batch fuel management scheme has also been done. For each of the fuel management schemes, an assessment of the sensitivity of core performance to the fuel loading (kernel size and packing fraction) has been performed. The results for whole-core depletion studies are presented in Sections 5.4 to 5.8.

\subsection{REBUS-3/DIF3D Whole-Core Model for NGNP Core}

The REBUS-3 calculational path chosen for this work uses as flux solver the DIF3Dnodal capability that solves the multigroup neutron diffusion equations. In the DIF3D calculations, six neutron energy groups have been employed predominantly. An assessment of this approximation is presented in Section 5.2. The products of the DIF3D calculations are the eigenvalue, neutron flux and power distributions, and reaction rate distributions. The reaction rates are passed to the REBUS-3 depletion solver. Following the depletion calculation at a given step, the latest number densities are used for composing updated cross sections that are then passed to the DIF3D module.

The DIF3D code solves the multigroup diffusion equations over homogeneous hexagonal-prismatic nodes (see Figure 14). An assembly pitch of $36 \mathrm{~cm}$ is assumed. In the current study, each column is spatially represented using 32 axial nodes. The whole length of the 
active core (about $793 \mathrm{~cm}$ ) and the lower and upper graphite reflector zones are modeled (the lower and upper reflectors have heights of 160.0 and $120.0 \mathrm{~cm}$, respectively). Twenty of the 32 axial nodes are used for representing the active core. The remaining 12 axial nodes are used for the lower and upper reflector zones. Eleven rings of columns are represented radially in the DIF3D model. Ten of these rings correspond to the ten core rings containing the annular core and the surrounding inner and outer replaceable reflectors. The eleventh ring is used for representing

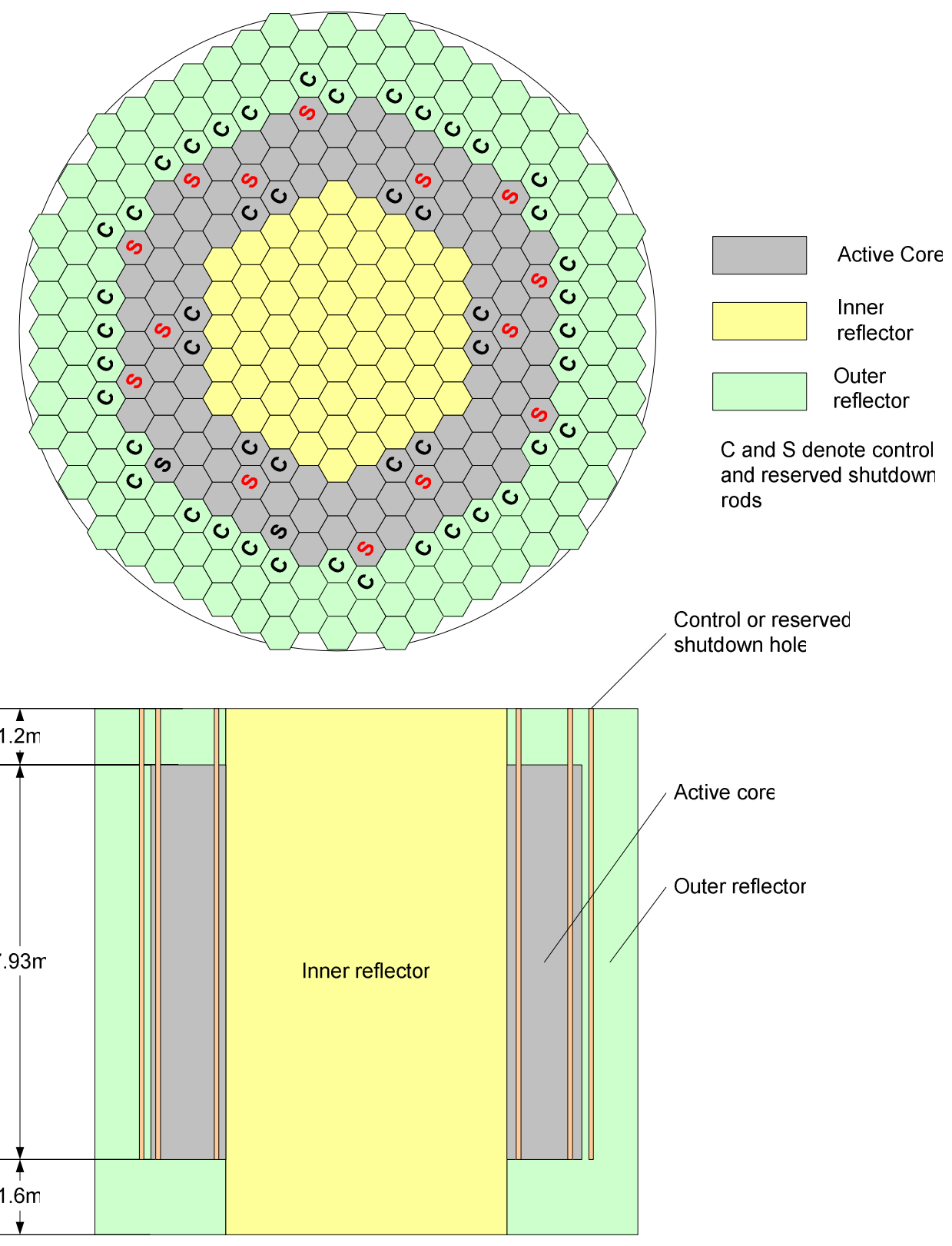

Figure 14. DIF3D Core Model for NGNP Whole-Core Calculations. 
the permanent reflector that surrounds the core. The sixth, seventh, and eighth rings contain nodes representing the active core. The first to fifth and ninth and tenth rings contain the inner and outer graphite reflectors. A no-return-current boundary condition is imposed on all external surfaces.

The core boundary symmetry used for minimizing the DIF3D computational burden depends on the problem being solved. Fuel shuffling in particular affects application of this solution feature, as fuel shuffling will only be possible between fuel elements of the same kind because the configurations of control, shutdown and standard fuel elements are different from each other. Consequently, while a sixth-core symmetry model could be used to reduce the computational time for a single-batch fuel management core and a third-core symmetry model for a two-batch core, no such azimuthal symmetry is available for the three-batch scheme, and a full core model is therefore used in this case.

Both the equilibrium cycle and non-equilibrium cycle options of the REBUS-3 code with no recycle have been employed for the depletion calculations. The non-equilibrium cycle option has been used for calculating the transitional cycles, while the equilibrium cycle option is used for deriving the equilibrium-core performance data. The actinides represented in the REBUS-3 transmutation chain are U-233, U-234, U-235, U-236, U-237, U-38, Np-237, Np-239, Pu-238, $\mathrm{Pu}-239, \mathrm{Pu}-240, \mathrm{Pu}-242, \mathrm{Pu}-242, \mathrm{Am}-241, \mathrm{Am}-242 \mathrm{~m}, \mathrm{Am}-243, \mathrm{Cm}-242, \mathrm{Cm}-243, \mathrm{Cm}-244$, and Cm-245. Two models for representing the fission products have been utilized. In the first, the nearly 100 fission products that are used in the WIMS8 lattice calculations and for which broad group cross sections are generated have been included explicitly in the REBUS-3 model. This model is however time consuming because of the size of the transmutation (burn) matrix whose exponential is to be computed. A sensitivity study summarized below indicated that a reduction of the number of fission products to few nuclides (Xe-135, I-135, Sm-149, Pm-149 and parentdependent lumped fission products) does not significantly affect solution accuracy but reduces the overall computational time substantially (about a factor of ten), because of the drastic reduction in the time utilized for the fuel depletion calculation. The reduced fission products chain is the basis of simplified lumped fission product (LFP) model that was used predominantly in this work. 
With the simplified LFP model, it was possible to perform routinely depletion calculations with large number of burn zones. The burn zones correspond to the distinct regions over which transmutation and decay equations are solved. Each burn zone typically includes a group of axial nodes in the active core. Models with one, five, and 10 axial burn zones were developed and utilized in this study. The number of radial burn zones depends on the particular problem (fuel management scheme and shuffling option). In the case of fuel shuffling, the fuel element would reside in at most $n$ locations in the core (where $n$ is the number of fuel batches). To track the fuel burnup, each of these locations would be designated a distinct burn zone. Therefore in a full core model (employing no radial symmetry), one could have 102 burn zones in the radial direction. It is noted that the REBUS-3 computation time is strongly related to the number of burn zones, particularly for large problems.

Burnup-dependent, broad-group, nuclide cross sections data have been generated for the core and reflector regions using the WIMS8 code. Data for heavy-metals (U-233 to Cm-245), light elements (oxygen, carbon (graphite), boron, silicon, helium, etc.), and fission products (about 100) were generated by the code at the core average temperatures (fuel at $1350^{\circ} \mathrm{K}$ and graphite block at $1200^{\circ} \mathrm{K}$ ). An auxiliary program has been used to write these cross-section data into a format usable by the REBUS-3/DIF3D fuel cycle (and depletion) code. The REBUS-3 code capability that permits the fitting of both capture and fission cross sections of the active isotopes is employed in the calculations. This approach accounts for cross section variations due to changes in the nuclide self-shielding and neutron spectrum as a function of the depletion.

\subsection{Verification and Sensitivity Studies of REBUS-3/DIF3D Model}

\section{Evaluation of REBUS-3 Transmutation and Decay Chains}

Fuel-element burnup calculations have been performed to confirm that the cross section representation of the NGNP fuel element has been accurately implemented. This was done by comparing the REBUS-3 calculation results for the fuel element to those obtained with WIMS8. The fuel element data used in this study are taken from Section 2.0 along with fuel kernel diameter of $350 \mu \mathrm{m}$ and enrichment of $10.31 \mathrm{w} / \mathrm{o}$ U-235. Figure 15 displays the fuel element $\mathrm{k}_{\infty}$ calculated by the two codes. AFP-32G and AFP-06G denote the 32-group and 6-group results, 
respectively, of the REBUS3 calculations utilizing all the fission products (about 100) employed in the WIMS8 calculations explicitly. The different WIMS8 cases denote results with different structures for the group condensation of cross sections. Very similar results are obtained by the two codes.

This exercise confirmed that the data generated by WIMS8 are correctly transferred to the ISOTXS file. It also confirmed that the cross-section data have been appropriately interpolated by REBUS-3 and that the transmutation and decay chain data are consistent. This REBUS-3 transmutation and decay model has been used for generating the data reported in following sections.

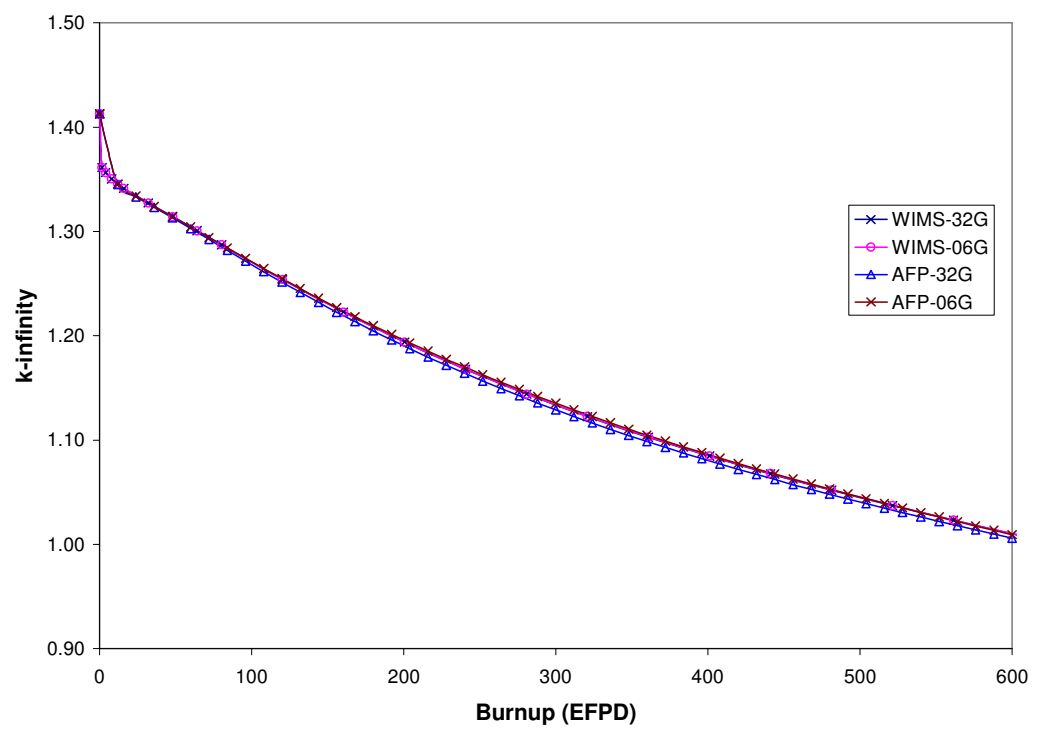

Figure 15. Fuel Element $k_{\infty}$ from WIMS8 and REBUS-3 Depletion Calculations.

\section{Evaluation of REBUS-3 Lumped Fission Products (LFP) Model}

Preliminary sensitivity studies indicated that even with modern day computers the computation time for whole-core depletion calculations employing about 100 fission products in the transmutation (burn) chains could result in substantial computation time. In order to be able to perform the planned calculations within reasonable time it was necessary to reduce the size of the burn matrix used in the solution of the nuclide number densities. This was done by using a 
lumped fission products (LFP) representation of the detailed fission products. In this model, a few of the fission products (Xe-135, I-135, Sm-149, Pm-149) were explicitly represented because of their reactivity impacts, and the remaining fission products were lumped together into a few parent-dependent lumped fission products. This process requires that representative LFP yields and cross sections be generated in a systematic way. Figures 16 and 17 display the impact of the LFP model on the REBUS-3 fuel element and whole-core results. The whole-core calculations were performed with two different fuel kernel diameters $(350$ and $425 \mu \mathrm{m})$. The figures show that the LFP and "all-fission products" (AFP) models give very similar trends for the multiplication factor ( $k_{\infty}$ or k-effective) but there are non-negligible differences at the end of cycle. The sensitivity studies performed to date indicate that the difference in the k-effective calculated by the LFP and AFP models is about 0.2 to $1.5 \%$, with the LFP model giving the higher value. In order to correct for this difference in the whole-core depletion calculations using the LFP model, the end of cycle searches have been done for a k-effective value of 1.01 .

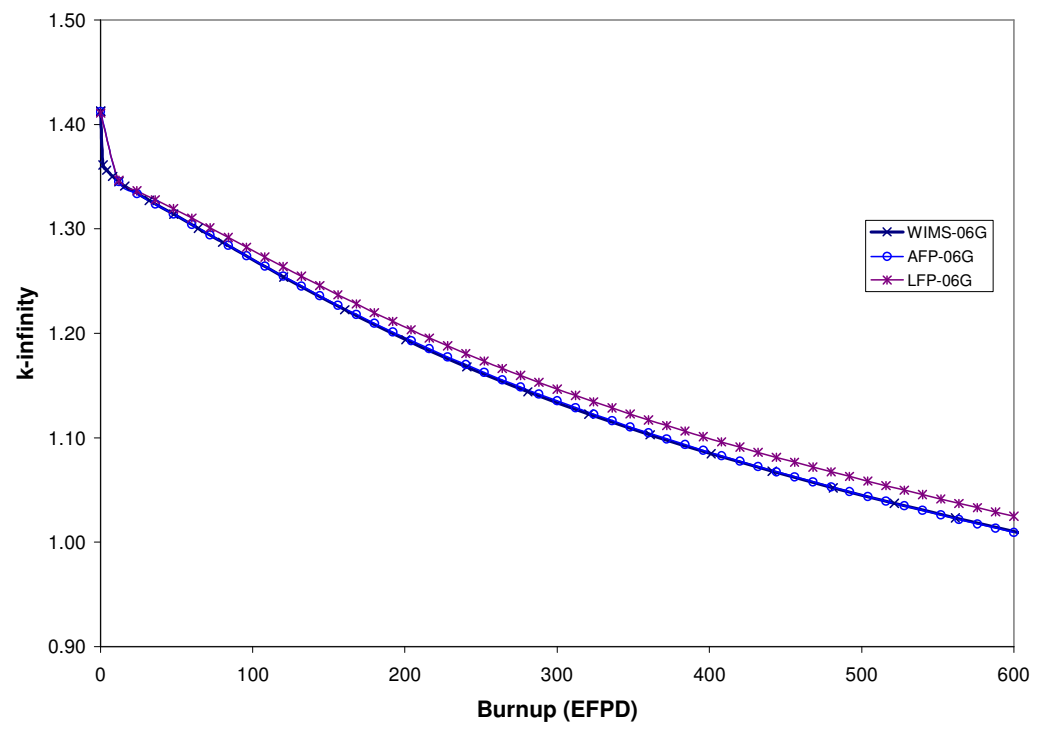

Figure 16. Fuel Element Burnup-Dependent Multiplication Factors with Lumped and Explicit Fission Products Models. 


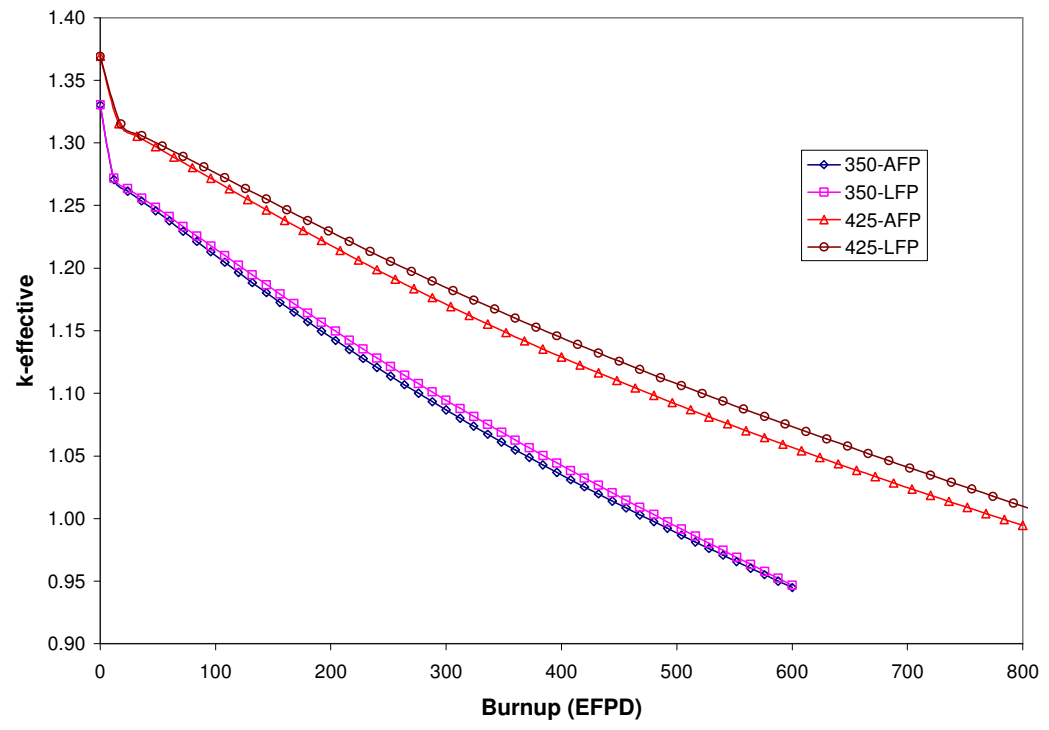

Figure 17. Whole Core Burnup-Dependent Multiplication Factors with Lumped and Explicit Fission Product Models.

\section{Evaluation of Number of Axial Depletion (Burn) Zones}

Computation time considerations dictate that an optimum number of burn zones be defined and used in the whole-core calculations. Ideally, it is attractive to let each spatial computation mesh have its own burnup zone. This however is impractical, particularly with a large number of spatial meshes and in equilibrium cycle calculations. While it is possible in principle to reduce the number of radial burn zones (i.e. collecting radial columns into the same burn zone), this was not done in this study because of the need to track very accurately the impact of fuel management scheme (fuel batches) on the power peak. As a result, we have attempted to minimize the number of burn zones by finding the optimum number of axial burn zones. This was done by evaluating the results obtained with 1, 5, and 10 burn zones in REBUS-3 calculations. An evaluation of the impact of the LFP and AFP models on the results was also performed. For this study, a single-batch or two-batch fuel management scheme for a core using $425 \mu \mathrm{m}$ diameter and 14 w/o-U235 enriched fuel with a packing fraction of $25 \%$ was used. The results from this study are summarized in Figure 18.

These results indicate that regardless of the fission products model used, the eigenvalue letdown is independent of the number of axial burn zones employed for the depletion 
calculations. However, the core total power peaking factor is strongly dependent on the number of axial burnup zones. The result show consistently that for most cases the 5 and 10 axial burnzones give very similar results for the core power peaking factor, hence suggesting that either of these models could be used for the whole-core calculations. These trends apply to both the 425 and $350 \mu \mathrm{m}$ fuel cases. Most of the calculations performed in the present work used 10 axial burn zones.
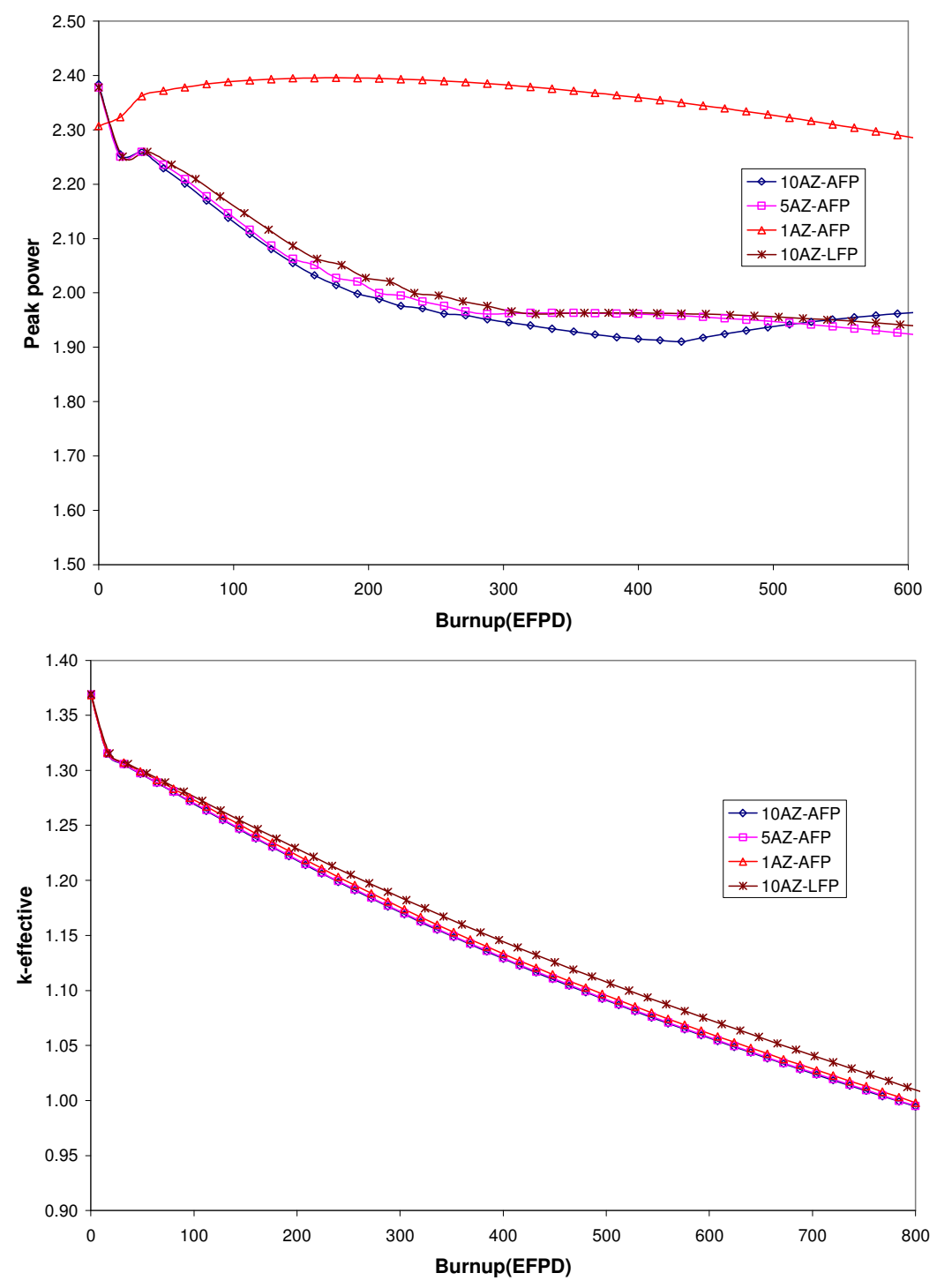

Figure 18. Sensitivity Study on Number of Axial Burn Zones.

(Top figure: peak power; bottom figure: k-effective). 


\section{Comparison of Equilibrium and Non-Equilibrium Models}

The REBUS-3 code has an equilibrium cycle capability that provides an efficient search for the equilibrium core state for a reactor operating under a fixed fuel management scheme. The solution for the core state could also be found by performing repeated cycle-by-cycle analysis using the non-equilibrium cycle capability of the code.

For completeness of this report, the results from the two models for the same depletion case have been compared. This comparison was done for a core using a two-batch fuelmanagement scheme with $350 \mu \mathrm{m}$ diameter fuel (packing fraction of $28 \%$, enrichment of $10 \%$ ) and $425 \mu \mathrm{m}$ diameter fuel (packing fraction of $25 \%$, enrichment of $14 \%$ ). Ten axial burn zones were used in the calculations.

The results for the two fuel diameter cases are summarized in Figure 19. The nonequilibrium calculation followed the core evolution over six cycles, starting with a core of uniform fresh fuel loading. At the beginning of a given cycle, one half of the fuel elements are discharged and replaced with fresh fuel.

In Figure 19, the equilibrium cycle results for the total power peaking factor and the k-effective have been repeated for the six cycles, primarily to show the convergence of the nonequilibrium cycle model to the equilibrium cycle state. It can be seen that the non-equilibrium cycle results converge to those of the equilibrium cycle results. However, relative to the equilibrium cycle model, the non-equilibrium cycle model slightly overestimates the k-effective and underestimates the peaking factor at $\mathrm{BOC}$ even after the $6^{\text {th }}$ cycle, since the burned fuel compositions are not fully converged to the equilibrium state. 

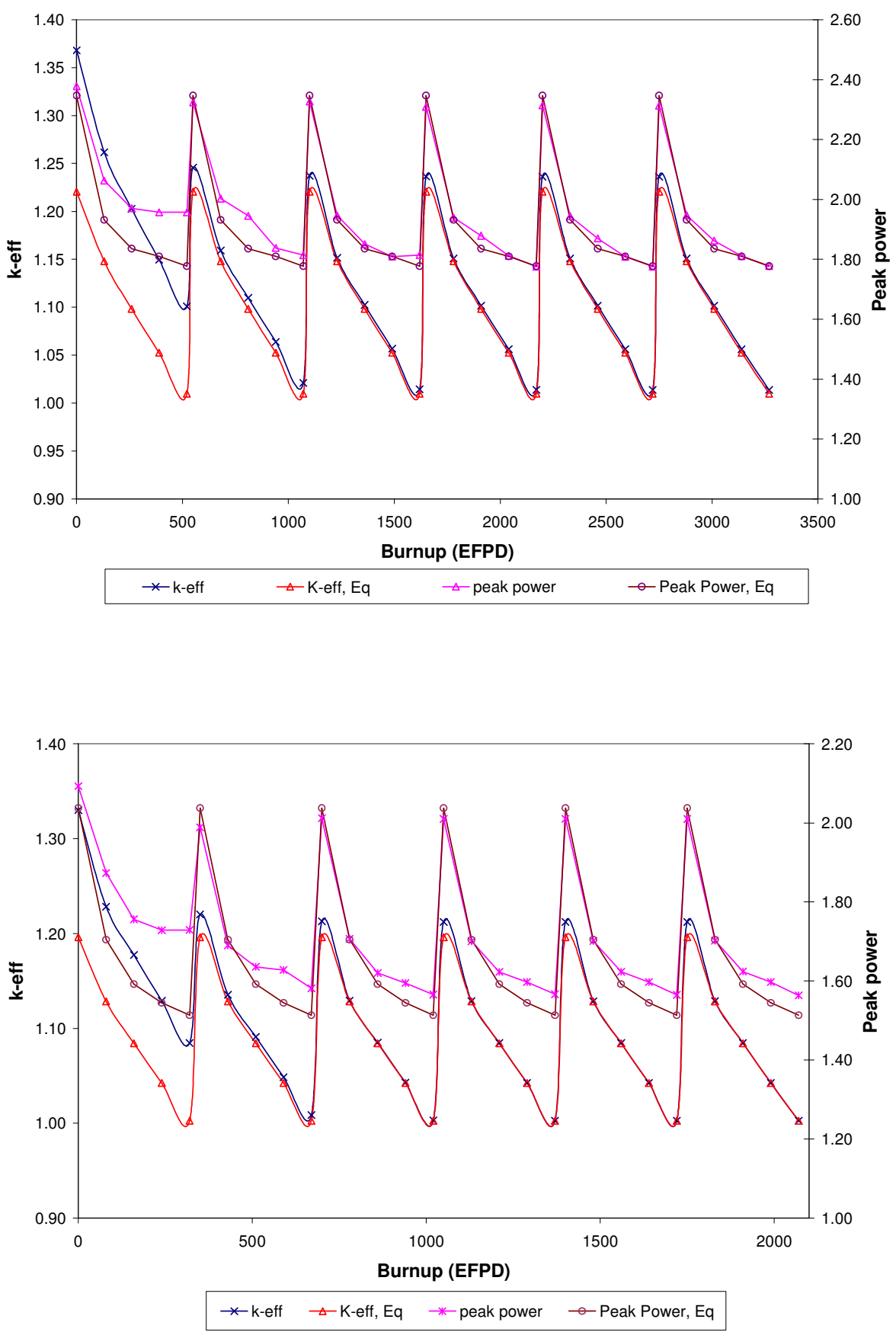

Figure 19. Comparison of Equilibrium and Non-Equilibrium Results (top picture: $425 \mu \mathrm{m}$ fuel; bottom picture: $350 \mu \mathrm{m}$ fuel). 


\section{Evaluation of Number of Groups}

The number of energy groups used in depletion calculation affects both the computation time and the solution accuracy. For the extensive depletion calculations done in this work, six energy groups have been used; the group boundaries are $20 \mathrm{MeV}, 0.820 \mathrm{MeV}, 9.118 \mathrm{KeV}$, $4.0 \mathrm{eV}, 0.625 \mathrm{eV}, 0.1 \mathrm{eV}$, and $0.0 \mathrm{eV}$. The impact of the number of energy groups on the k-effective letdown curve has been evaluated. The calculations were done for a core employing single-batch fuel management scheme with $350 \mu \mathrm{m}$ diameter fuel kernel. Cases utilizing 6-group and 32-group ISOTXS libraries generated by WIMS8 have been compared and results are shown in Figure 20. These results show that for the k-effective letdown, the 6- and 32-group structures give quite similar results. Similar conclusions can be made for the peaking factor, though in this case there is about a 5\% difference in the power peaking value between the cases. The group effect may be more pronounced for reactivity coefficients, but this has not been investigated in this work. It is recommended that a higher number of groups (than 6) be used in the depletion calculations if higher precision in the peaking factor is required. Computational requirements necessitates that an optimum value be found.

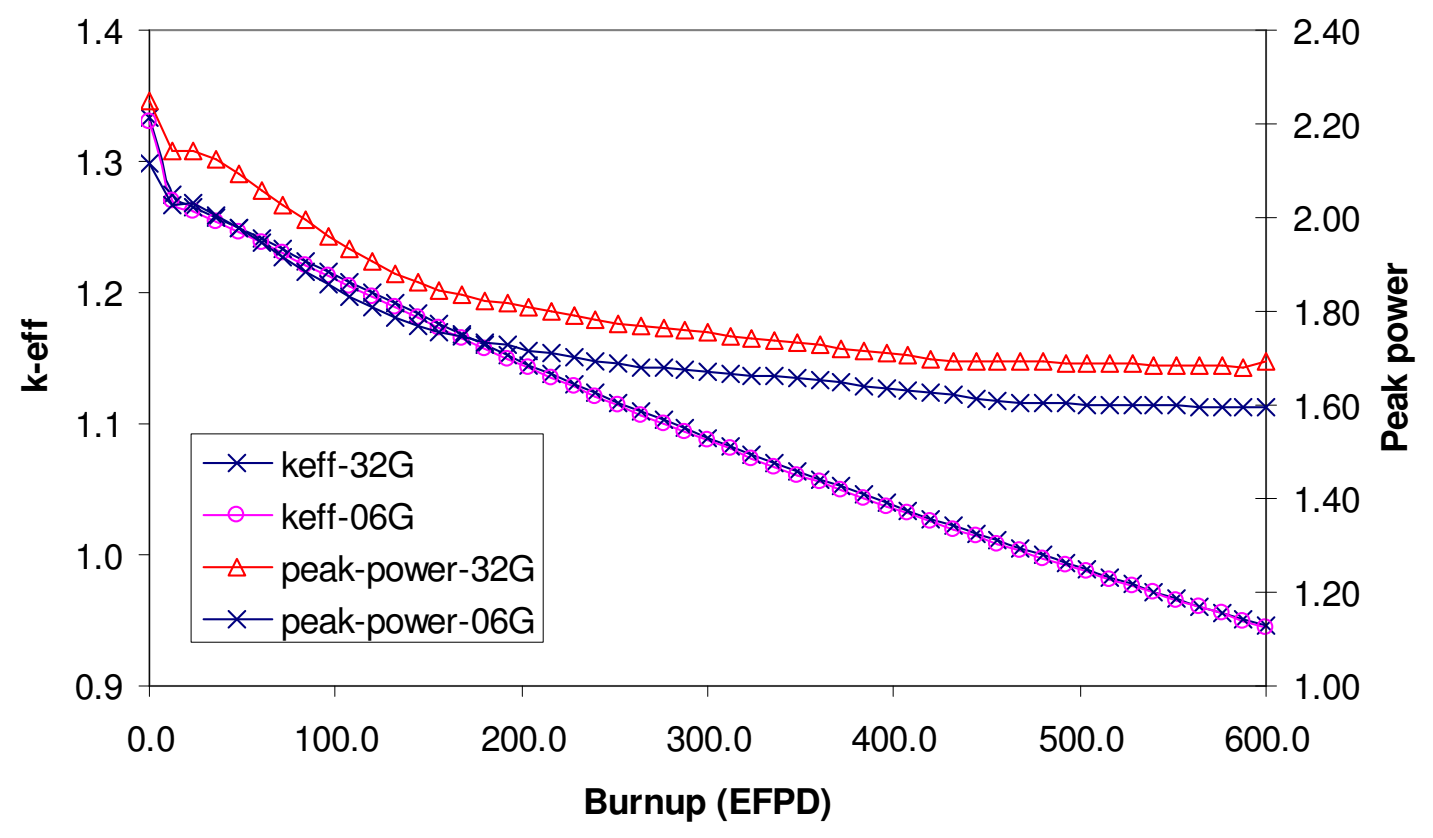

Figure 20. k-effective with 6- and 32-Group REBUS-3/DIF3D Calculations. 


\subsection{Radial Peaking Factor Calculation with MCNP4C}

The nodal method used for the whole-core analysis employs spatial solution meshes greater than the fuel compact (pin) dimension. Typically in the state-of-the-art analysis of reactors, the intra-nodal power distributions recovered from such solutions are modulated with those from local (assembly) pin power calculations to obtain accurate representation of the pin power distribution. This is sometimes referred to as the de-homogenization step. The DIF3Dnodal code currently does not have an integrated de-homogenization capability applicable to the block-type VHTR design. The code however does a conservative estimation of the power peaking factor and those are the ones presented so far in Section 5.2 and would be used as indicators of the core power peaking for the balance of this report. The approach involves sampling surface-averaged values of the power and choosing the maximum value. The nodal power is approximately reconstructed in this case.[8,9] More elaborate and correct evaluation of the power peaking factor can also be obtained using the VARIANT capability of the DIF3D code or the RCT code [13] that reconstructs the pin power and burnup characteristics from nodal solutions, but has not been tested in this work.

To get an accurate indication of the radial power peaking within the core, MCNP4C calculations have been done for the representative problem shown in Figure 21. This case is for a core with $14 \%$ enriched fuel and $425 \mu \mathrm{m}$ kernel diameter. The same fuel loading and age is used for the calculation. This case would be quite representative of the initial core state for the singlebatch fuel management scheme design. One million neutron histories were used for the calculation. The resulting normalized element peaking factor is shown in Figure 22. Quite significant power peaking is observed (1.84 at the corner point adjacent to the reflector). When this is multiplied by the maximum axial peaking factor for a given column (typically about 1.29 at BOC), it is evident that large core total peaking factors (about 2.37) could result. The conservatively estimated value from DIF3D-nodal is about 2.40 for this core (see Figure 19 above). Clearly, this is not for the actual fuel compact positions, but provides a fairly accurate estimate of the core total peaking factor. However, more elaborate formulation has to be developed in future work. 
This large power peaking factor (2.4) could be mitigated by using (1) multiple batches; (2) a graded fuel loading in the element, with fuel compacts of lower loading (fuel buffer) in the outer rows adjacent to the inner graphite reflector; (3) using strategically placed burnable poison pins is fuel elements; (4) using absorber pins in the inner reflector rows adjacent to the active core; and etc. Options involving different fuel-element loadings would however complicate fuel handling and shuffling functions at the plant.

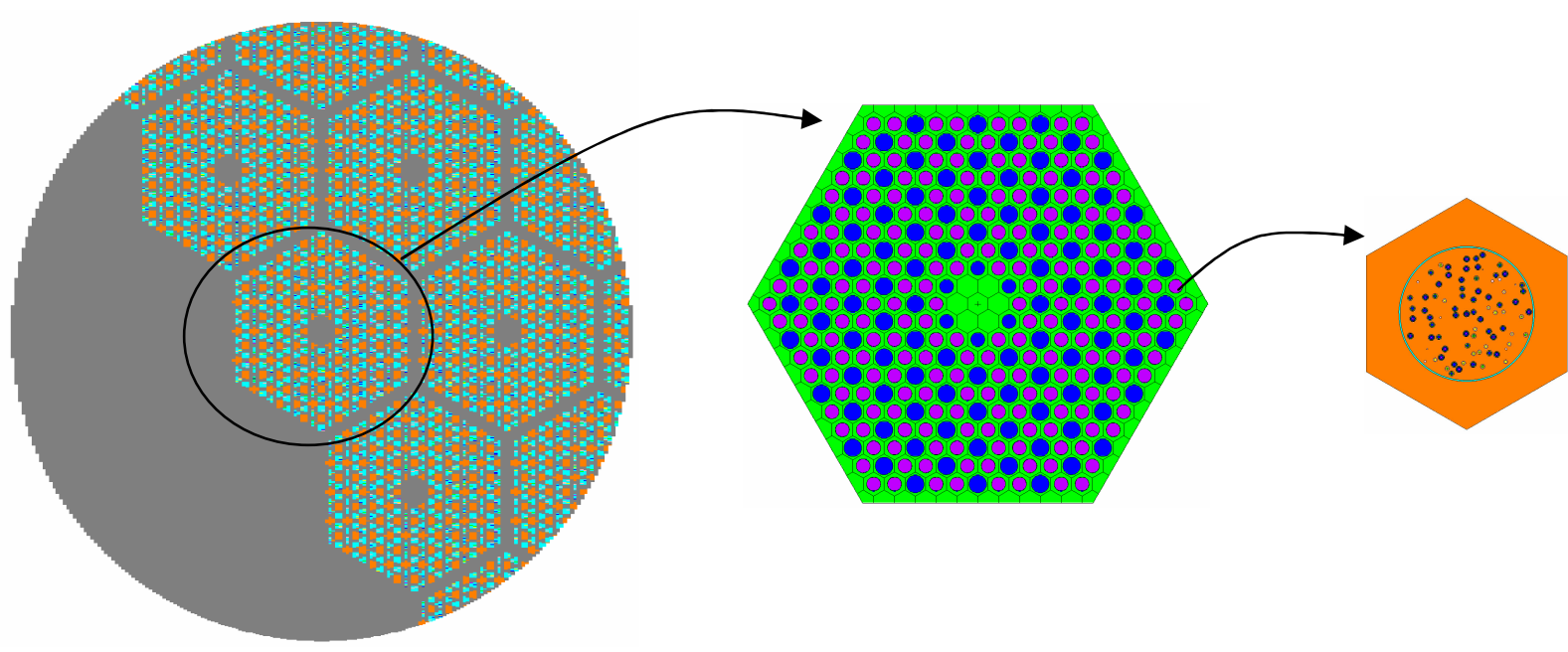

Simplified core

fuel element

fuel cell

Figure 21. Simplified Core Model for Peaking Factor Estimation with MCNP4C. 


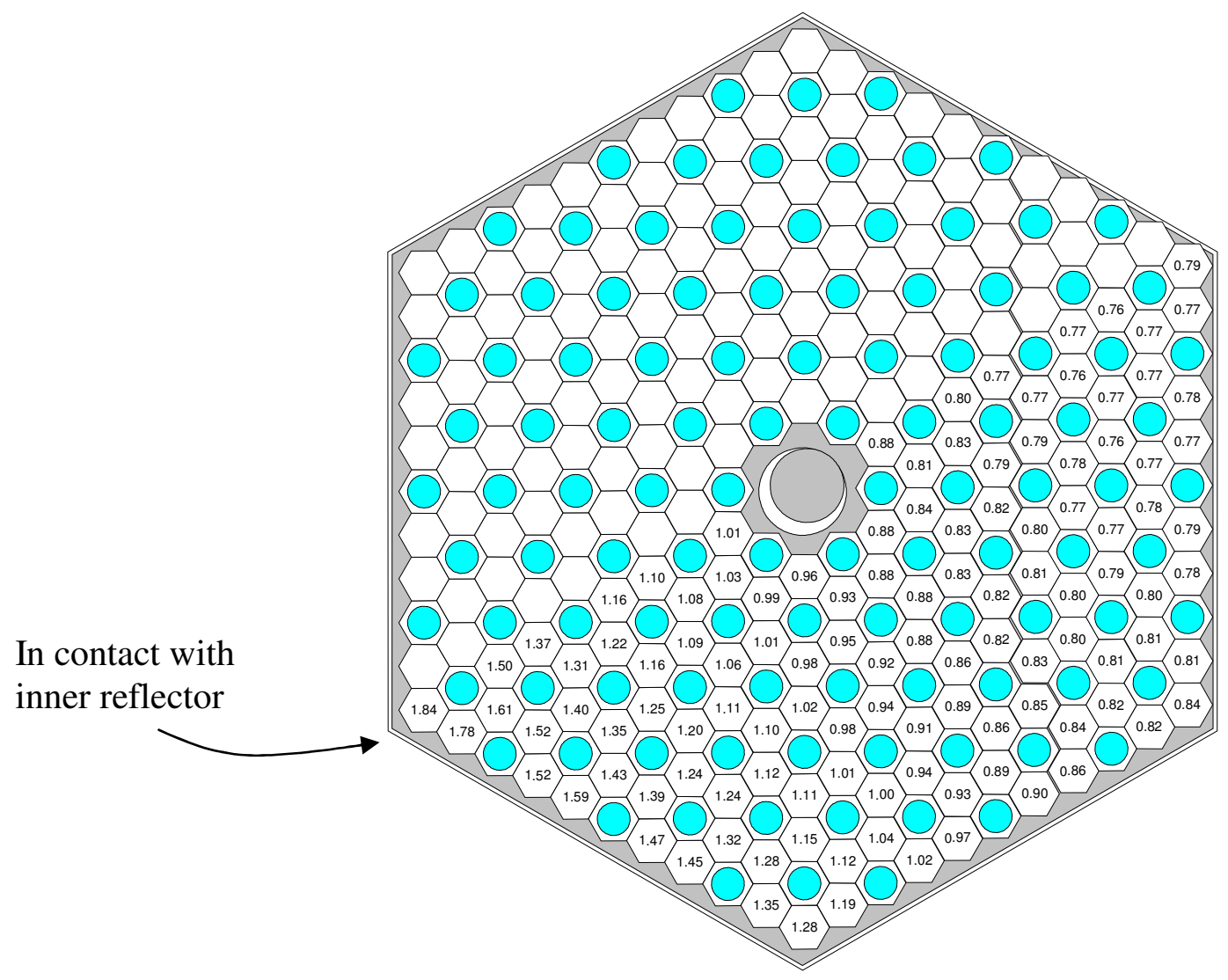

Figure 22. Pin Power Distribution in Fuel Element Adjacent to Inner Reflector. 


\subsection{Fuel Management Option - Single-Batch Core}

The results of depletion calculations for a core using a single-batch fuel management scheme are summarized in this section. The two- and three-batch equilibrium cycle results are presented in Sections 5.5 and 5.6, respectively. Section 5.7 presents the transitional cycle results for two- and three-batch schemes. An integrated summary is provided in Section 5.8.

A single-batch core implies that the fuel elements in the core are loaded and discharged at the same time. The end of core corresponds to the minimum reactivity states that ensure that the core is still critical. Two sets of calculations using different fuel design parameters have been performed for this core. In the first, $350 \mu \mathrm{m}$ diameter and $10 \%$ enriched fuel with a packing fraction of $28.9 \%$ is used, whereas in the second, $425 \mu \mathrm{m}, 14 \%$ enriched fuel with a packing fraction of $25 \%$ is used. For most of the discussions that follow, the fuel loadings are referred to simply by the fuel kernel diameter.

Table 4 is a summary of the cycle length, discharge burnup, peak power (derived conservatively by DIF3D-nodal) and the k-effective for the beginning and end of cycle (BOC and EOC). The predicted cycle lengths and discharge burnup are quite consistent with those contained in Table 3 in Section 4.0. Those results were obtained with lattice calculations.

\section{Table 4. Single-Batch Fuel Management Option with $350 \mu \mathrm{m}$ and $425 \mu \mathrm{m}$ Kernel-Diameter Fuel.}

\begin{tabular}{|c|c|c|c|c|c|}
\hline \multirow[b]{2}{*}{$\begin{array}{l}\text { Fission products } \\
\text { modeling }\end{array}$} & \multirow{2}{*}{$\begin{array}{l}\text { Number of } \\
\text { axial burning } \\
\text { zones }\end{array}$} & \multicolumn{4}{|c|}{ Results } \\
\hline & & $\begin{array}{l}\text { Cycle length } \\
\text { (EFPD) }\end{array}$ & $\begin{array}{c}\text { Discharge } \\
\text { burnup, } \\
\text { GWd/t }\end{array}$ & Peak Power ${ }^{\text {a) }}$ & $\begin{array}{c}\mathrm{k}_{\mathrm{eff}} \text { at } \\
\mathrm{BOC} / \mathrm{EOC}\end{array}$ \\
\hline \multicolumn{6}{|c|}{$350 \mu \mathrm{m}$ Diameter/10\% Enriched/28.9\% Packing Fraction Fuel } \\
\hline \multirow{3}{*}{ Explicit fission products } & 1 & 486.5 & 55.3 & 2.13 & \\
\hline & 5 & 476.6 & 54.2 & 2.10 & \\
\hline & 10 & 474.5 & 53.9 & 2.12 & \\
\hline Lumped fission products & 10 & 465.8 & 52.9 & 2.10 & $1.3301 / 1.0100$ \\
\hline \multicolumn{6}{|c|}{$425 \mu \mathrm{m}$ Diameter $/ 14 \%$ Enriched $/ 25 \%$ Packing Fraction Fuel } \\
\hline \multirow{3}{*}{ Explicit fission products } & 1 & 781.4 & 76.8 & 2.38 & \\
\hline & 5 & 783.7 & 77.1 & 2.38 & \\
\hline & 10 & 794.0 & 78.1 & 2.40 & \\
\hline Lumped fission products & 10 & 799.4 & 78.6 & 2.38 & $1.3690 / 1.0100$ \\
\hline
\end{tabular}

a) Peak power as calculated by DIF3D-nodal.. 
The results show that using the higher fuel loading and enrichment (425 $\mu \mathrm{m}$ case) gives a higher reactivity swing (37\% versus $33 \% \Delta \mathrm{k}$ ) than the $350 \mu \mathrm{m}$ fuel case. This implies that a higher loading of burnable poisons or higher strength control rods might be needed for the $425 \mu \mathrm{m}$ kernel-diameter case (relative to the $350 \mu \mathrm{m}$ case), as would be expected.

With the $425 \mu \mathrm{m}$ kernel-diameter core, it is possible to achieve a cycle length of about 800 days (over 2 years assuming a capacity factor of 90\%). However, only a burnup of about $90 \mathrm{GWd} / \mathrm{t}$ is possible with this loading and so, the targeted discharge burnup is not met.

Additionally, the $425 \mu \mathrm{m}$ case gives a higher total core peaking factor (2.4). This high peaking factor occurs at the beginning of cycle for the 350 and $425 \mu \mathrm{m}$ kernel-diameter cases.

The core radial and axial power distributions for the two cases are presented in Figures 23 to 27. It is observed that the core radial distribution are fairly flat for the two cases and the maximum column power density is about 1.20 -1.25 of the core average. Consistently with the higher total core peaking value, the $425 \mu \mathrm{m}$ case has higher values for the core axial and radial peak powers. It is noted that for both cases, the power peaks (total, radial, and axial) become smaller with burnup (i.e., the core power distribution becomes flatter with burnup).

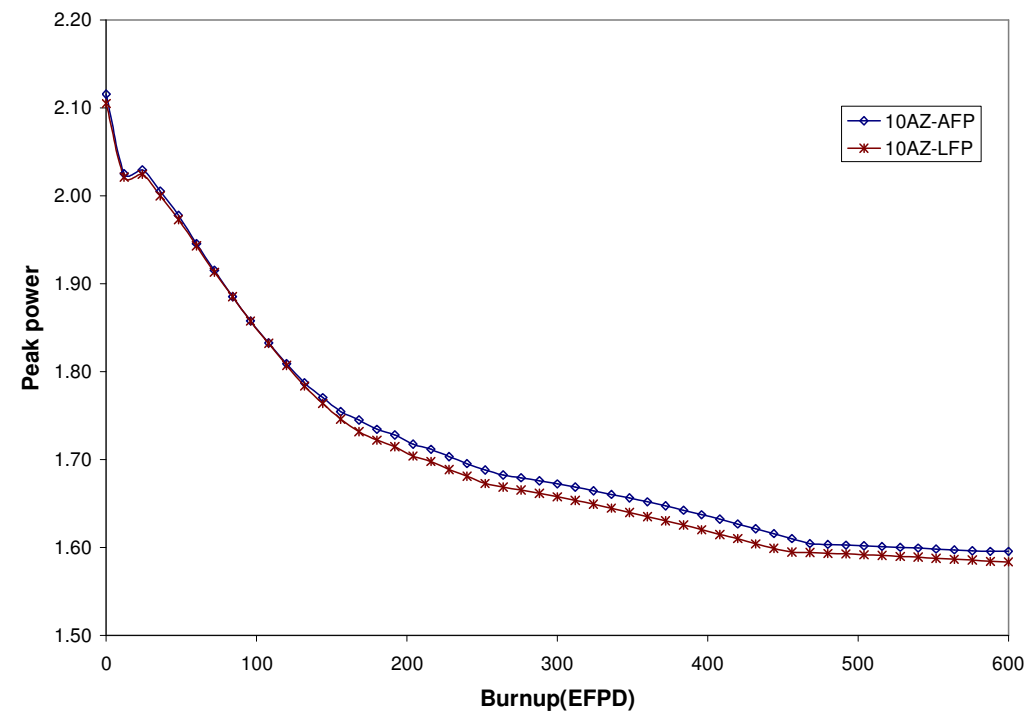

Figure 23. Core Total Power Peaking Factor as Function of Burnup (Single-Batch Core: $350 \mu \mathrm{m}$ Kernel-Diameter Case). 


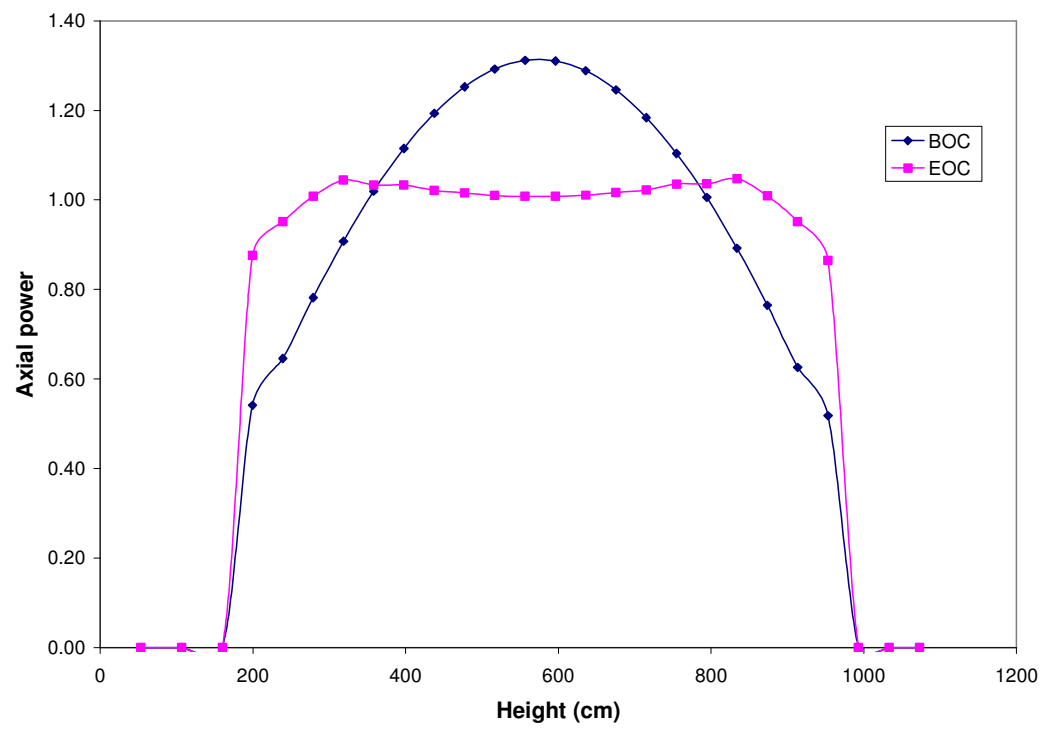

Figure 24. Core Axial Power Distributions at Beginning and End of Cycle (Single-Batch Core: $350 \mu \mathrm{m}$ Kernel-Diameter Case).

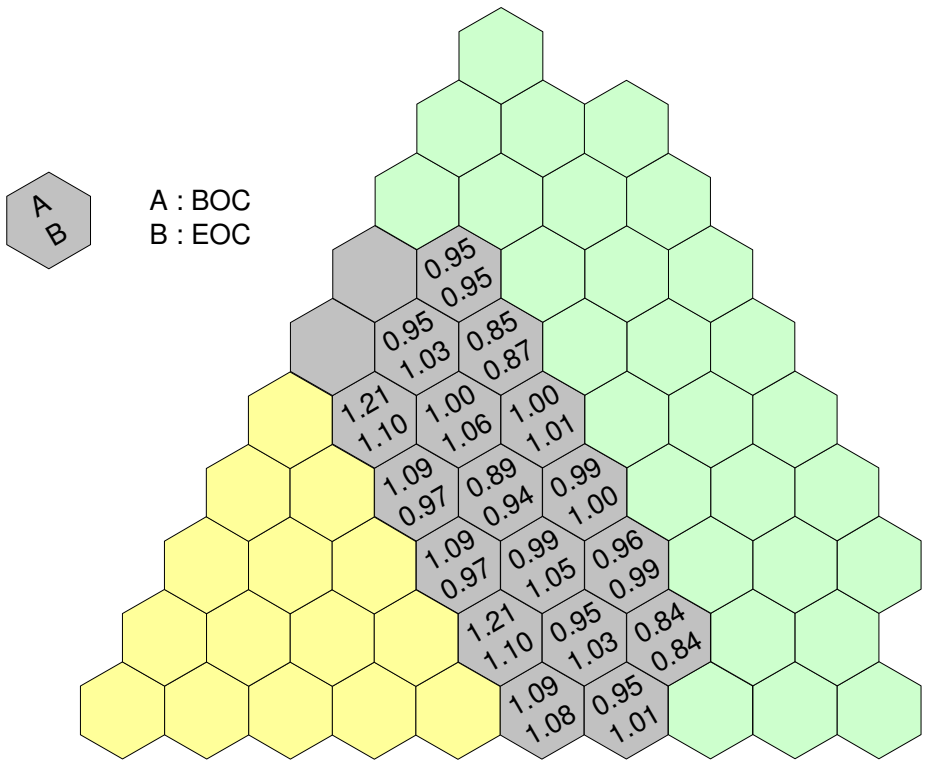

Figure 25. Core Radial Power Distributions for Single-Batch Core with $350 \mu \mathrm{m}$ Kernel-Diameter Fuel. 


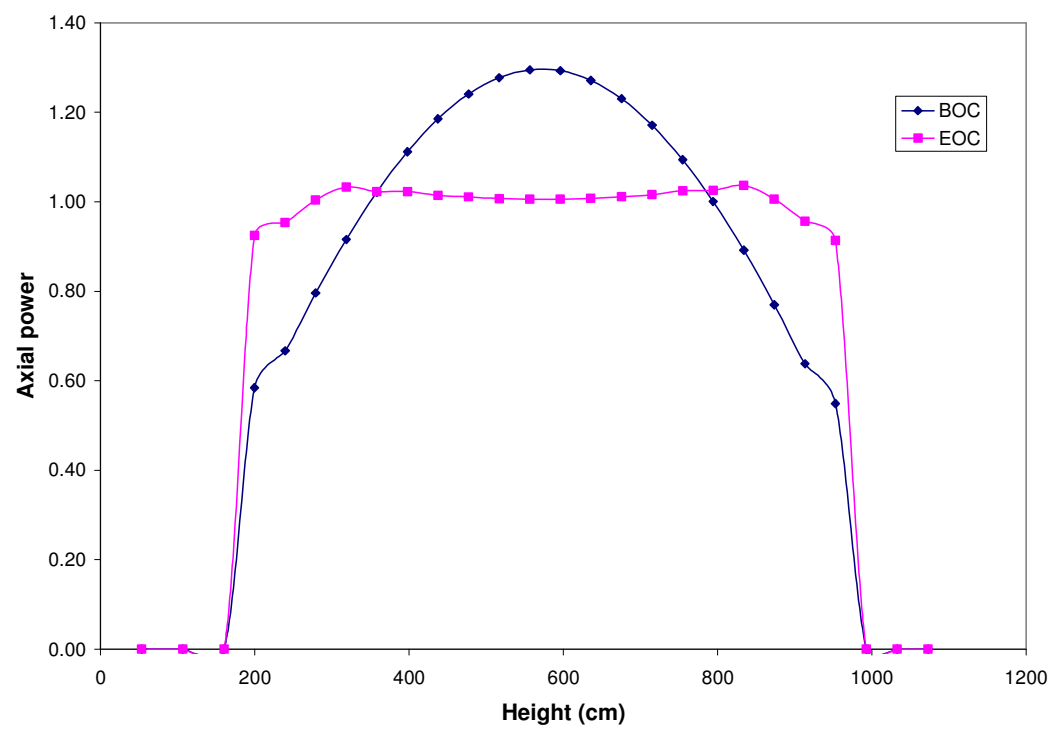

Figure 26. Core Axial Power Distributions at Beginning and End of Cycle. (Single-Batch Core: 425 m Kernel-Diameter Case).

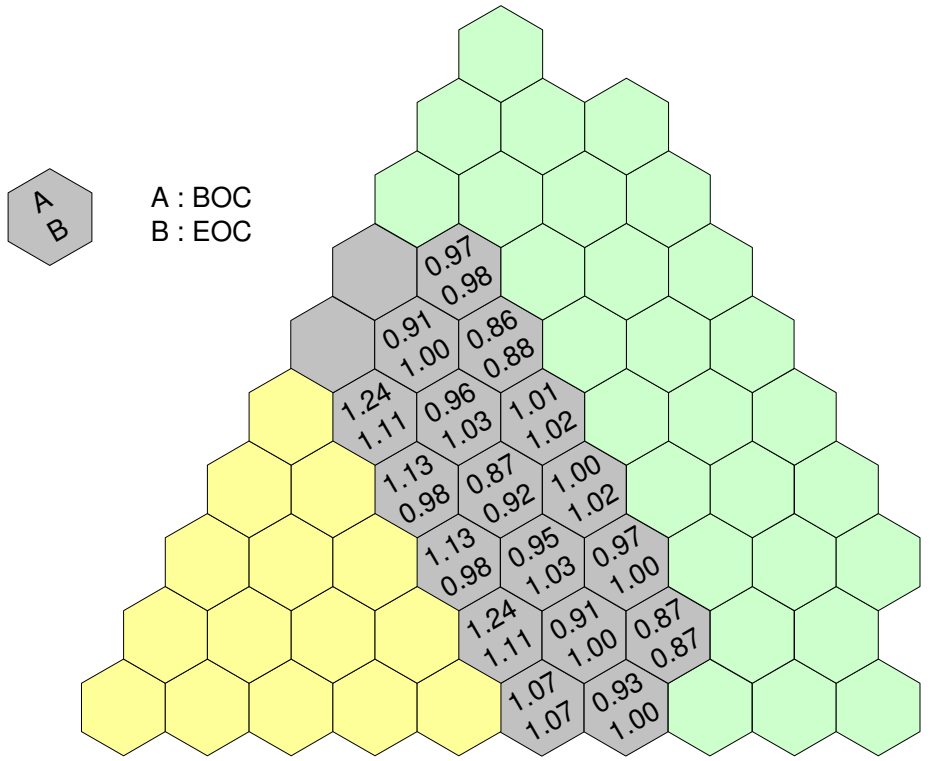

Figure 27. Core Radial Power Distributions for Single-Batch Core with $425 \mu \mathrm{m}$ Kernel-Diameter Fuel. 


\subsection{Fuel Management Option - Two-Batch Equilibrium Core}

The results of depletion studies using two-batch fuel management schemes are presented in this section. This fuel loading scheme implies that at the beginning of each cycle, a half of the core is replaced and loaded with fresh fuel elements. Because the NGNP power peaks at the inner core interface with the reflector, the fuel loading scheme devised for the two-batch core prohibits (when possible) the loading of fresh elements in the inner ring of the active core. Figure 28 shows one of the two-batch loading patterns used in this work. The other is presented as a parametric case that reduces the core radial power peaking factor. As noted in Section 5.1, a $1 / 3$-core symmetry was used for the two-batch calculations because of the different core element types. Different fuel management paths (movements) have been used for the standard fuel, reserve-shutdown, and control elements. In Figure 28, PF, PS and PC denote the fuel management paths for standard fuel, reserve-shutdown, and control elements, and the number of resident cycle is presented in the parenthesis. There are several sub-paths within each path. For example, there are 12 sub-paths for standard fuel elements; The fuel assembly located in location PF1(0) is shuffled to location PF1(1) in the second cycle and then is discharged from the core.

Calculations have been done for two cases having different fuel parameters. These are the $350 \mu \mathrm{m}$ kernel-diameter case (using $350 \mu \mathrm{m}$ kernel diameter/10\% enriched fuel and 28.9\% packing fraction) and the $425 \mu \mathrm{m}$ kernel-diameter case (using $425 \mu \mathrm{m}$ diameter/14\% enriched fuel and 25\% packing fraction). Results for these cases are summarized in Table 5. The peak power values in the table are those estimated conservatively by DIF3D calculations.

The general trends in the cycle length and discharge burnup values for the 350 and 425 $\mu \mathrm{m}$ kernel-diameter cases are similar to those for the single-batch scheme. The $425 \mu \mathrm{m}$ kerneldiameter case gives the longer cycle length and higher discharge burnup, due primarily to the higher fissile loadings, relative to the $350 \mu \mathrm{m}$ kernel-diameter case. Compared to the single-batch scheme, the two-batch scheme has a lower reactivity swing (about 20\% versus $\sim 35 \%$ ). As expected, the two-batch scheme gives a longer discharge burnup and a shorter cycle length compared to the single-batch scheme. 
The most significant result is that the two-batch core using $425 \mu \mathrm{m}$ kernel-diameter fuel meets the requirements on both the cycle length and the discharge burnup (about 1.61 years and $\sim 100 \mathrm{GWd} / \mathrm{t}$, respectively, assuming a capacity factor of $90 \%$ ). This is not however the case for the two-batch core using $350 \mu \mathrm{m}$ kernel-diameter fuel.

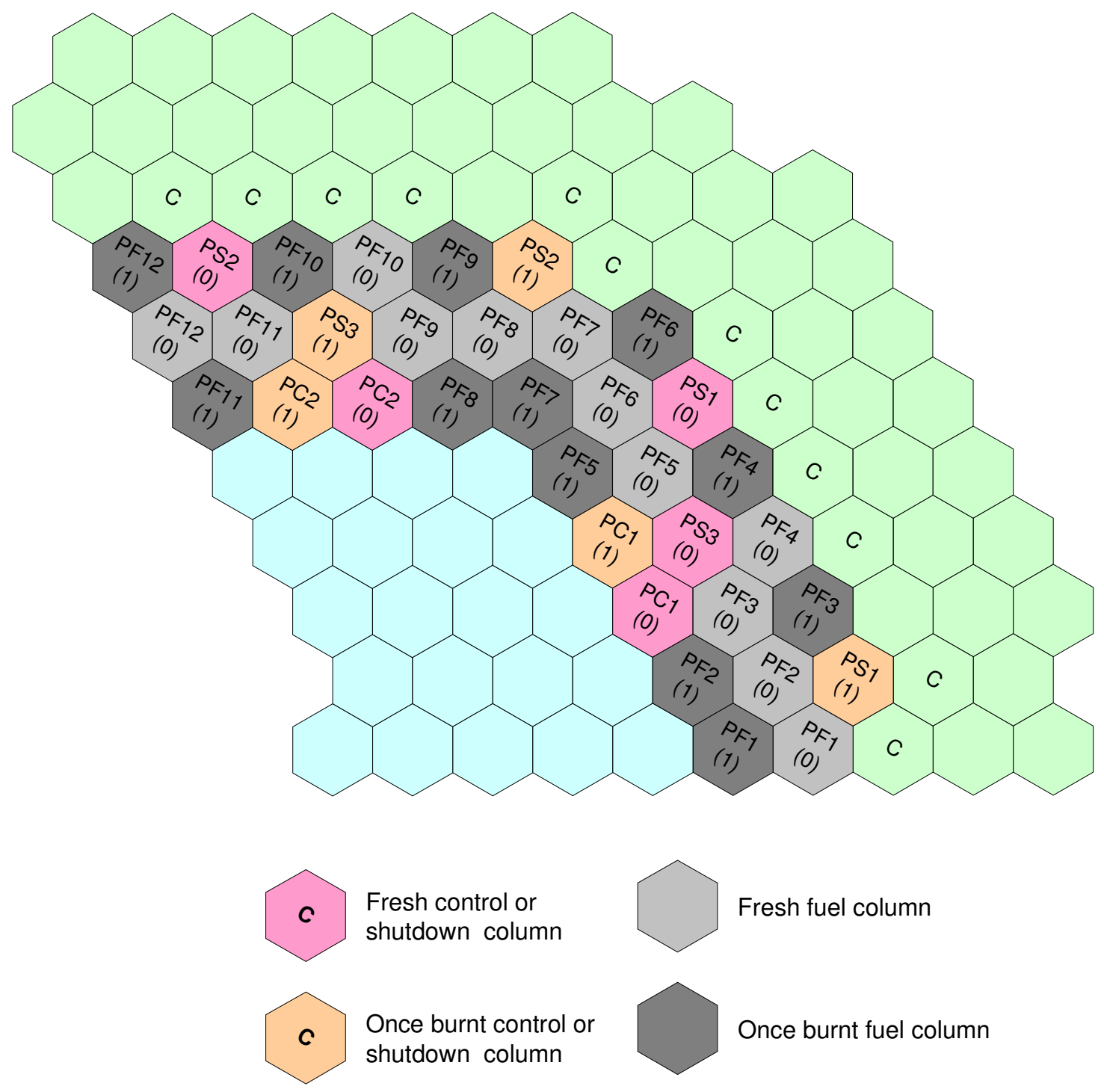

Figure 28. Two-Batch Fuel Management Scheme for NGNP Core. 
Table 5. Two-Batch Fuel Management Option with $350 \mu \mathrm{m}$ and $425 \mu \mathrm{m}$ Diameter Fuel.

\begin{tabular}{|c|c|c|c|c|c|}
\hline \multirow[b]{2}{*}{$\begin{array}{l}\text { Fission products } \\
\text { modeling }\end{array}$} & \multirow{2}{*}{$\begin{array}{l}\text { Number of } \\
\text { axial burning } \\
\text { zones }\end{array}$} & \multicolumn{4}{|c|}{ Results } \\
\hline & & $\begin{array}{l}\text { Cycle length } \\
\text { (EFPD) }\end{array}$ & $\begin{array}{l}\text { Discharge } \\
\text { burnup, } \\
\text { GWd/t }\end{array}$ & Peak Power & $\begin{array}{c}\mathrm{k}_{\mathrm{eff}} \text { at } \\
\mathrm{BOC} / \mathrm{EOC}\end{array}$ \\
\hline \multicolumn{6}{|c|}{$350 \mu \mathrm{m}$ Diameter/10\% Enriched/28.9\% Packing Fraction Fuel } \\
\hline Explicit fission products & 1 & 319.8 & 72.1 & 2.19 & \\
\hline \multirow{3}{*}{ Lumped fission products } & 1 & 316.2 & 71.4 & 2.18 & \\
\hline & 5 & 309.7 & 69.9 & 2.03 & \\
\hline & 10 & 317.9 & 71.7 & 2.04 & $1.1961 / 1.0028$ \\
\hline \multicolumn{6}{|c|}{$425 \mu \mathrm{m}$ Diameter/14\% Enriched/25\% Packing Fraction Fuel } \\
\hline Explicit fission products & 1 & 528.4 & 100.4 & 2.50 & \\
\hline \multirow{3}{*}{ Lumped fission products } & 1 & 533.0 & 101.2 & 2.49 & \\
\hline & 5 & 559.6 & 105.3 & 2.57 & \\
\hline & 10 & 526.1 & 99.9 & 2.35 & $1.2205 / 1.0098$ \\
\hline
\end{tabular}

The power distributions for both the 350 and $425 \mu \mathrm{m}$ kernel-diameter cases are quite similar, hence only the power distribution results for the $425 \mu \mathrm{m}$ kernel-diameter case are presented here. These power distributions are displayed in Figures 29 to 31. The column-wise power distribution is quite flat (see Figure 31). Although not the same distributions as for the single-batch core, the maximum values (about 1.25) for the two cores are quite similar. In Figures 29 and 30 the core average and maximum column axial power distributions are presented. It is noted that the column power distributions are the local power density divided by the core average power density. The flattening of the axial power distribution with burnup is evident.

\section{Sensitivity Study on Radial Loading Pattern}

An attempt was made to flatten the column-wise distribution further. It was noticed that the maximum column power (1.27 in location $(6,3)$ in the fractional core) occurs in a onceburned column location surrounded mostly by fresh fuel elements (see Figure 28). In order to reduce the power in this location $(6,3)$ the fresh fuel element located in $(7,4)$ is exchanged with the once-burnt fuel element in location $(8,2)$. This exchange does not affect the cycle length, but the column power in location $(6,3)$ changes from 1.27 to 1.20 . This power distribution is displayed in Figure 32. (The calculation is for a core loaded with $425 \mu \mathrm{m}$ kernel-diameter fuel). The maximum column power in this case is 1.20 . 


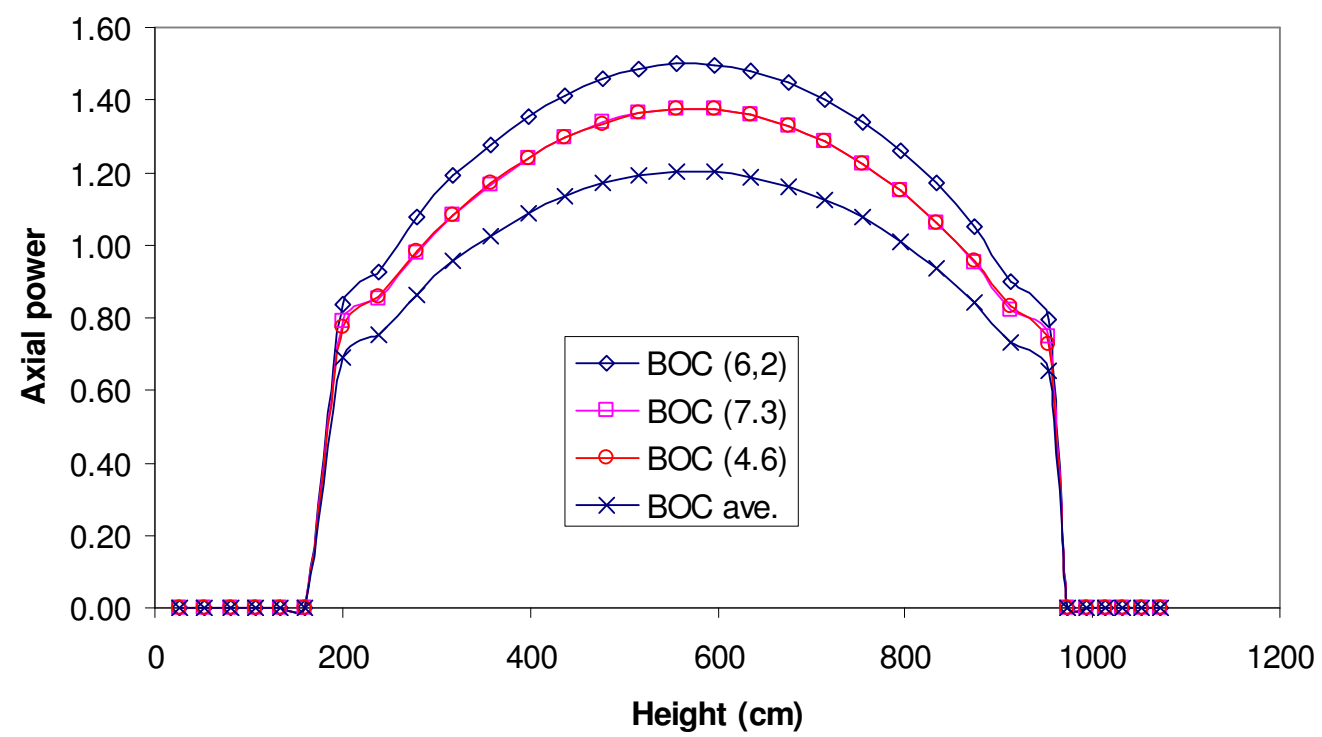

Figure 29. BOC Axial Power Distributions at Leading Peak Power Locations for the TwoBatch Core with $425 \mu \mathrm{m}$ Kernel-Diameter Fuel.

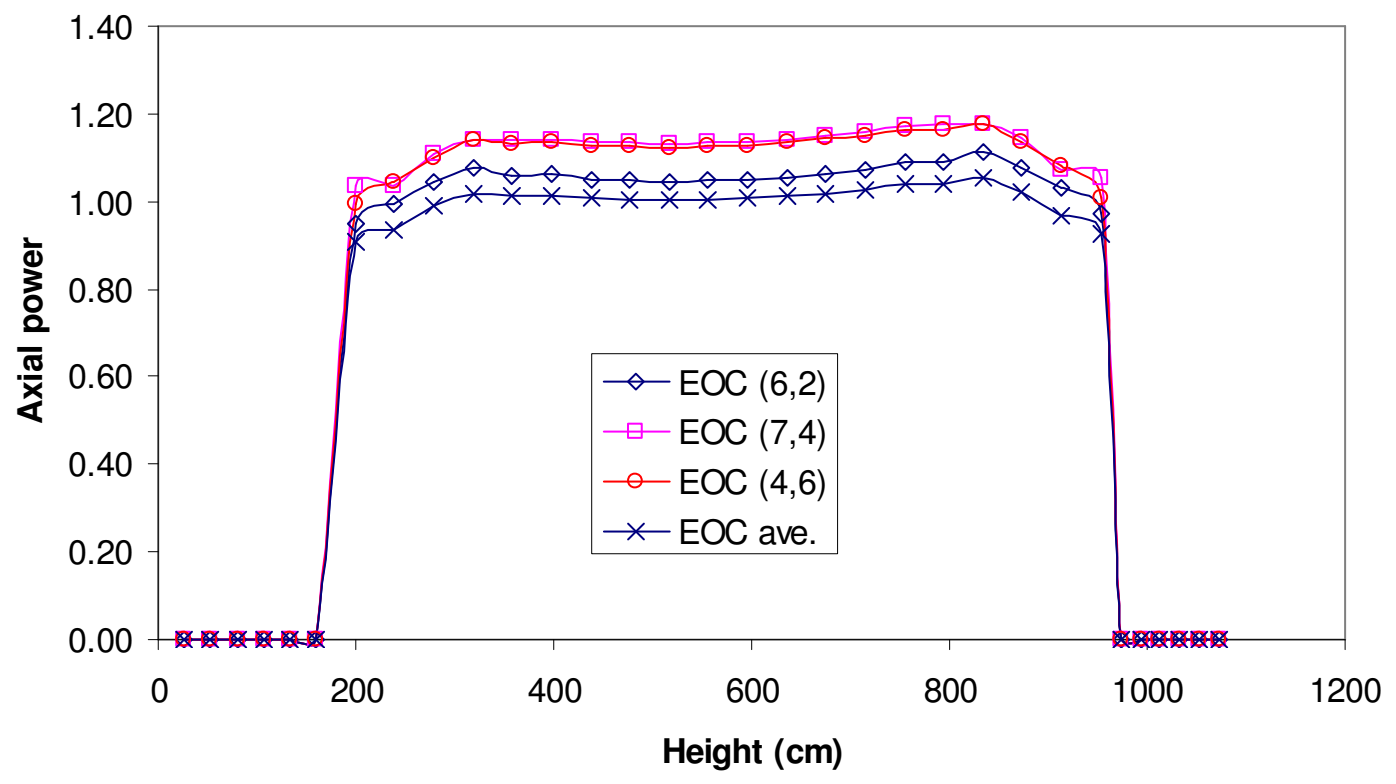

Figure 30. EOC Axial Power Distributions at Leading Peak Power Locations for the TwoBatch Core with $425 \mu \mathrm{m}$ Kernel-Diameter Fuel. 


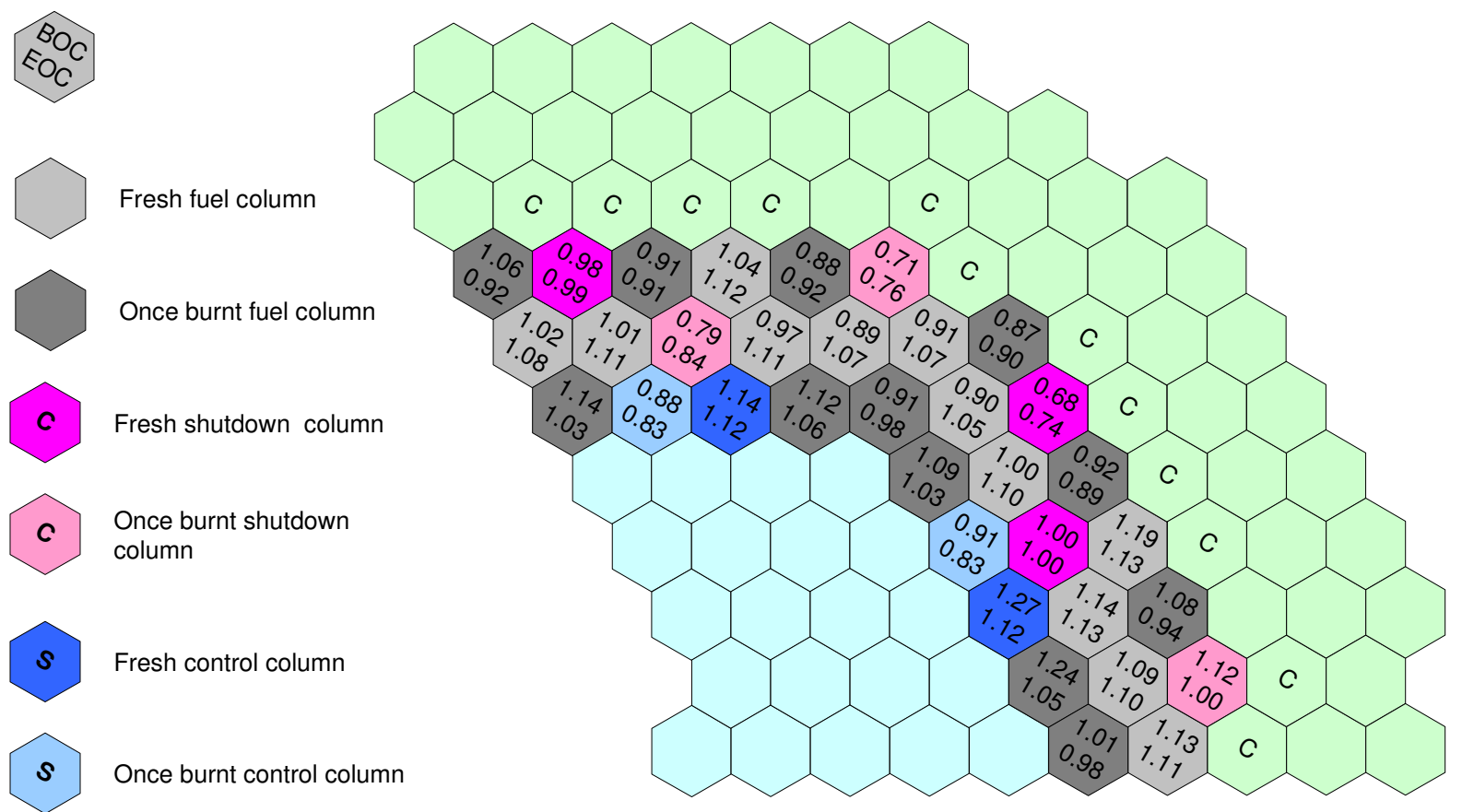

Figure 31. Radial Power Distribution for Two-Batch Core with $425 \mu \mathrm{m}$ Kernel-Diameter Fuel.

Fresh fuel column

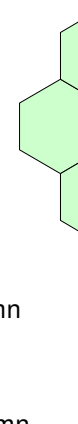

Once burnt fuel column

Fresh shutdown column

Once burnt shutdown column

Fresh control column

S Once burnt control column

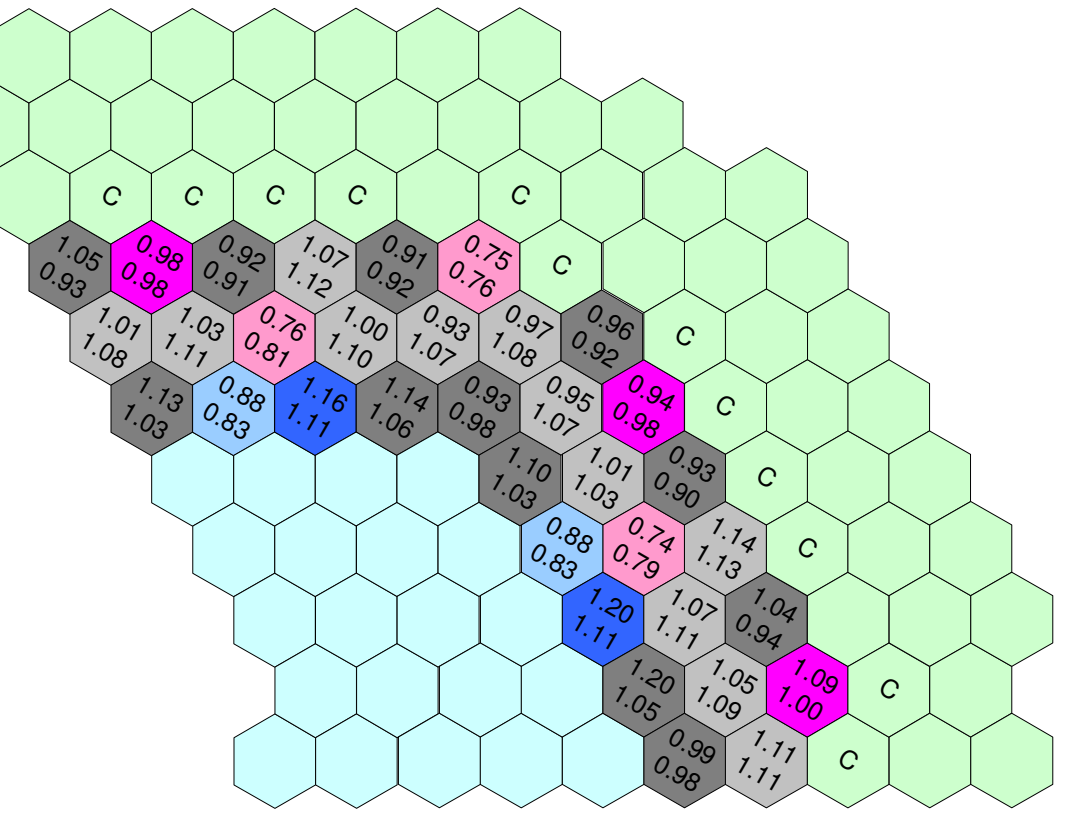

Figure 32. Radial Power Distribution for Modified Two-Batch Core with $425 \mu \mathrm{m}$ Kernel-Diameter Fuel. 


\section{Sensitivity Study on Axial Shuffling}

The utilization of fuel elements stacked end-to-end in the core suggests that fuel shuffling can be done axially. The goal would be to use this approach to lower the fuel axial power peaking factor, and potentially the radial peaking factor. Different schemes could be envisaged. In one approach, fuel of the same age (burnup) could be grouped into a single axial plane and the most burned fuel could be loaded into the core center. Another approach is to use alternating radial loading patterns axially. This approach ensures that a given fuel element is surrounded by assemblies of a different age. This loading pattern, called the alternating fuel pattern, was considered for the GT-MHR, and has been evaluated for the NGNP in this study. A schematic of the core loading pattern concept is shown in Figure 33.

The core axial power distributions for the base radial shuffling case and alternating fuel pattern case for a core using $425 \mu \mathrm{m}$ kernel-diameter fuel are compared in Figures 34 and 35. The two cases give very similar core axial power distributions. The core radial power distribution and the axial power distributions for the columns with the highest powers are displayed in Figures 36 to 38. The undulating column axial power shapes are not dissimilar from those shown for three-batch GT-MHR core in Ref. 4. The peak values of the column power distributions for the alternating fuel pattern case are much higher than those of the radial shuffling case (about 1.76 versus 1.49 ). The core radial power distribution for the alternating fuel pattern case is displayed in Figure 38. The maximum column power is slightly higher in this case than for the radial fuel shuffling case (1.29 versus 1.27). 

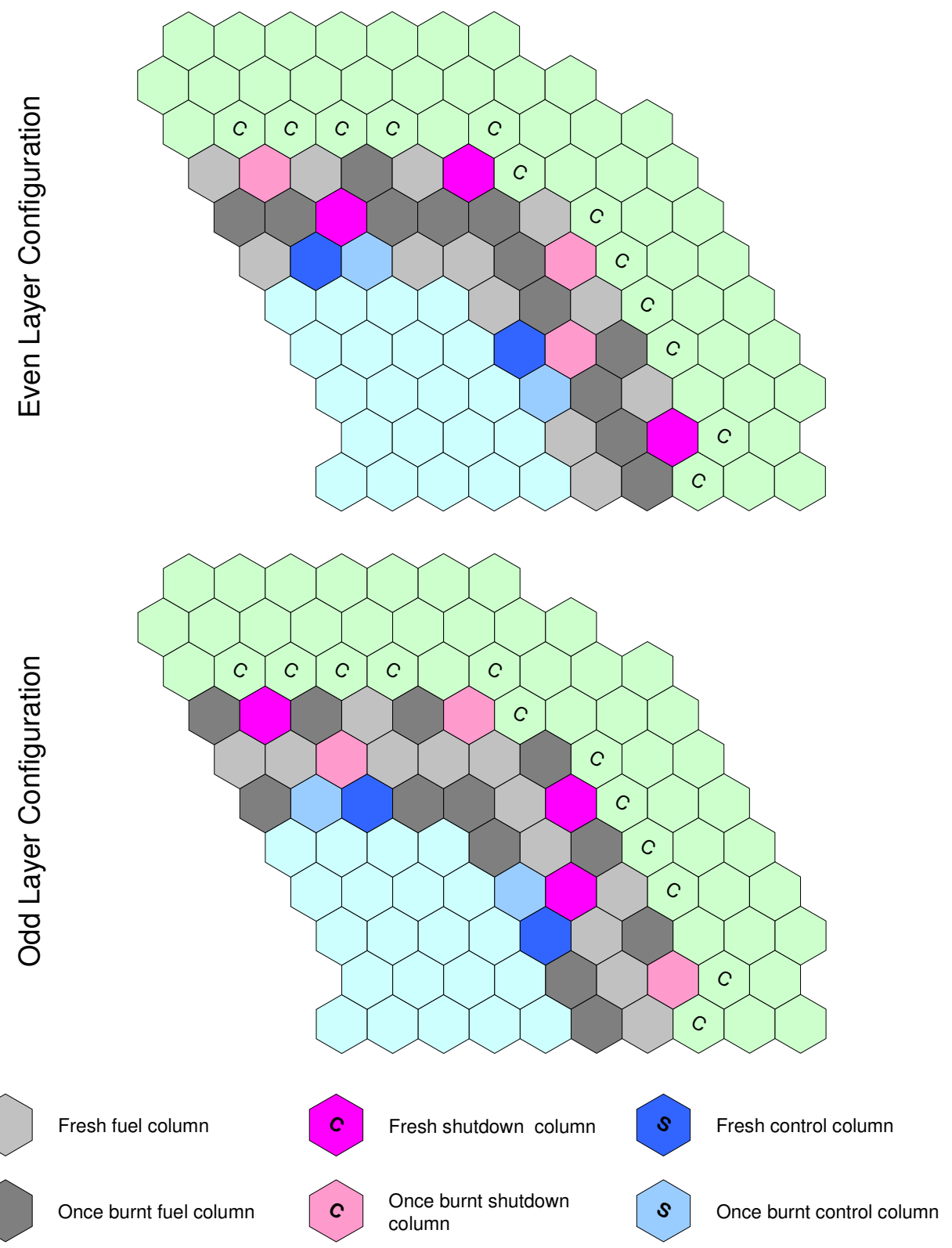

Figure 33. Alternating Fuel Pattern Scheme for Two-Batch Core. 


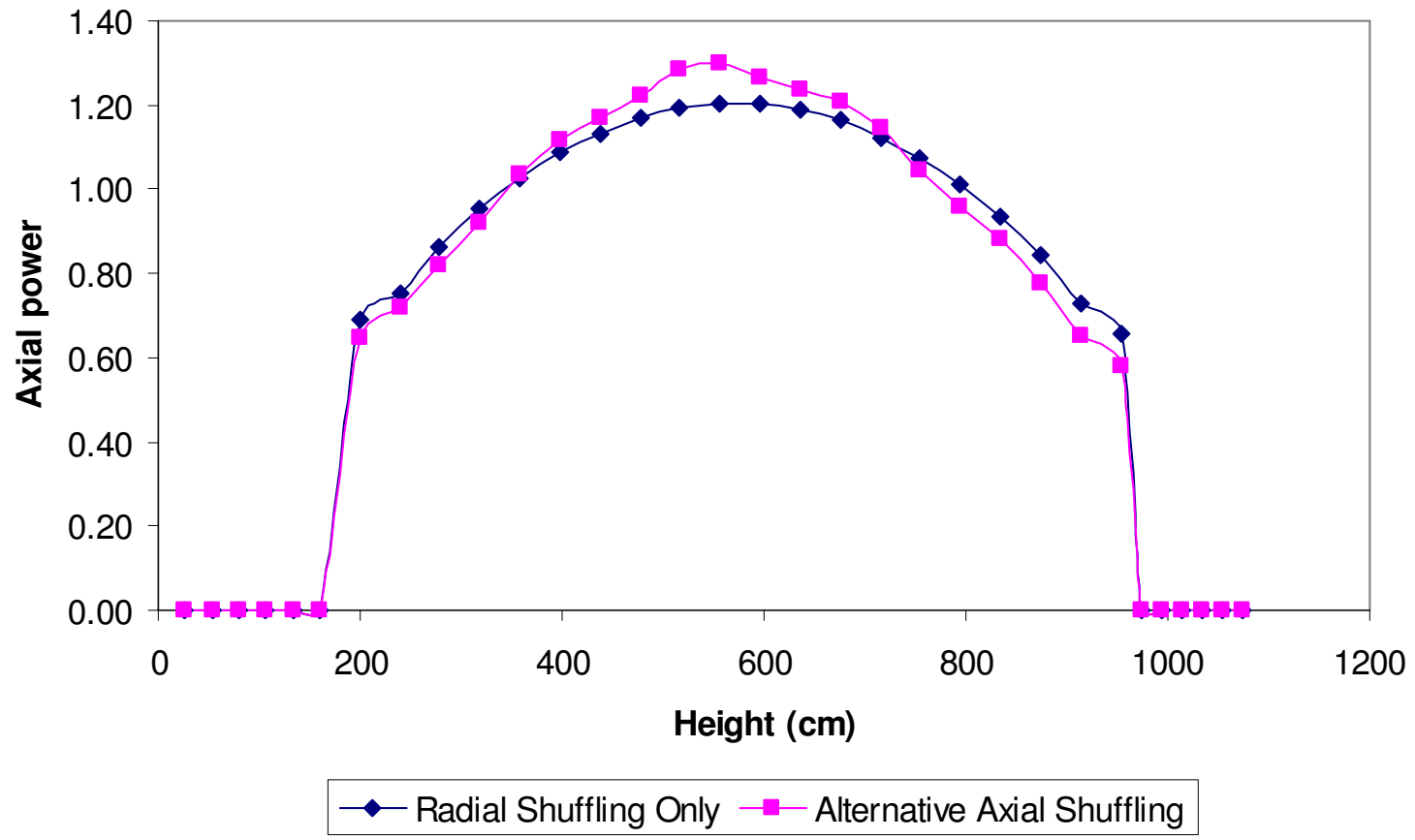

Figure 34. BOC Axial Power Distributions for Two-Batch Alternating Fuel Pattern and Regular Shuffling Scheme with $425 \mu \mathrm{m}$ Kernel-Diameter Fuel.

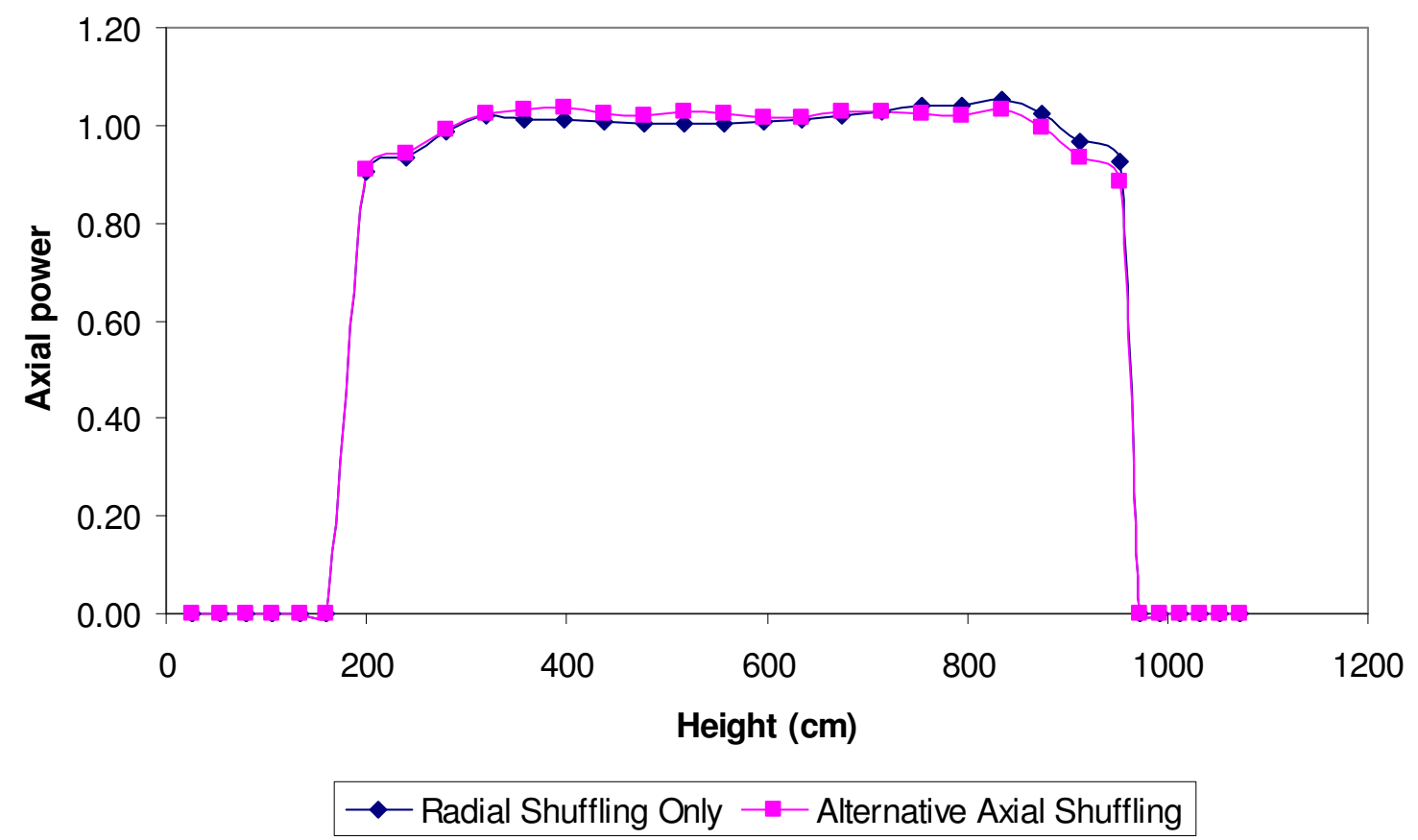

Figure 35. EOC Axial Power Distributions for Two-Batch Alternating Fuel Pattern and Regular Shuffling Scheme with $425 \mu \mathrm{m}$ Kernel-Diameter Fuel. 


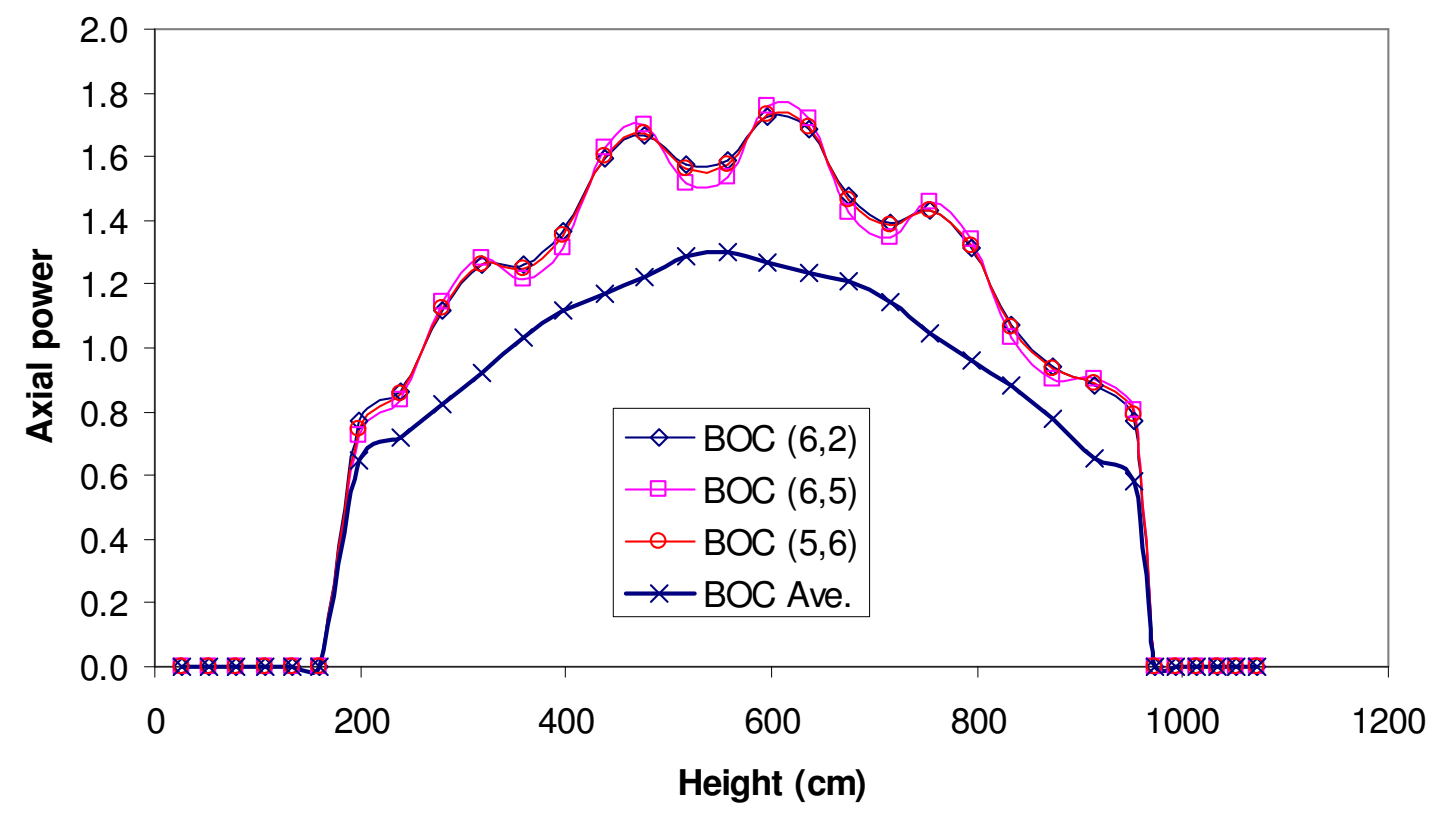

Figure 36. BOC Axial Power Distributions at Leading Column Power Locations for Alternating Fuel Pattern Two-Batch Core with $\mathbf{4 2 5} \mu \mathrm{m}$ Diameter Fuel.

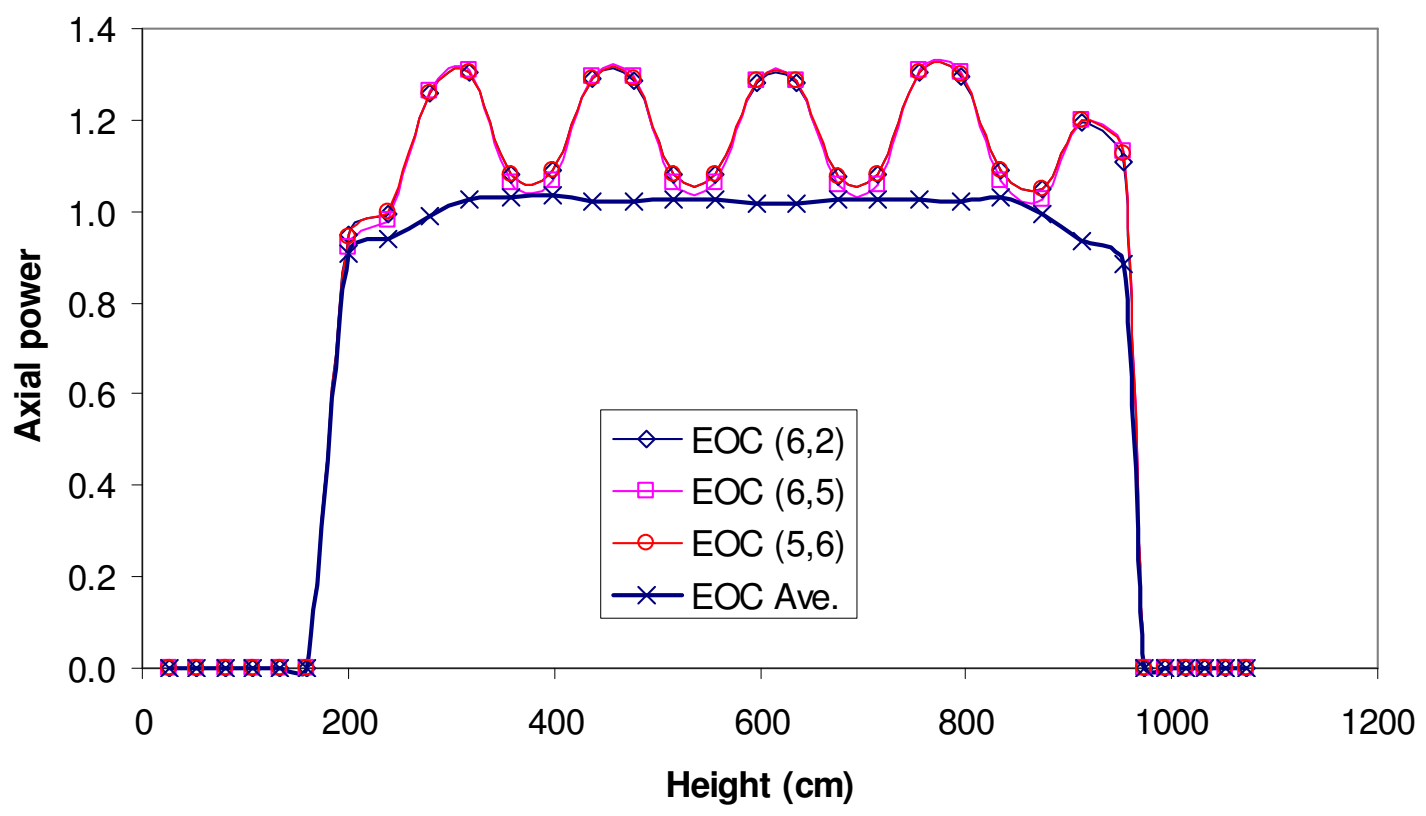

Figure 37. EOC Axial Power Distributions at Leading Column Power Locations for Alternating Fuel Pattern Two-Batch Core with $\mathbf{4 2 5} \mu \mathrm{m}$ Diameter Fuel. 


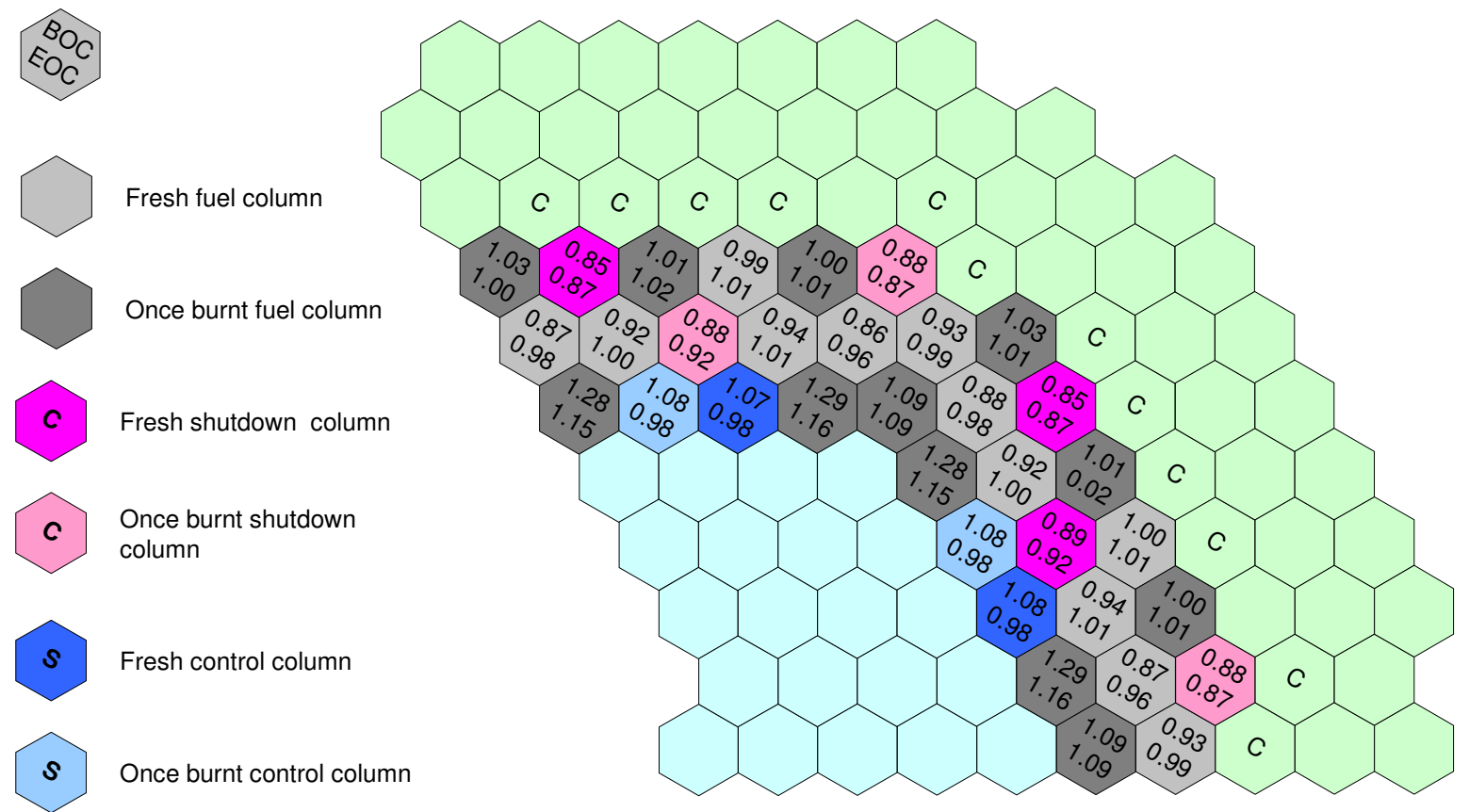

Figure 38. Radial Power Distributions for Alternating Fuel Pattern Two-Batch Core with $425 \mu \mathrm{m}$ Kernel-Diameter Fuel. 


\subsection{Fuel Management Option - Three-Batch Equilibrium Core}

Depletions calculations have been done for a core using the three-batch fuel management scheme. As in the two-batch case, fresh fuel elements are not loaded (when possible) into the inner ring positions in order to minimize core power peaking factors. Figure 39 shows the threebatch core loading pattern used in the work. Because of the arrangements of the core control elements, no core symmetry exists and hence only whole-core calculations are performed. In Figure 39, PF, PS and PC denote the fuel management paths for standard fuel, reserve shutdown and control elements, and the number of resident cycle is represented in the parenthesis. PF1(0), PF1(1) and PF1(2) respectively denote for example the path of an assembly from the initial loading and subsequent shuffling position. Calculations have been performed for cores using 350 and $425 \mu \mathrm{m}$ kernel-diameter fuel. Because of the enormous computational time requirements, only cases with five axial burn zones have been performed. Core performance results are summarized in Table 6. Power distributions for the $425 \mu \mathrm{m}$ kernel-diameter fuel only are displayed in Figures 40 to 42 . The shapes of these distributions are similar to those for the 350 $\mu \mathrm{m}$ kernel-diameter case, although the $425 \mu \mathrm{m}$ diameter case has a higher total peaking factor.

Results in Table 6 show that the $425 \mu \mathrm{m}$ fuel-diameter case gives a discharge burnup of about $115 \mathrm{GWD} / \mathrm{t}$, which meets the targeted discharge burnup range. The cycle length is however about 390 EFPD (1.18 years, assuming 90\% capacity factor) and hence does not meet the targeted value of 1.5 years.

The core radial power distribution shows that the maximum column power is 1.35 (located in an inner ring position that has fresh fuel). More work could be done to reduce this power level, however, this additional work was not done here because the targeted cycle length is unmet.

The core and column axial power distributions follow the same trends as the single- and two-batch cases, with the distribution having pronounced peaks at the beginning of cycle (BOC); these peaks burn out and the power distribution are relatively flatter at the end of cycle (EOC). The core total power peaking factors for this case is however 2.21. The core reactivity swing (about 15\%) is also the lowest of the three fuel management schemes considered. 


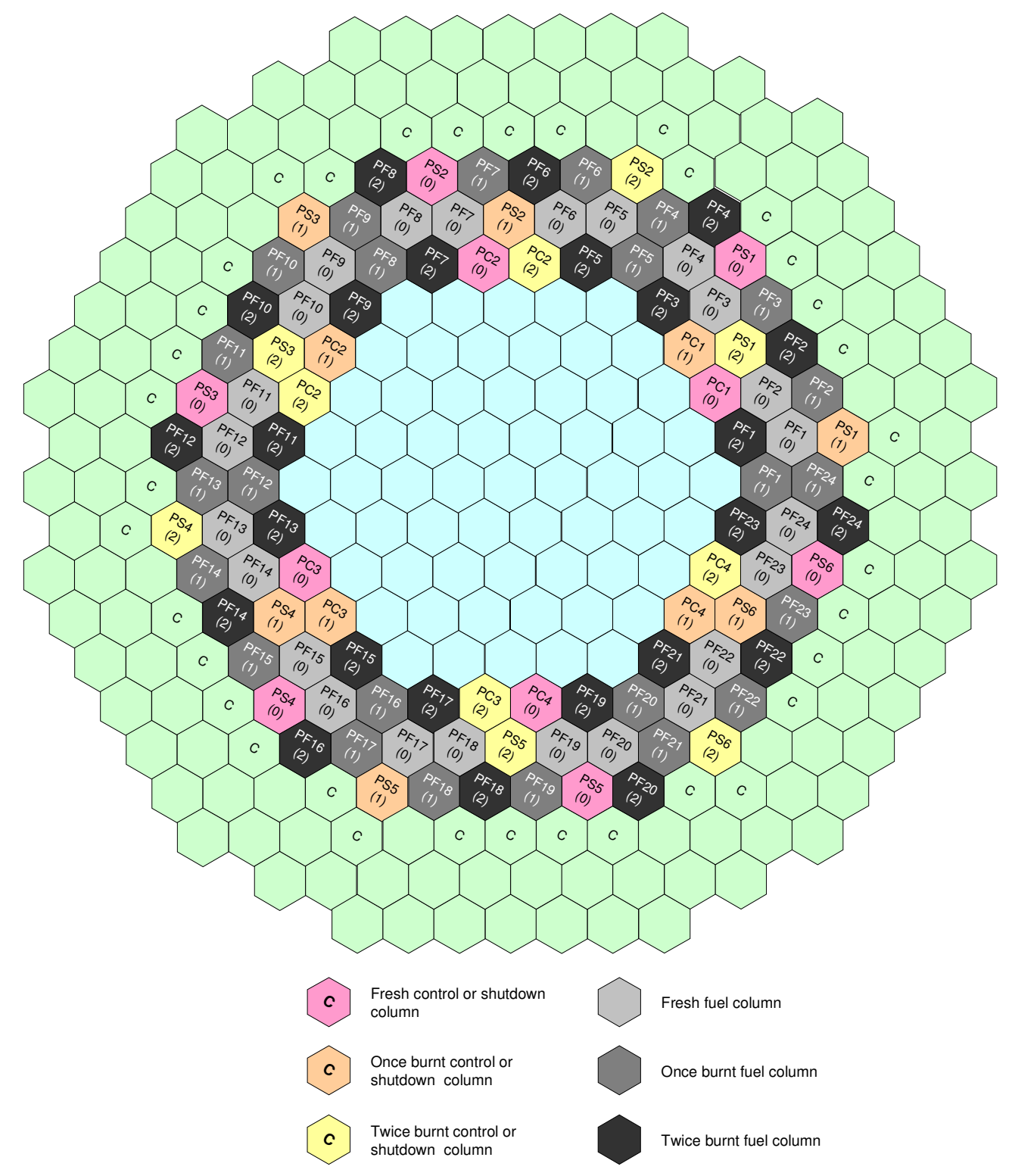

Figure 39. Three-Batch Fuel Management Scheme for NGNP Core. 
Table 6. Three-Batch Fuel Management Option with $350 \mu \mathrm{m}$ and $425 \mu \mathrm{m}$ Kernel-Diameter Fuel.

\begin{tabular}{|c|c|c|c|c|c|}
\hline \multirow[b]{2}{*}{$\begin{array}{l}\text { Fission products } \\
\text { modeling }\end{array}$} & \multirow[b]{2}{*}{$\begin{array}{l}\text { Number of } \\
\text { axial burning } \\
\text { zones }\end{array}$} & \multicolumn{4}{|c|}{ Results } \\
\hline & & $\begin{array}{l}\text { Cycle length } \\
\text { (EFPD) }\end{array}$ & $\begin{array}{c}\text { Discharge } \\
\text { burnup, } \\
\text { GWd/t }\end{array}$ & Peak Power & $\begin{array}{c}\mathrm{k}_{\mathrm{eff}} \text { at } \\
\mathrm{BOC} / \mathrm{EOC}\end{array}$ \\
\hline \multicolumn{6}{|c|}{$350 \mu \mathrm{m}$ Diameter/10\% Enriched/28.9\% Packing Fraction Fuel } \\
\hline Explicit fission products & 1 & 238.7 & 82.3 & 2.13 & \\
\hline Lumped fission products & 5 & 226.0 & 78.0 & 1.92 & $1.1495 / 1.0173$ \\
\hline \multicolumn{6}{|c|}{$425 \mu \mathrm{m}$ Diameter/14\% Enriched/25\% Packing Fraction Fuel } \\
\hline Explicit fission products & 1 & 385.6 & 114.9 & 2.49 & \\
\hline Lumped fission products & 5 & 396.9 & 115.2 & 2.21 & $1.1600 / 1.0103$ \\
\hline
\end{tabular}




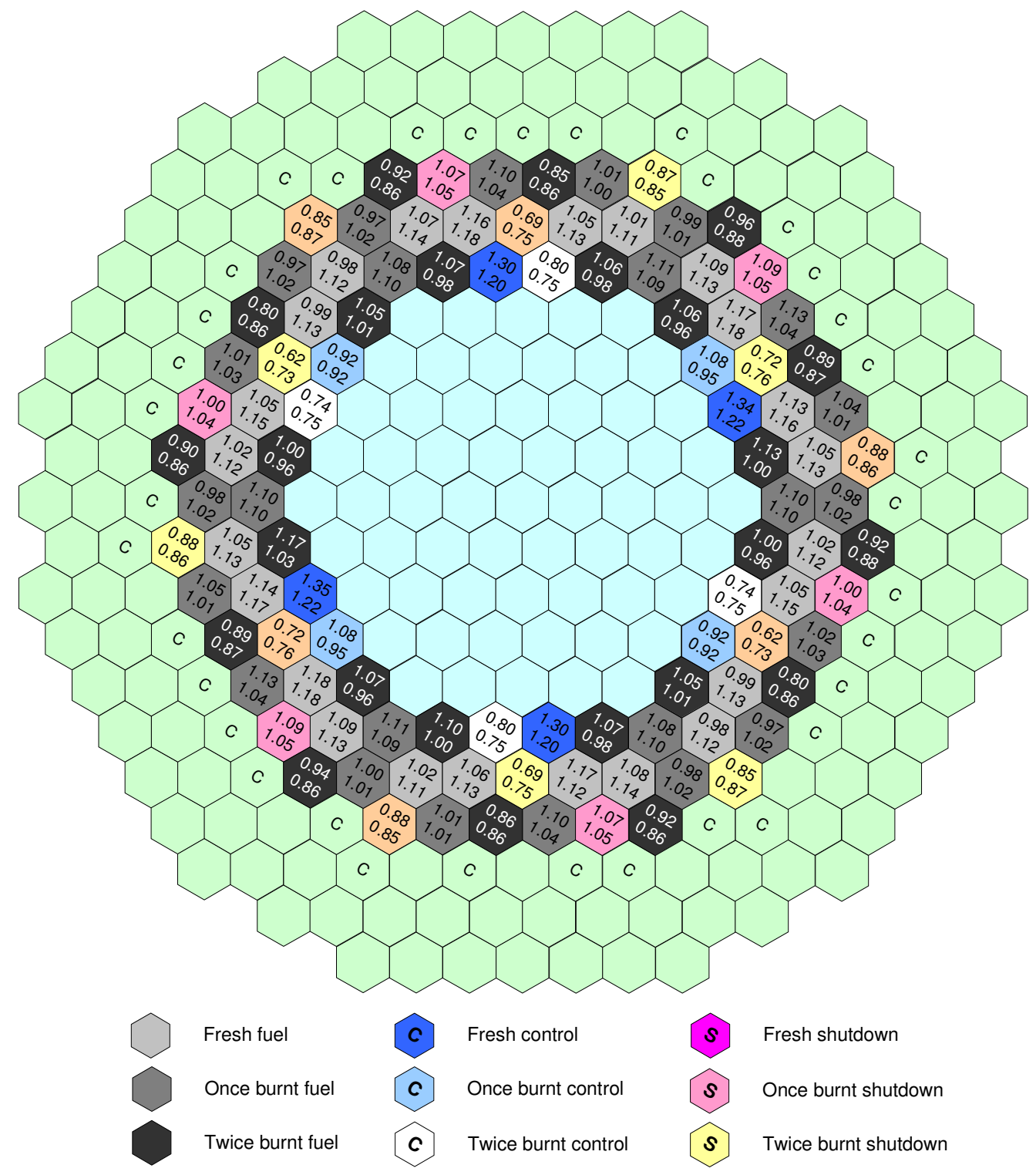

Figure 40. Radial Power Distribution for Three-Batch Core with $425 \mu \mathrm{m}$ Diameter Fuel. 


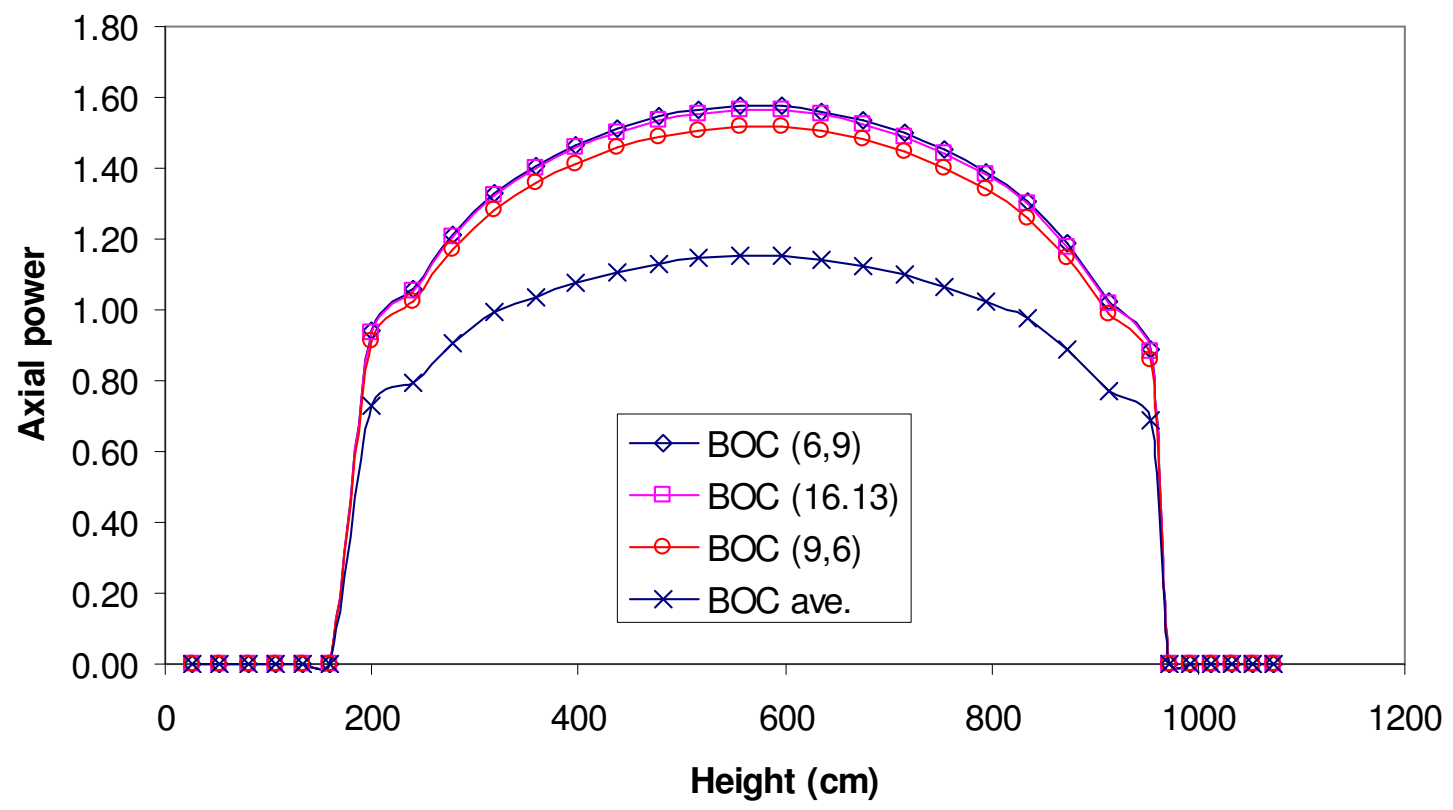

Figure 41. BOC Axial Power Distribution at Leading Peak Power Locations for Three-Batch Core with $425 \mu \mathrm{m}$ Diameter Fuel.

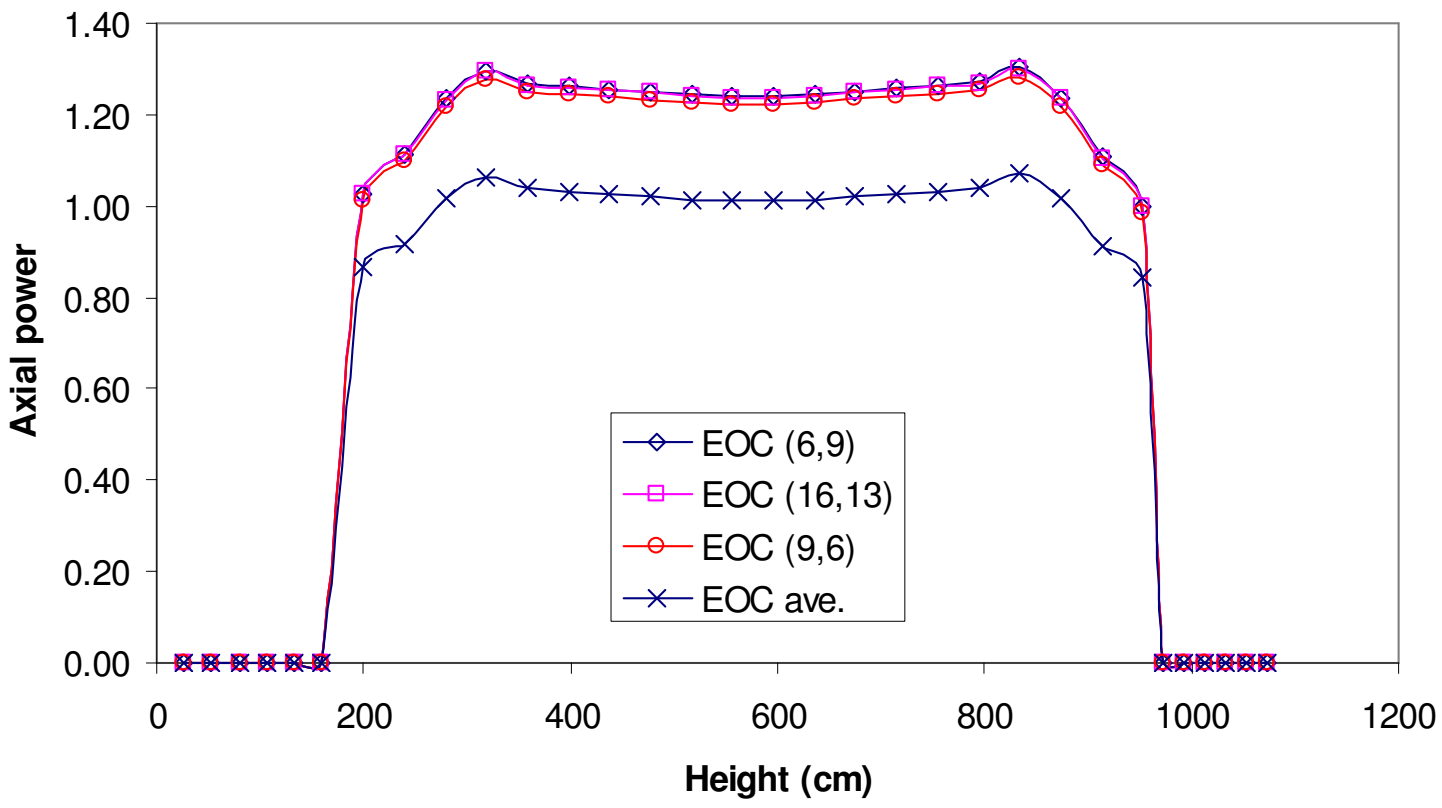

Figure 42. EOC Axial Power Distribution at Leading Peak Power Locations for Three-Batch Core with $425 \mu \mathrm{m}$ Diameter Fuel. 


\subsection{Evaluation of Two- and Three-Batch Transitional Cores}

The whole-core depletion calculations presented in the previous sections have been for equilibrium cores. Approaches to these equilibrium cores are evaluated in this section by performing transitional core calculations using the $425 \mu \mathrm{m}$ kernel-diameter fuel. Transitional cores for both the two-batch and three-batch fuel management schemes have been evaluated using the non-equilibrium option of the REBUS-3 code.

In designing the transitional cores, it is first assumed that elements containing the $425 \mathrm{um}$ kernel-diameter and 14\% enriched fuel and with a packing fraction of 25\% (base fuel loading) would be present in the equilibrium cycle core. Then lower enrichments are found for fractional loading of the core in the early cycle to ensure that the equilibrium cycle length is preserved. For example, for the first transitional cycle of the two-batch core, a half of the core is loaded with the base fuel, and a half is loaded with fuel of lower enrichment (in this case 5\% instead of 14\%). At the beginning of the second transitional cycle, the burnt 5\% enriched fuel is replaced by $14 \%$ enriched fuel. For subsequent cycle, the most burned $14 \%$ enriched fuel is discharged and replaced by fresh $14 \%$ enriched fuel.

The above stated approach is also used for the three-batch core, with the exception that in the first core, $2 / 3$ of the core is loaded with two sets of lower enrichment fuel ( $7 \%$ and $3 \%)$. At the end of the first transitional cycle, the burned 3\% fuel is replaced by $14 \%$ enriched fuel and at the end of the second transitional cycle the twice burnt $7 \%$ enriched fuel is discharged and replaced by $14 \%$ enriched fuel. Subsequently, the most burned $14 \%$ enriched fuel is replaced with fresh $14 \%$ enriched fuel.

Figures 43 and 44 show the evolution of the k-effective and core total power peaking factors predicted by REBUS-3/DIF3D for the two- and three-batch cores using $425 \mu \mathrm{m}$ kerneldiameter fuel. Results for the equilibrium cycles are included for comparison (actually repeated, to show the evolution of the transitional cycles towards the equilibrium cycle). Figures 45 and 46 show the evolution of the discharge burnups for the cases. After about $n+1$ transitional cycles $(n$ is number of batches), the equilibrium cycle values are approached. Similar trends were found for the axial power and radial power distributions (see Figures 47 and 48 for example). 


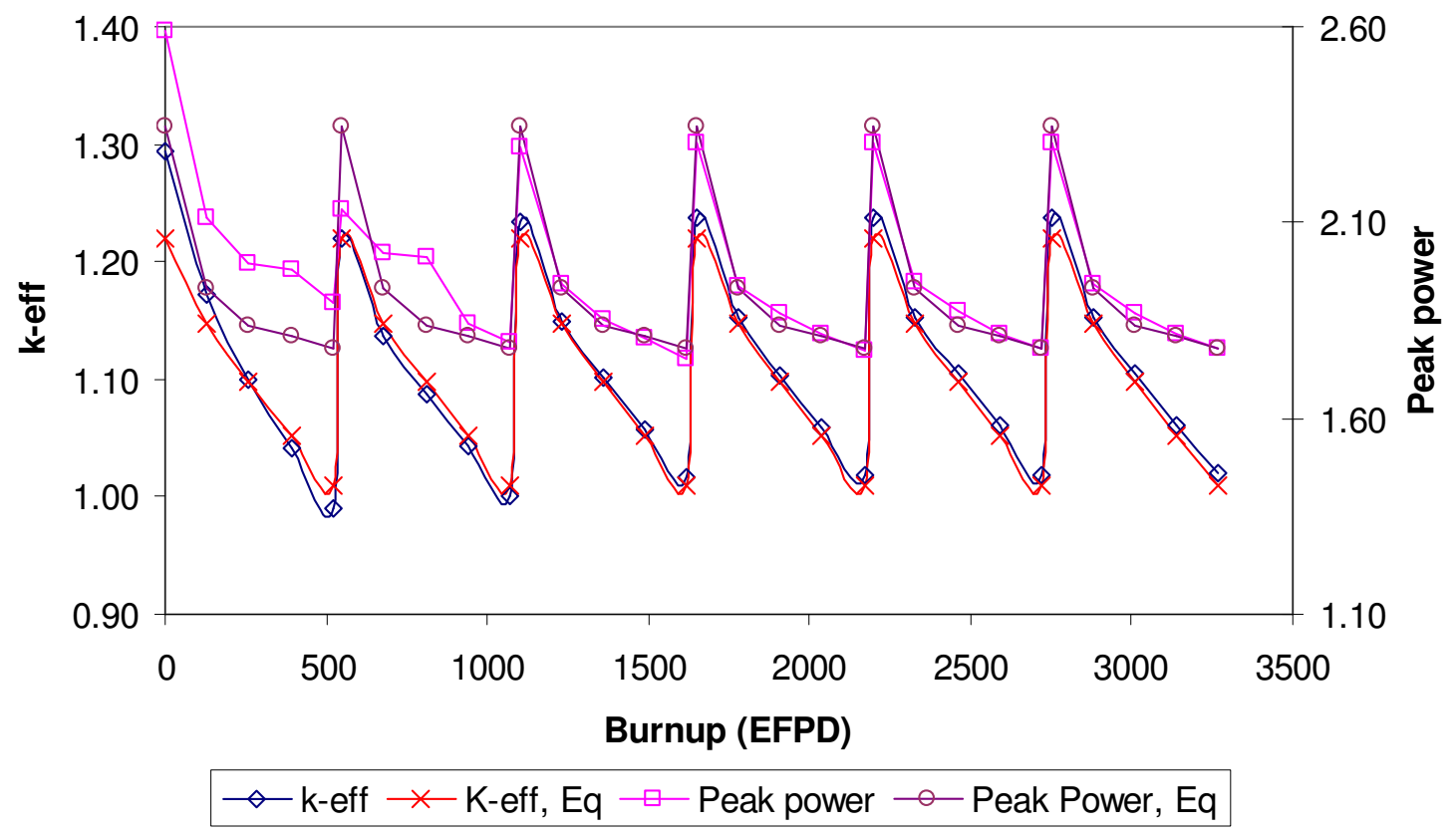

Figure 43. Core k-effective and Total Peaking Factor during Transitional Cycles for Two-Batch Fuel Management Scheme with $425 \mu \mathrm{m}$ Kernel-Diameter Fuel.

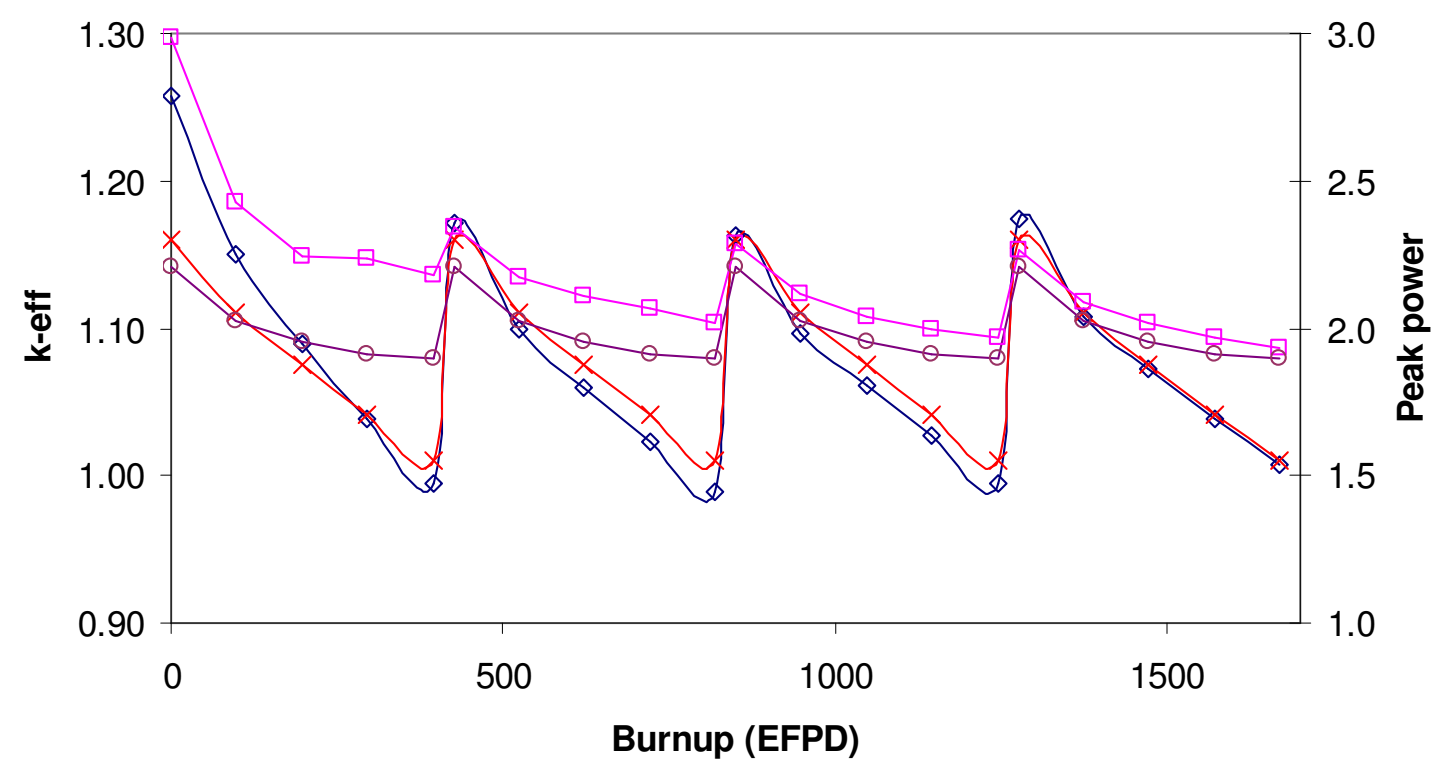

$\diamond$ k-eff $\rightarrow$ K-eff, Eq $\rightarrow$ Peak power $\multimap$ Peak Power, Eq

Figure 44. Core k-effective and Total Peaking Factor during Transitional Cycles for Three-Batch Fuel Management Scheme with $425 \mu \mathrm{m}$ Kernel-Diameter Fuel. 


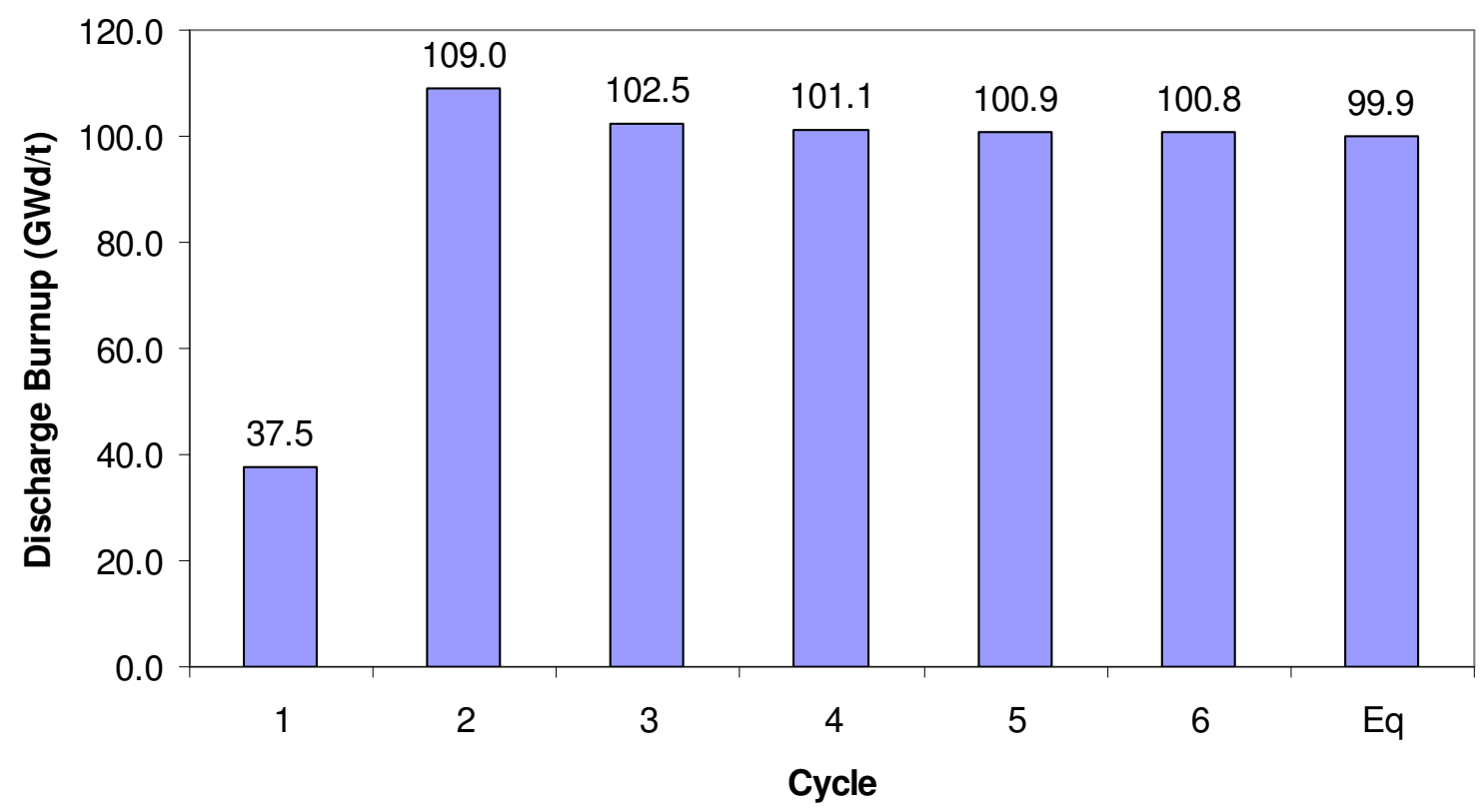

Figure 45. Average Discharge Burnup during Transitional Cycles for Two-Batch Fuel Management Scheme with $\mathbf{4 2 5} \mu \mathrm{m}$ Kernel-Diameter Fuel.

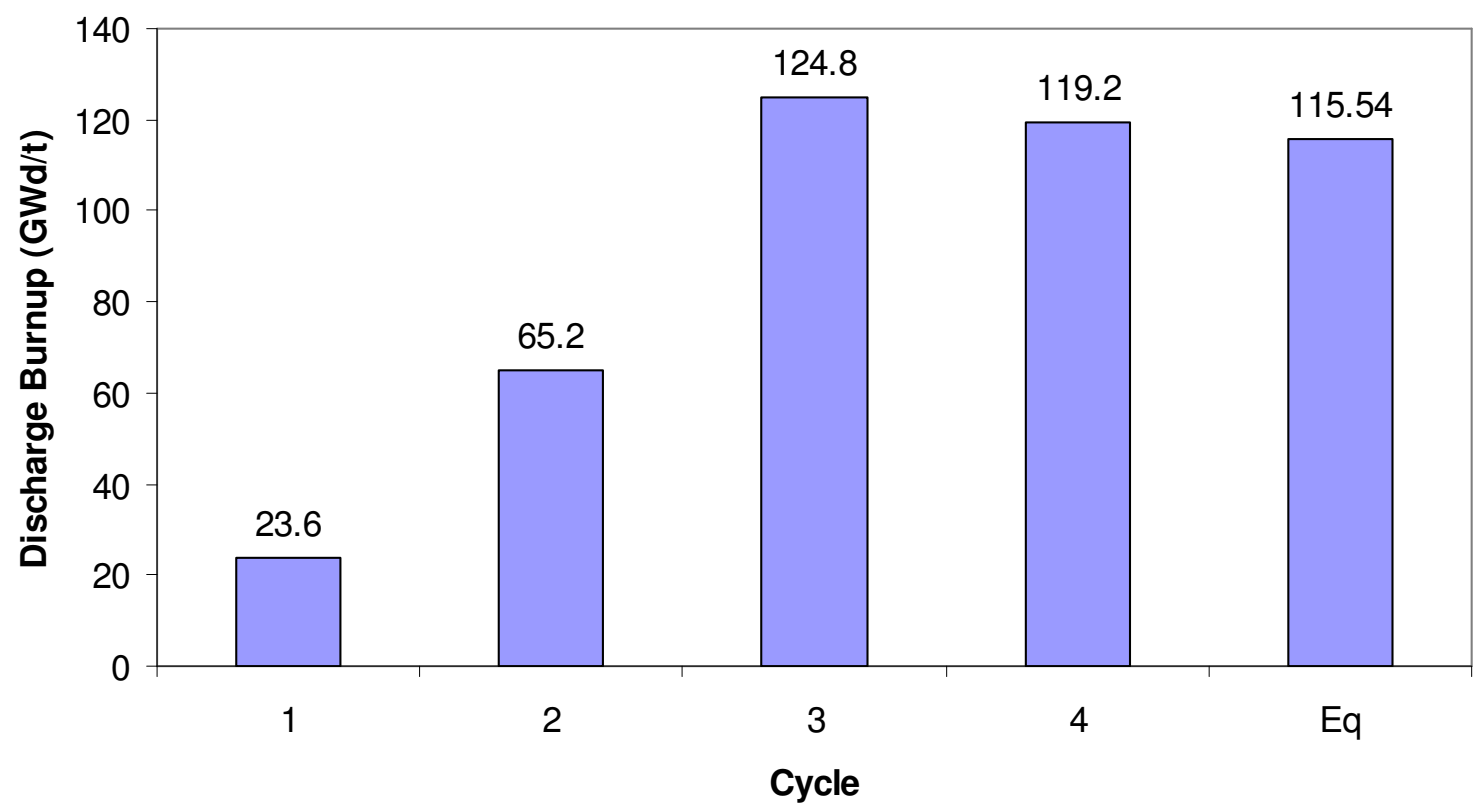

Figure 46. Average Discharge Burnup during Transitional Cycles for Three-Batch Fuel Management Scheme with $\mathbf{4 2 5} \mu \mathrm{m}$ Kernel-Diameter Fuel. 


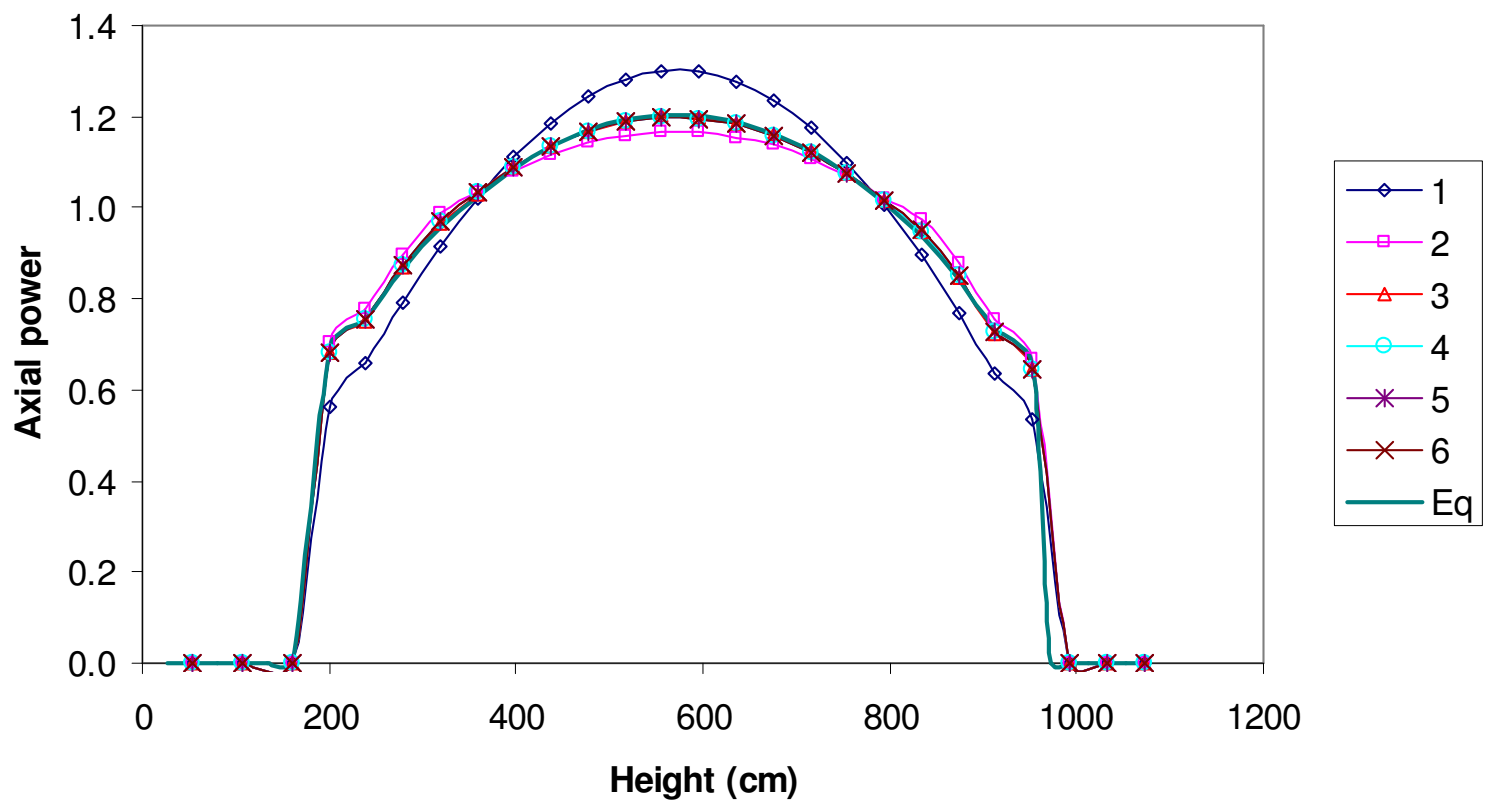

Figure 47. BOC Axial Power Distributions during Transitional Cycles for Two-Batch Fuel Management Scheme with $425 \mu \mathrm{m}$ Kernel-Diameter Fuel.

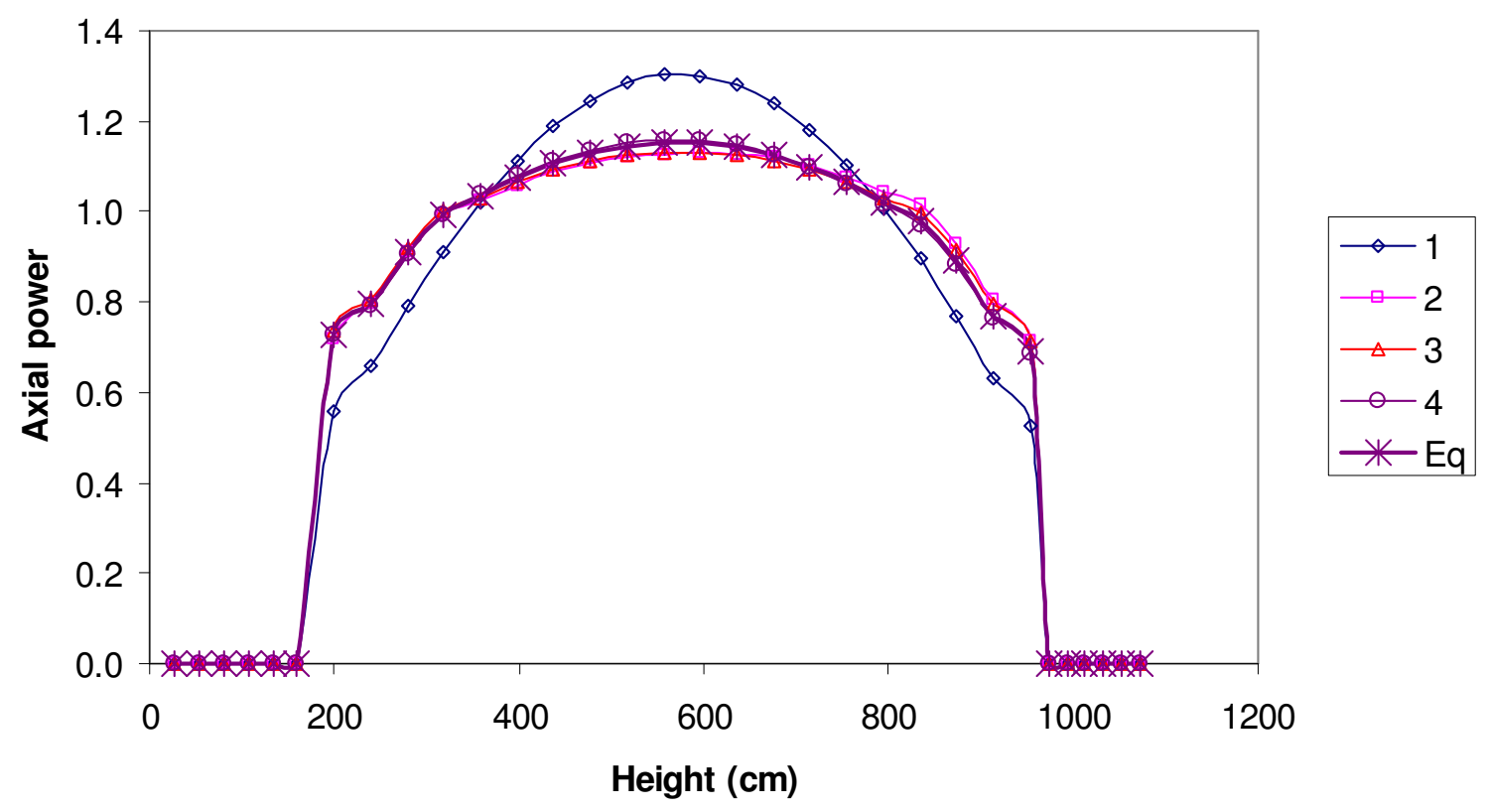

Figure 48. BOC Axial Power Distributions during Transitional Cycles for Three-Batch Fuel Management Scheme with $425 \mu \mathrm{m}$ Kernel-Diameter Fuel. 


\subsection{Summary of Fuel Management Studies}

Tables 7 and 8 summarize some of the key results derived from the numerous calculations performed in this work. The following conclusions are evident:

- Cycle length decreases with increasing number of batches.

- Discharge burnup increases with increasing number of batches.

- Reactivity swing decreases with increasing number of batches.

- Peak power decreases with increasing number of batches.

- Generally, the cycle length, discharge burnup, peak power, reactivity swing and peak fast fluence increase with increasing uranium enrichment, for the combination of other fuel parameters (kernel diameter and packing fraction).

- Three-batch scheme is better than the single- and two-batch schemes in terms of discharge burnup, peak power, and reactivity swing. However, its cycle length is shorter than the targeted cycle length (18 month). Thus, to attain a three-batch scheme that meets the cycle length and burnup requirements, a higher enrichment (>14\%) is necessary.

- The peak fast fluence $(\mathrm{E}>0.18 \mathrm{MeV})$ is satisfied by the single- and two-batch fuel management schemes, but not by the three-batch scheme (based on the estimates for $\mathrm{E}>0.11 \mathrm{MeV})$.

- Results indicate that the two-batch scheme with $425 \mu \mathrm{m}$ kernel-diameter fuel (with $14 \%$ enrichment, $25 \%$ packing fraction) satisfies the targeted cycle length and discharge burnup. 
Table 7. Summary of NGNP Excess Reactivity, Peak Power and Fluence .

\begin{tabular}{|c|c|c|c|c|c|}
\hline $\begin{array}{c}\text { Kernel } \\
\text { diameter } \\
(\mu \mathrm{m})\end{array}$ & $\begin{array}{c}\text { Number of } \\
\text { batches }\end{array}$ & $\mathrm{N}_{\mathrm{C}} / \mathrm{N}_{\mathrm{U}}{ }^{\mathrm{a})}$ & $\begin{array}{l}\Delta \mathrm{k}_{\mathrm{eff}} \text { between } \\
\text { BOC \& EOC }\end{array}$ & Peak power & $\begin{array}{c}\text { Peak fast } \\
\text { fluence } \\
\left(\mathrm{n} / \mathrm{cm}^{2}\right)\end{array}$ \\
\hline \multirow{3}{*}{350} & Single & \multirow{3}{*}{427.0} & 0.3201 & 2.10 & $1.71 \mathrm{E}+21$ \\
\hline & Two & & 0.1933 & 2.04 & $2.50 \mathrm{E}+21$ \\
\hline & Three & & 0.1322 & 1.92 & $2.67 E+21$ \\
\hline \multirow{3}{*}{425} & Single & \multirow{3}{*}{363.5} & 0.3590 & 2.38 & $3.09 \mathrm{E}+21$ \\
\hline & Two & & 0.2107 & 2.35 & $3.88 \mathrm{E}+21$ \\
\hline & Three & & 0.1497 & 2.21 & $4.53 E+21$ \\
\hline
\end{tabular}

a) Number density ratio of carbon to uranium in homogenized fuel element.

Table 8. Summary of NGNP Heavy-Metal Loading, Cycle Length and Discharge Burnup.

\begin{tabular}{|c|c|c|c|c|c|}
\hline \multirow{2}{*}{$\begin{array}{c}\text { Kernel } \\
\text { diameter } \\
(\mu \mathrm{m})\end{array}$} & $\begin{array}{c}\text { Number of } \\
\text { batches }\end{array}$ & $\begin{array}{c}\text { Initial heavy } \\
\text { metal loading } \\
(\mathrm{kg})\end{array}$ & $\begin{array}{c}\text { Cycle length } \\
(\text { EFPD })\end{array}$ & \multicolumn{2}{|c|}{ Discharge burnup, GWd/t } \\
\cline { 5 - 6 } & Single & 5209.3 & 465.8 & 52.9 & 112.3 \\
\cline { 2 - 6 } 350 & Two & 5101.7 & 317.9 & 71.8 & 121.6 \\
\cline { 2 - 6 } & Three & 5056.7 & 226.0 & 78.0 & 131.9 \\
\hline \multirow{3}{*}{425} & Single & 6101.3 & 799.4 & 78.6 & 162.6 \\
\cline { 2 - 6 } & Two & 5926.8 & 526.1 & 99.9 & 188.1 \\
\cline { 2 - 6 } & Three & 5836.1 & 396.9 & 115.2 & 211.7 \\
\hline
\end{tabular}




\subsection{Conclusions}

ANL has developed whole-core deterministic depletion models and utilized them for analyzing the NGNP core. This activity was conducted in the framework of a task defined to provide reactor physics support for fuel specification and testing efforts ongoing under the advanced gas-cooled reactor program. Both ANL and INEEL participated in this task, with INEEL focusing of the stochastic Monte Carlo capability (MCNP coupled to ORIGEN). The current report is a summary of ANL depletion models and fuel management results obtained with the models. This is a companion report to another one completed and submitted to the USDOE in April 2004, in which lattice (WIMS8 and DRAGON) and MCNP code models for the NGNP were developed and assessed.

In the current report, the deterministic depletion calculational path that was developed for the NGNP is discussed. Since this task is not an NGNP core design effort, pertinent calculations were performed for a previously designed General Atomics GT-MHR core, with minor modifications to represent the NGNP.

The fuel cycle optimization study performed in this study assumes that the NGNP utilizes a VHTR prismatic core design that employs a once-through fuel cycle. A single fuel particle (fissile) is used, as opposed to the application of both fissile and fertile fuel particles as in some previous prismatic gas-cooled core designs. The current work assumes that the targeted core operational cycle length is 18 to 24 months to be consistent with current practices in U.S. utilities and an average fuel discharge burnup of 100 to $150 \mathrm{GWd} / \mathrm{t}$. Design constraints were imposed on the fuel packing fraction in the compact, the fuel kernel diameter, and the fuel enrichment. Based on input from fuel experts a limit on fuel packing fraction of $30 \%$ is imposed on this study. Similarly a limit of $15 \%$ is imposed on the enrichment. For the fuel kernel diameter a range of 300 to $450 \mu \mathrm{m}$ range has been employed. In addition to these constraints, the minimization of core reactivity control requirements was also considered.

The WIMS8 lattice code was used for preliminary analysis of the NGNP core with respect to meeting performance goals for the cycle length and discharge burnup, under the constraints on fuel specification parameters such as the fuel diameter, fuel enrichment, and fuel 
packing fraction in the graphite compact. The preliminary evaluation facilitated limiting the search space for the more computationally expensive whole-core depletion calculations, by providing a narrow range for the pertinent design parameters to be evaluated.

The whole-core depletion studies evaluated various fuel management schemes (single-, two-, and three batch schemes) for the equilibrium and transitional cycles. The study also evaluated the impact of radial and axial fuel shuffling on the core power peaking and reactivity swing, which directly affect reactor safety requirements. The neutron fluence loads on the fuel particle designs that meet reactor core performance requirements (e.g., the cycle length and discharge burnup) were also evaluated.

The results indicated that within the limits on the fuel packing fraction (less than 30\%) and the fuel enrichment (less than 15\%), only the two-batch fuel management scheme can meet simultaneously the targeted cycle length and discharged burnup goals. The single-batch scheme could only satisfy the cycle length goal (about 18 month) when a fuel kernel diameter of $425 \mu \mathrm{m}$ is employed. By increasing the number of fuel batches it is possible to increase the discharge burnup to $100 \mathrm{GWd} / \mathrm{t}$ with a two-batch scheme and $115 \mathrm{GWd} / \mathrm{t}$ with a three batch scheme. Using the three-batch scheme however, the cycle length is reduced to less than 15 months. Regarding the reactivity swing, it was found that this quantity can be reduced by a factor of $\sim 2.4$ if the three-batch fuel management scheme is used versus the single-batch scheme. The application of more fuel batches and fuel shuffling would also help to reduce the power peaking factor. The study found that utilizing axial element shuffling is possible but would provide only limited benefit to the reduction of the power peaking factor. (The fuel column axial power peaks are significantly increased with the axial shuffling approach used in this study.) The maximum fast fluence estimated with cutoff energy of $0.11 \mathrm{MeV}$ is less than the limiting value of $4 \times 10^{21} \mathrm{n} / \mathrm{cm}^{2}(>0.18 \mathrm{MeV}$ ) for all the single- and two-batch cores; this value is exceeded in the three-batch core. A summary of results is presented in Section 5.8.

The current capabilities employed in this study require additional improvements to support the final analysis of the NGNP. Specifically, a more robust cross section functionalization capability is required for the representation of feedback effect on the broadgroup neutron cross sections. In this regard, a simplified and accurate thermal-hydraulic 
capability should be incorporated into the REBUS-3 code for the analysis of the NGNP core. Additionally, the impacts of solution refinements (spatial details and transport effect) on the results need to be evaluated. The deterministic code results could also be compared to higher fidelity capability such as those based on coupled Monte Carlo and ORIGEN codes. This latter effort would only be for a representative benchmark state, as these tools do not currently have the capability to model reactivity-feedback effects. In addition to the core physics parameters that have been studied in this work, it is necessary to provide values of safety-related parameters (e.g., reactivity coefficients). It is therefore recommended that these parameters be calculated in follow on studies. The availability of a robust capability with a reactivity feedback model would make this task straightforward (less tedious). 


\section{References}

1. Technical Program Plan for the Advanced Gas Reactor Fuel Development and Qualification Program, developed by the Advanced Gas Reactor Team, ORNL/TM-2002/262, April 2003.

2. T. K. Kim, W. S. Yang, M. A. Smith, T. A. Taiwo, and H. S. Khalil, “Assessment of Monte Carlo and Deterministic Codes for Next Generation Nuclear Plant (NGNP) Core Modeling," Argonne National Laboratory Gen IV Report, April 15, 2004.

3. P. E. MacDonald et al., "NGNP Preliminary Point Design - Results of Initial Neutronics and Thermal-Hydraulic Assessment," INEEL/EXT-03-00870 Rev. 1, Idaho National Engineering and Environmental Laboratory, September 2003.

4. R. C. Potter et al., "Gas Turbine-Modular Helium Reactor (GTMHR) Conceptual Design Description Report," GA Report 910720, Revision 1, General Atomics, July 1996.

5. "WIMS - A Modular Scheme for Neutronics Calculations," User's Guide for Version 8, ANSWER/WIMS(99)9, The ANSWERS Software Package, AEA Technology.

6. G. Marleau, et al, “A User Guide for DRAGON," Technical report IGE-174 Rev. 4, Ecole Polytechnique de Montréal, September 1998 (1998).

7. B. J. Toppel, “A User's Guide to the REBUS-3 Fuel Cycle Analysis Capability,” ANL-83-2, Argonne National Laboratory (1983).

8. K. L. Derstine, "DIF3D: A Code to Solve One-, Two-, and Three-Dimensional FiniteDifference Diffusion Theory Problems," ANL-82-64, Argonne National Laboratory (1984).

9. R. D. Lawrence, “The DIF3D Nodal Neutronics Option for Two- and Three-Dimensional Diffusion Theory Calculations in Hexagonal Geometry," ANL-83-1, Argonne National Laboratory (1983).

10. G. Palmiotti, E. E. Lewis, and C. B. Carrico, "VARIANT: VARIational Anisotropic Nodal Transport for Multidimensional Cartesian and Hexagonal Geometry Calculation," ANL95/40, Argonne National Laboratory (1995).

11. "MCNP - A General Monte Carlo N-Particle Transport Code," Version 4C, Los Alamos National Laboratory, LA-13709-M.

12. T. Newton, Private Communication, June 2004.

13. W. S. Yang, Argonne National Laboratory, unpublished information, 1993. 